\title{
Estudio de la avifauna de la cueva de Praileaitz I (Deba, Gipuzkoa)
}

\author{
Praileaitz I (Deba, Gipuzkoa) haitzuloaren hegazti-faunaren ikerketa \\ The avian remains from Praileaitz I cave (Deba, Gipuzkoa)
}

PALABRAS CLAVE: Aves, Paleolítico, País Vasco.

GAKO-HITZAK: Hegaztiak, Paleolitoa, Euskal Herria.

KEYWORDS: Bird remains, Palaeolithic, Basque Country.

Marta MORENO-GARCÍA ${ }^{(1)}$

\section{RESUMEN}

Presentamos los resultados del estudio de las aves recuperadas en la cueva de Praileaitz I, Deba, Gipuzkoa. Se analiza la diversidad y abundancia taxonómica del conjunto ornitoarqueológico en el marco espacial y cronológico definido. La familia Corvidae domina todos los espacios y períodos. La Chova piquigualda (Pyrrhocorax graculus) y la Chova piquirroja (Pyrrhocorax pyrrhocorax) suponen más del $70 \%$ del total. El espectro registrado comprende una mayoría de aves residentes en el litoral cantábrico y de amplia distribución geográfica a través de diferentes zonas climáticas. Se exceptúa el Lagópodo Escandinavo (Lagopus lagopus) cuya presencia en el Solutrense constituye una clara evidencia de condiciones ambientales más frías que las actuales. El patrón de representación esquelética, el estado de conservación de los huesos y la recuperación de individuos juveniles sugieren la acumulación natural de carcasas junto a aportaciones puntuales de rapaces diurnas, sin que se detecte intervención humana.

\section{LABURPENA}

Hemen aurkezten ditugu Praileaitz I haitzuloan (Deba, Gipuzkoa) aurkitutako hegaztien ikerketaren emaitzak. Ikerketan aztertzen da multzo ornitoarkeologikoaren aniztasun eta ugaritasun taxonomikoa esparru eta kronologia mugatu batean. Corvidae familia nagusitzen da eremu eta aro guztietan. Belatxinga mokohoria (Pyrrhocorax graculus) eta Belatxinga mokogorria (Pyrrhocorax pyrhocorax) dira \%70 baino gehiago. Erregistratutako espektroan, hegazti gehienak dira Kantauri itsasbazterrean bizi eta hainbat klima-zonatan banaketa geografiko zabala dutenak. Legopodo eskandinaviarra izan ezik, zeren eta Solutre aldian agertzeak esan nahi baitu ingurune-baldintzak egun baino nabarmen hotzagoak zirela. Eskeleto-ordezkaritzaren patroiak, hezur-kontserbazioaren egoerak eta gazte-banakoak berreskuratzeak aditzera ematen du karkasen pilaketa naturala eta harrapari eguargitarren ekarpen puntualak, giza esku-hartzerik antzeman gabe.

\section{ABSTRACT}

The results presented in this contribution focus on the avian remains recovered from Praileaitz I cave, Deba, Gipuzkoa. Taxa diversity and frequency are analysed within the recognized spatial and chronological frameworks. Corvids are the most abundant in all spaces and periods. The Alpine chough (Pyrrhocorax graculus) and the Red-billed chough (Pyrrhocorax pyrrhocorax) account for more than $70 \%$ of the bone specimens identified. The assemblage is comprised by bird species resident in the Cantabrian coast but which also may be found in a wide range of climatic and ecological zones. The Willow ptarmigan (Lagopus lagopus) constitutes an exception. Its occurrence in the Solutrean probably relates to colder conditions than the present. Skeletal part distribution, bone preservation and juvenile individuals suggest the mixed origin of the accumulations, with carcasses of naturally dead birds and occasional prey from diurnal raptors. No anthropic activity was acknowledged.

\section{1.- INTRODUCCIÓN}

Este trabajo recoge el estudio de la avifauna recuperada durante diez campañas de excavación de la cueva de Praileaitz I, Deba, Gipuzkoa realizadas entre los años de 2000 y 2009, bajo la dirección de X. Peñalver.

La cueva de Praileaitz I se localiza en la orilla derecha del río Deba, a una cota de 50 metros sobre el nivel del mar. Se han intervenido un total de $191 \mathrm{~m}^{2}$ distribuidos en seis espacios a los que se ha denominado: rellano exte- rior de la cueva, vestíbulo, galería noroeste, tránsito entre el vestíbulo y la primera sala interior, primera sala interior y segunda sala interior. En nuestro estudio analizamos todos los restos de aves recuperados en estos espacios salvo en la parte exterior de la cueva y en aquellos estratos estériles, de superficie o limpieza de cortes.

A través de la excavación arqueológica se definieron varios niveles de ocupación correspondientes a diferentes momentos cronológicos. La cueva fue ocupada durante el Epipaleolítico, pasando por el Magdaleniense

(1) Instituto de Historia, Centro de Ciencias Humanas y Sociales. Consejo Superior de Investigaciones Científicas. Albasanz 26-28, 28037 Madrid. marta.moreno@cchs.csic.es 
Superior/Final e Inferior, así como por el Solutrense y el Gravetiense. En la galería noroeste se identificaron además industrias de factura antigua con una datación correspondiente al Gravetiense (25.320 \pm 140 B.P).

Los restos óseos fueron lavados y siglados, tal como se recoge en el inventario que figura en el Anexo 3, y se entregaron para su estudio en el Laboratorio de Arqueozoología del Instituto de Historia $(\mathrm{IH})$, Centro de Ciencias Humanas y Sociales (CCHS), CSIC en Madrid.

Los objetivos del presente análisis son:

- Realizar las identificaciones taxonómicas y osteológicas de los restos de aves recuperados en cada uno de los espacios localizados en el interior de la cueva.

- Calcular las frecuencias de las principales familias y especies a lo largo de la secuencia cronológica definida.

- Reconocer a través de los perfiles anatómicos y el estado de fragmentación los procesos de formación de la tafocenosis.

- Evaluar el significado de los conjuntos arqueofaunísticos desde una perspectiva paleoecológica.

\section{2.- MATERIAL Y MÉTODOS}

El conjunto de la muestra ha proporcionado un total de 5460 restos de aves. Al haberse cribado la totalidad del sedimento con cedazos de entre 3 y $4 \mathrm{~mm}$, la recuperación de la asociación ornitoarqueológica es excelente. Se trata de uno de los mayores conjuntos ornitofaunísticos estudiados en el País Vasco y en general, en la Región Cantábrica peninsular.

\subsection{Identificación}

La identificación se ha realizado con ayuda de la colección comparativa del Laboratorio de Arqueozoología del Instituto de Historia, Centro de Ciencias Humanas y Sociales del Consejo Superior de Investigaciones Científicas. Debido al estado de conservación de algunas muestras y a la dificultad de llegar a identificaciones específicas en el caso de familias con un elevado número de especies, morfológicamente muy similares (por ejemplo, los Anatidae), optamos por el registro taxonómico a nivel de género, familia o incluso apenas el orden. Además hemos utilizado los estudios de osteomorfología comparada de Tomek, Bochenski (2000) para los córvidos, de Kraft (1972) para los lagópodos, de Fick (1974) para los Columbidae y de Schmidt-Burger (1982) y Solti (1996) para los falconiformes.

La descripción sistemática de las especies se realiza conforme al trabajo de Svensson et al., (2009).

\subsection{Cuantificación}

Fueron registrados y cuantificados todos los fragmentos recuperados. En la Tabla 1 se presentan el núme- ro total de restos analizados (NR) y la abundancia relativa (\%NR) de los fragmentos determinados respecto a los indeterminados en los espacios arriba señalados. La Tabla 2 resume estos valores teniendo en cuenta la secuencia cronológica.

En el caso de las familias y/o especies dominantes se cuantifica también el número mínimo de elementos (NME) de los principales huesos, excluyendo partes pequeñas como falanges, vértebras y costillas. El NME es la suma de los huesos completos (derechos e izquierdos) más los fragmentos proximales (derechos e izquierdos) o fragmentos distales (derechos e izquierdos) más numerosos.

De igual forma, con el objetivo de entender el origen de la tafocenosis - si se trata de restos derivados de consumo humano, de presas capturadas por depredadores no humanos (en especial rapaces nocturnas y diurnas) o de animales que han muerto de forma natural en la cueva- se calculó la frecuencia y la fragmentación de determinadas partes anatómicas (BOCHENSKI, 2005). A partir del número total de restos (NR) se analizaron los siguientes parámetros:

a) Frecuencia de huesos completos en relación al número total de fragmentos de un determinado tipo de hueso.

b) Ratio de elementos de las alas versus huesos de las patas (ERICSON, 1987). Esta ratio se obtiene dividiendo el número de fragmentos de huesos del ala (húmero+ulna+carpometacarpo) entre la suma total de huesos del ala y de la pata (fémur +tibiotarso+tarsometatarso), expresado como un porcentaje.

c) Ratio de elementos proximales (escápula, coracoides, húmero, fémur y tibiotarso) y distales (ulna, radio, carpometacarpo y tarsometatarso).

Y utilizando el NME:

a) Frecuencia de los principales huesos del esqueleto apendicular.

b) Número mínimo de individuos (NMI).

c) Frecuencia de huesos conservados (\%C). Se aplica la ecuación de Brain (1981) (\%C de y=100*NME $\left.\mathrm{y} / \mathrm{NMI}^{\star} 2\right)$.

\subsection{Biometría}

Los datos osteométricos siguen los criterios de von den Driesch (1976). Las abreviaturas utilizadas son las mismas citadas en este trabajo. Todas las medidas se expresan en milímetros y únicamente fueron tomadas en restos pertenecientes a individuos adultos bien conservados. En el caso de los córvidos se tomaron las medidas anotadas en Tomek, Bochenski (2000). 


\section{3.- RESULTADOS}

Del número total de 5460 restos de aves fue posible identificar 4058 fragmentos (en alguno de los niveles taxonómicos mencionados), lo que representa el $74 \%$ del conjunto analizado (Tabl. 1). La porción indeterminada oscila entre $15 \%$ y $45 \%$ siendo la más alta la de la segunda sala interior y la más baja la de la primera sala interior, que son por otro lado los espacios con me- nor número de restos (Tabl. 2). La distribución espacial no es homogénea sino que se observa una mayor concentración de ornitofauna en el vestíbulo que disminuye significativamente a medida que se penetra hacia el interior de la cueva (Tabl. 1). La frecuencia semejante de restos determinados e indeterminados en las otras zonas, coincidente con los valores medios del total de la asociación, sugiere además la buena conservación del material óseo.

\begin{tabular}{|c|c|c|c|c|c|c|}
\hline & VESTÍBULO & $\begin{array}{c}\text { GALERÍA } \\
\text { NOROESTE }\end{array}$ & $\begin{array}{c}\text { TRÁNSITO } \\
\text { VESTÍBULO-1 } \\
\text { SALA INTERIOR }\end{array}$ & $\begin{array}{c}\text { PRIMERA } \\
\text { SALA } \\
\text { INTERIOR }\end{array}$ & $\begin{array}{c}\text { SEGUNDA } \\
\text { SALA } \\
\text { INTERIOR }\end{array}$ & $\begin{array}{c}\text { TOTAL } \\
\text { NR DETERMINADOS }\end{array}$ \\
\hline$\%$ & 7260 & 425 & 317 & 28 & 55 & 7058 \\
\hline NR INDETERMINADOS & 1125 & 74 & 77 & 5 & 23 & 1402 \\
\hline$\%$ & 26 & 26 & 23 & 15 & 45 & 26 \\
\hline TOTAL ANALIZADO & 4385 & 578 & 413 & 33 & 51 & 5460 \\
\hline$\%$ & 80 & 11 & 7 & 1 & 1 & 100 \\
\hline
\end{tabular}

Tabl. 1. Praileaitz I. Número (NR) y frecuencia (\%) de restos determinados taxonómicamente (a nivel de especie, género, familia u orden) e indeterminados en cada sector. / Praileaitz I. Number (NR) and frequency of taxonomically determined (to species, genus, family or order level) and undetermined remains in each sector.

El conjunto correspondiente al Solutrense es el más abundante en cuanto a número de restos (NR= 2029, $37 \%$ del total) seguido de cerca por la muestra del Magdaleniense Inferior ( $N R=1677,31 \%$ del total). Los restos asociados al Epipaleolítico representan apenas el 13\% $(\mathrm{NR}=726)$, a los que siguen los de los niveles del Magdaleniense Superior/Final (NR=450, $8 \%$ del total) y el paquete inferior de la galería noroeste, donde se recuperó industria de tipología antigua asociada a una datación del periodo gravetiense (NR=301, 6\%). La asociación se completa con el paquete superior de la galería noroeste que comprende materiales del Epipaleolítico al Magdaleniense Inferior (NR= 277, 5\% del total; Tabl. 2). Las proporciones de huesos determinados e indeterminados en cada uno de estos niveles no sufren variaciones significativas respecto a lo descrito para cada uno de los espacios.

\subsection{Composición faunística}

Los restos incluidos en la fracción determinada pertenecen a 8 órdenes, 13 familias, 16 géneros y 18 especies (Tabl. 3). El orden de los Passeriformes y en particular la familia Corvidae dominan totalmente el conjunto ornitoarqueológico en todos los espacios y períodos. El Cuervo (Corvus corax) y la Urraca (Pica pica) complementan el papel destacado de la Chova Piquigualda (Pyrrhocorax graculus) y la Chova Piquirroja (Pyrrhocorax pyrrhocorax) que con algo más de 2900 restos suponen $72 \%$ del total identificado. La contribución de los Columbiformes con
$5 \%$ es la segunda en importancia, tras la que se encuentran los Accipitriformes (2\%) - Buitre Leonado (Gyps fulvus), Águila Real (Aquila chrysaetos), posible Aguilucho Cenizo (cf. Circus pygargus), Cernícalo Vulgar (Falco tinnunculus) y posible Esmerejón (cf. Falco columbarius) y Anseriformes (1\%) - Ganso (Anser sp.), Ánade Azulón (Anas platyrhynchos), Porrón Europeo (Aythya ferina), posible Silbón Europeo (cf. Anas penelope) y posible Ánade Rabudo (cf. Anas acuta)-. Las bajas frecuencias de los otros órdenes reflejan su carácter residual.

Algunas familias y especies sólo aparecen en un periodo concreto. Por ejemplo, los escasos restos de Laridae y Sternidae corresponden al Magdaleniense Inferior. La Codorniz (Coturnix coturnix) y el Vencejo (Apus apus) apenas se registran en el Epipaleolítico, mientras que el posible Aguilucho Cenizo (cf. Circus pygargus), el Búho Real (Bubo bubo) se asocian con el Magdaleniense Inferior y el posible Esmerejón (cf. Falco columbarius) con el Solutrense (Tabl. 3).

El número relativamente bajo de especies identificadas (18) no refleja la diversidad real de la avifauna del entorno de la cueva. El espectro registrado comprende una mayoría de aves residentes en el litoral cantábrico que además tienen una amplia distribución geográfica a través de diferentes zonas climáticas, por lo que su significación ecológica o ambiental es reducida. El dominio de dos especies como son la Chova Piquigualda y la Chova Piquirroja, entre los que se identificaron especímenes juveniles, apunta a la utilización de la cavidad como lugar de reproducción de estas especies en algunos momentos de la secuencia. 


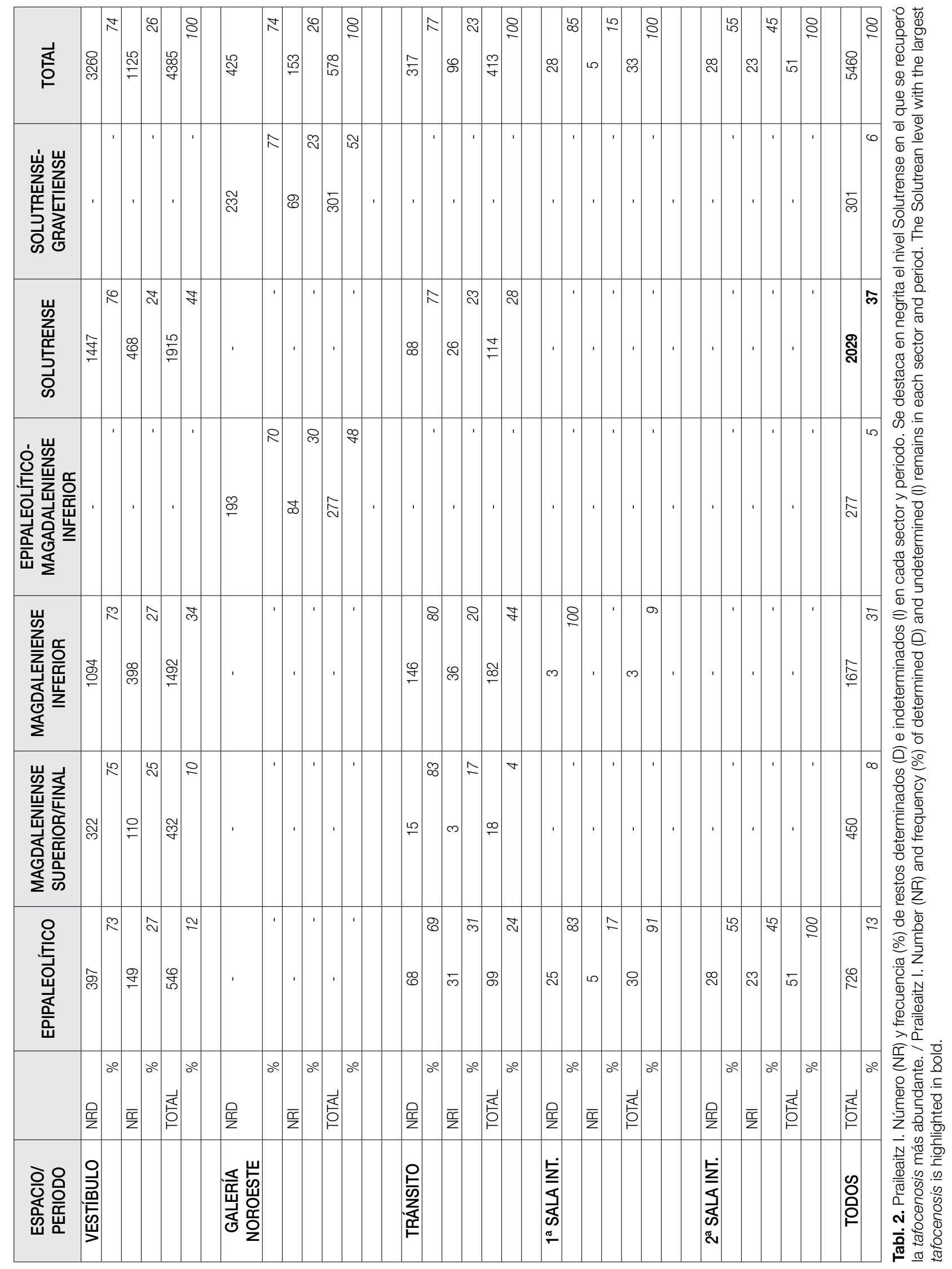




\begin{tabular}{|c|c|c|c|c|c|c|c|}
\hline & & 1 & 2 & 3 & 4 & 5 & 6 \\
\hline \multicolumn{8}{|c|}{ ANSERIFORMES } \\
\hline \multirow[t]{7}{*}{ Anatidae } & Anser sp. & 2 & - & - & - & - & - \\
\hline & Anas sp. & 11 & 1 & 1 & 1 & - & - \\
\hline & Anas platyrhynchos & 1 & - & - & 2 & - & 2 \\
\hline & cf. Anas penelope & 2 & - & - & - & - & - \\
\hline & cf. Anas acuta & - & - & - & 1 & - & - \\
\hline & Aythya ferina & 2 & - & 1 & - & - & - \\
\hline & Anatidae no det. & 6 & 9 & 6 & 2 & 2 & - \\
\hline \multicolumn{8}{|c|}{ GALLIFORMES } \\
\hline \multirow[t]{3}{*}{ Tetraonidae } & Lagopus lagopus & - & - & 1 & - & 3 & - \\
\hline & Lagopus sp. & 1 & - & - & - & - & - \\
\hline & Tetraonidae no det. & - & - & 1 & - & - & - \\
\hline \multirow[t]{2}{*}{ Phasianidae } & Coturnix coturnix & 2 & - & - & - & - & - \\
\hline & Phasianidae no det. & - & 1 & - & - & - & - \\
\hline \multicolumn{8}{|c|}{ ACCIPITRIFORMES } \\
\hline \multirow[t]{5}{*}{ Accipitridae } & Aquila chrysaetos & 2 & 4 & 11 & - & 12 & 5 \\
\hline & Gyps fulvus & - & - & - & - & - & 1 \\
\hline & Gyps/Aegypius & - & - & - & - & - & 1 \\
\hline & cf. Circus pygargus & - & - & 1 & - & - & - \\
\hline & Accipitridae no det. & 6 & 1 & 12 & 1 & 13 & 1 \\
\hline \multirow[t]{4}{*}{ Falconidae } & Falco tinnunculus & 1 & - & 1 & - & 5 & - \\
\hline & cf. Falco columbarius & - & - & - & - & 2 & - \\
\hline & Falco tin./F. col. & - & 2 & 1 & - & - & - \\
\hline & Falco sp. & 1 & - & - & - & - & - \\
\hline \multicolumn{8}{|c|}{ CHARADRIIFORMES } \\
\hline Alcidae & & 1 & 1 & - & - & - & - \\
\hline Laridae & & - & - & 2 & - & - & - \\
\hline Sternidae & & - & - & 1 & - & - & - \\
\hline \multicolumn{8}{|c|}{ COLUMBIFORMES } \\
\hline \multirow[t]{2}{*}{ Columbidae } & Columba livia/oenas & 74 & 39 & 49 & 13 & 35 & 3 \\
\hline & Columbidae no det & - & - & - & - & - & 2 \\
\hline \multicolumn{8}{|c|}{ STRIGIFORMES } \\
\hline \multirow[t]{2}{*}{ Strigidae } & Bubo bubo & - & - & 1 & - & - & - \\
\hline & Strigidae no det. & - & 1 & 2 & 1 & 1 & - \\
\hline \multicolumn{8}{|c|}{ APODIFORMES } \\
\hline Apodidae & Apus apus & 2 & - & - & - & - & - \\
\hline \multicolumn{8}{|c|}{ PASSERIFORMES } \\
\hline \multirow[t]{6}{*}{ Corvidae } & Corvus corax & 7 & 2 & 4 & - & 1 & 4 \\
\hline & Pyrrhocorax graculus & 59 & 37 & 201 & 27 & 375 & 79 \\
\hline & Pyrrhocorax pyrrhocorax & 87 & 74 & 182 & 42 & 102 & 41 \\
\hline & Pyrrhocorax sp. & 159 & 100 & 529 & 71 & 672 & 69 \\
\hline & Pica pica & 1 & - & 7 & - & 3 & - \\
\hline & Corvidae no det. & 64 & 56 & 195 & 30 & 278 & 23 \\
\hline \multirow[t]{2}{*}{ Turdidae } & Turdus sp. & 2 & - & - & - & 2 & - \\
\hline & Paseriforme no det. & 25 & 9 & 34 & 2 & 29 & 1 \\
\hline
\end{tabular}

Tabl. 3. Praileaitz I. Relación del número de restos (NR) de aves identificados según diferentes categorías taxonómicas (orden, familia, género y especie) en la secuencia cronológica (1. Epipaleolítico; 2. Magdaleniense Superior/Final; 3. Magdaleniense Inferior; 4. EpipaleolíticoMagdaleniense Inferior; 5. Solutrense; 6. Solutrense-Gravetiense). / Praileaitz I. Number (NR) of identified bird remains according to different taxonomic categories (order, family, genus and species) in the chronological sequence (1. Epipaleolithic; 2 . Upper/Late Magdalenian; 3. Early Magdalenian; 4. Epipaleolithic- Early Magdalenian; 5. Solutrean; 6. Solutrean-Gravettian). 


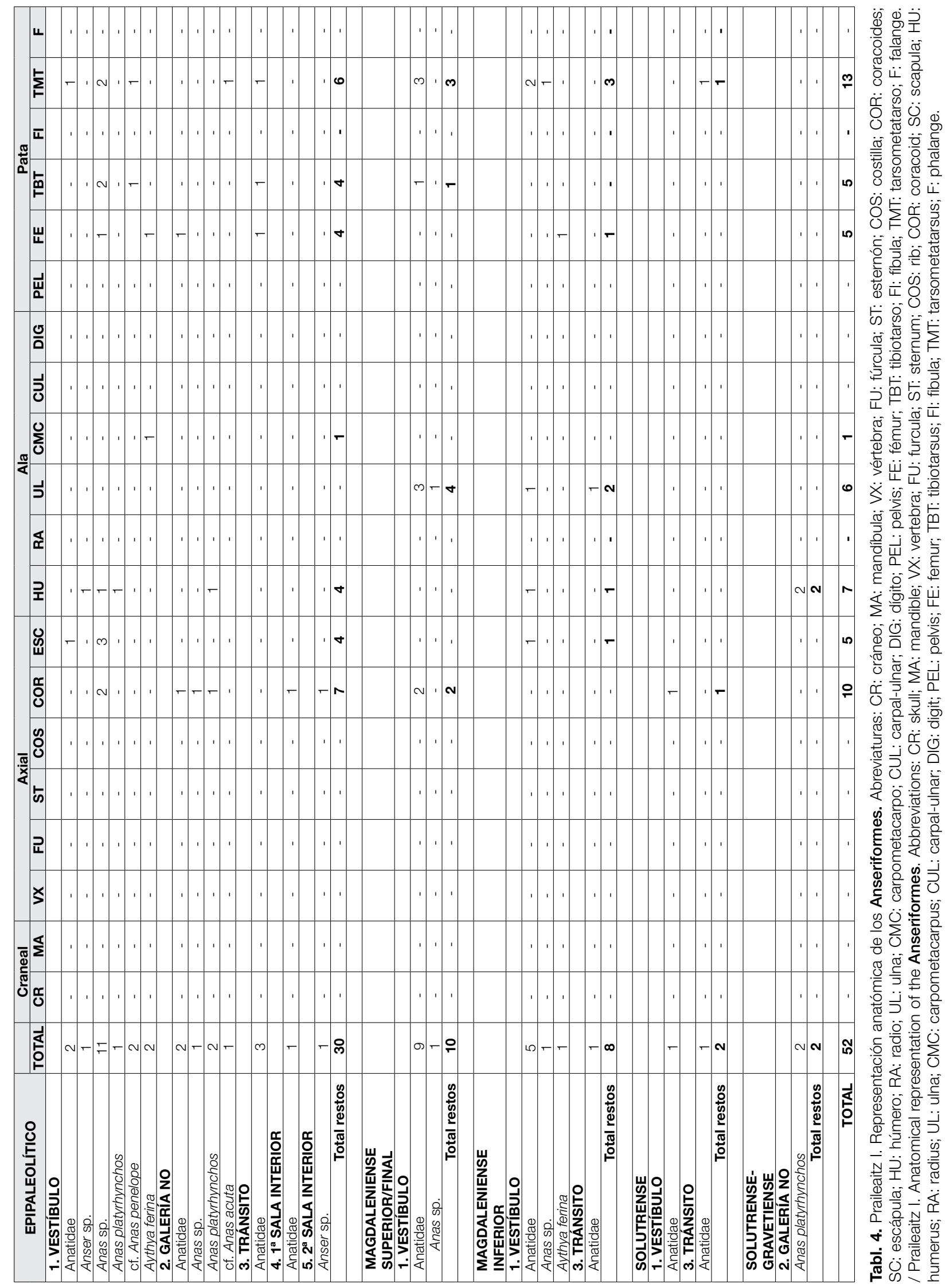




\subsection{Descripción sistemática}

\section{Orden ANSERIFORMES WARGLER, 1831 \\ FAMILIA ANATIDAE WARGLER, 1831}

En el total de la asociación se recuperaron 52 restos de Anseriformes, que en la mayor parte de los casos no pudieron ser determinados a nivel específico debido a la gran similitud morfológica existente entre los huesos de especies de dimensiones semejantes. Como refleja la Tabla 4 se constata un aumento de la abundancia de anátidos desde los niveles más antiguos de la galería noroeste hasta el Epipaleolítico, período en el que se registraron 30 restos y en el que también se observa la mayor diversidad: Ganso no determinado (Anser sp.), Ánade Azulón (Anas platyrhynchos), Porrón Europeo (Aythya ferina) y probablemente Silbón Europeo (cf. Anas penelope) y Ánade Rabudo (cf. Anas acuta). Entre los 13 fragmentos de Anas sp. se observan elementos que por sus dimensiones reducidas estarían más próximos del Silbón (pato invernante en el litoral cantábrico peninsular) que de los otros dos ánades identificados. Sin embargo, el estado de conservación de los restos y el dimorfismo sexual que presentan estas especies impiden una determinación específica. El predominio de los patos frente a los ánsares es evidente, ya que sólo se recuperaron dos fragmentos de ganso en el vestíbulo (húmero proximal P.A.6F.214.54) y la segunda sala interior (coracoides P.A.16P'.379.19).

El esqueleto craneal, por su fragilidad y difícil conservación, no está representado. Los tarsometatarsos y los coracoides son los elementos dominantes (Tabl. 4). De acuerdo con Mourer-Chauviré (1983) este perfil anatómico es propio de materiales derivados del consumo de aves rapaces más que de humanos. Por su parte, Ericson (1987) señala que mientras en depósitos naturales de aves la proporción de las partes anatómicas muestra mayor abundancia de alas, seguida de patas y esqueleto axial y en último lugar, cráneos y mandíbulas, en acumulaciones de origen antrópico, las patas aparecen en primer lugar. No obstante, si se tienen en cuenta factores relacionados con la conservación diferencial de los huesos en taxones diferentes, es decir si se considera el grado de densidad ósea, estos resultados no son tan concluyentes (LIVINGSTON, 1989). Además en los análisis actualísticos realizados más recientemente por Bochenski (2005: 37) con egagrópilas y restos no consumidos por rapaces diurnas y nocturnas, se aprecia la existencia de cierta variabilidad en las partes anatómicas conservadas. Por ejemplo, coracoides, húmeros y tarsometatarsos dominan en muestras acumuladas por rapaces nocturnas y diurnas, aunque el húmero no es específico de esta situación. En materiales derivados de consumo humano es uno de los elementos más frecuentes. El dominio de los coracoides es característico de restos no ingeridos por Águila Imperial oriental (Aquila heliaca) y Águila Real (Aquila chrysaetos), así como abunda en las egagrópilas de Águila Imperial (Aquila adalberti). Los tarsometatarsos dominan también en las egagrópilas de Búho Real (Bubo bubo) y Águila Imperial. Y parece que el dominio de fémures es el que se restringe al consumo humano.

De igual forma, el tamaño del depredador y la presa, la erosión y otros factores post-deposicionales son factores a considerar en la interpretación de muestras arqueológicas (BOCHENSKI, 2005). Es decir, la identificación del agente acumulador es más complicada de lo que en un principio podría parecer y no debe de llevarse a cabo a través de un único criterio.

Desde esta perspectiva, el perfil anatómico obtenido para los anátidos en la muestra epipaleolítica de Praileaitz I, en la que se registró el mayor número de restos $(\mathrm{NR}=30)$, evidencia paralelos con los datos descritos para las presas de rapaces (BOCHENSKI, 2005) en las que coracoides (NME=7) y tarsometatarso (NME=6) son los elementos dominantes. La ratio de alas en relación a patas es de $26 \%$, valor que aparece sólo en las egagrópilas de Águila Imperial oriental actual (BOCHENSKI et al., 1997). Además se observaron pequeñas perforaciones en un fragmento distal de húmero de Anas sp. (P.A.6F.195.28) y en otro fragmento proximal de húmero de Ánade Azulón (P.A.4l.233.86; Fig.1), procedente del paquete solutrense-gravetiense de la galería noroeste, quizás debidas al impacto de un pico o de las garras (BOCHENSKl et al., 2009).

En conclusión, los agentes responsables de las acumulaciones de aves acuáticas en la cueva fueron probablemente aves rapaces (sin que se pueda excluir un aporte humano, puntualmente en el Epipaleolítico, por la mayor presencia de fémures) que encontraron en el

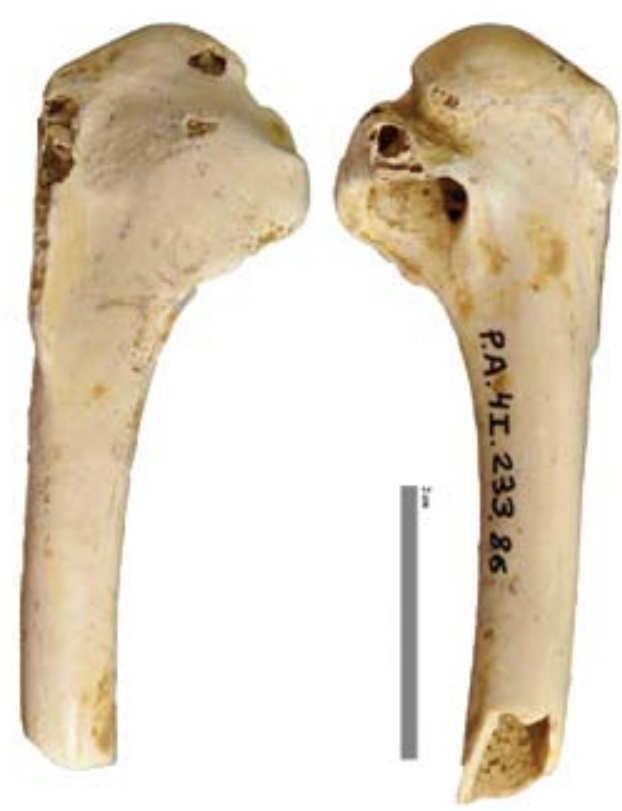

Fig. 1. Fragmento proximal de húmero de Ánade Azulón (Anas platyrhyncos) con perforaciones. P.A.4l.233.86. Galería noroeste. Solutrense-Gravetiense. / Proximal humerus of Mallard (Anas platyrhyncos) with perforations. P.A.4I.233.86. Northwest gallery. Solutrean-Gravettian. 
cauce del río Deba, ubicado a los pies de la cavidad, una buena fuente de alimentación.

Los datos métricos de los taxones identificados se resumen en el Anexo 1.

\section{Orden GALLIFORMES TEMmInCK, 1820}

Los nueve restos de galliformes proceden del vestíbulo de la cueva y pertenecen a dos familias: Tetraonidae y Phasianidae.

\section{FAMILIA TETRAONIDAE}

Lagopus lagopus (Linnaeus, 1758) / Lagopus muta (Montin, 1776)

Esta familia comprende los gallos de monte, aves robustas, de dimensiones medianas a grandes, no migradoras y propias de laderas montañosas y bosques boreales. En Praileaitz I se asignan 5 restos al género Lagópodo y uno a la familia Tetraonidae.

El único Lagópodo que existe en la actualidad en la Península lbérica es el Lagópodo Alpino o Perdiz Nival (Lagopus muta). Es una especie característica de la tundra del hemisferio norte, perfectamente adaptada al frío extremo. Hasta el primer cuarto del siglo XX habitó la cordillera Cantábrica, pero ahora sólo está presente en áreas alpinas de la cordillera axial pirenaica entre el macizo de Larra en Navarra y el Ripollés en Gerona (CANUT et al., 2003). Su presencia es relativamente común en yacimientos prehistóricos del País Vasco peninsular: cuevas de Ermittia (ELORZA, 1993), Urtiaga, Lumentxa y Aitzbitarte IV (ELORZA, 1990). Menos numerosos son los restos de la otra especie de lagópodo, el Lagópodo Común escandinavo (Lagopus lagopus). En concreto, su presencia ha sido señalada en los niveles solutrenses de la cueva de Aitzbitarte IV (ELORZA, 1990) y la cueva de Ermittia (ELORZA, 1993), en el Magdaleniense Final de la cueva de Urratxa III (ELORZA, 1997) y en el Tardiglacial de Laminak II, Berriatua (HERNÁNDEZ CARRASQUILLA, 1993). Aunque el registro de dos restos en los niveles magdalenienses de la cueva de Abauntz (Arraiz) en Navarra hace suponer que esta especie fue más asidua durante el Würm del País Vasco peninsular de lo que en principio cabría suponer (ALTUNA et al., 2001-2002).

Actualmente se distribuye en zonas árticas, subárticas y boreales de la región paleártica (CRAMP, SIMMONS, 1980). En Suecia, donde ambas especies son simpátricas, el Lagópodo Escandinavo tiene preferencia por áreas húmedas ricas en sauces (Salix spp.) o abedules (Betula spp.), con vegetación más densa pero de menor altitud que las frecuentadas por la Perdiz Nival (HÖRNELL-WILLEBRAND, 2005).

Durante el Cuaternario estas especies se comportan como un indicador climático frío (MOURER-CHAUVIRÉ, 1993).

La distinción osteológica entre los dos taxones es difícil, ya que son pocos los criterios morfológicos y métricos que las diferencian. El tarsometatarso es el elemento que en base a criterios métricos ha permitido rea- lizar identificaciones más seguras (BOCHENSKI, 1985; KRAFT, 1972; STEWART, 1999). En el nivel Solutrense de Praileaitz I se recuperó un tarsometatarso completo (P.A.12D.304.295.1) cuya longitud y anchura máxima de la diáfisis (Anexo 1) se sitúan en el rango de diversas poblaciones actuales de Lagópodos escandinavos y sobrepasan los valores del Lagópodo Alpino (Tabl. 5). Junto a este hueso aparecieron también un húmero (P.A.10C.326.194.3/9) y un fragmento proximal de fémur (P.A.12A.300.114.2) y en el nivel del Magdaleniense Inferior se recuperó una ulna distal (P.A.12A.288.174.8). La biometría de todos estos ejemplares está más próxima del Lagópodo Escandinavo que de su congénere, la Perdiz Nival (Tabl. 5), por lo que añadimos al registro existente en el País Vasco, durante el Solutrense y el Magdaleniense Inferior, los datos de Praileaitz I.

El húmero distal del Epipaleolítico (P.A.6F.188.22.1) es de menores dimensiones y probablemente pertenezca a Lagopus muta.

No se observaron marcas derivadas de acción antrópica (LAROULANDIE, 2005) ni de origen animal (de rapaz o carnívoro) y lo reducido de la muestra impide evaluar la importancia de las porciones anatómicas, por tanto carecemos de evidencias para determinar el/los agente/s responsable/s de la acumulación.

FAMILIA PHASIANIDAE VIGORS, 1825

Coturnix coturnix (Linnaeus, 1758)

La Codorniz es la más pequeña de las galliformes que existen en la Península Ibérica. Es un ave ligada a los medios abiertos, en general llanuras o terrenos suavemente ondulados. Es un migrante de largo recorrido que en el caso de las poblaciones de Europa occidental tiene los territorios de invernada situados al sur del Sahara, por lo que su presencia se relaciona con la época estival. En el País Vasco actualmente anida en el área subatlántica y mediterránea, donde ocupa preferentemente cultivos. Por el contrario, en el área atlántica vive en praderas de siega y landas por debajo de una altitud de 1000 m (ÁLVAREZ et al., 1985).

Se recuperaron dos húmeros completos de Codorniz en el nivel Epipaleolítico. Uno procede del vestíbulo (P.A.6F.199.290.21) y otro de la zona de tránsito entre el vestíbulo y la primera sala interior (P.A.14C'.308.24.1; Fig. 2). Los datos osteométricos se resumen en el Anexo 1. Ninguno presenta trazas de manipulación humana semejantes a las constatadas en Urratxa III (ELORZA, 1997) o de cualquier otro agente biológico.

\section{ORden ACCIPITRIFORMES VieILlot, 1816 (Tabl. 6)}

Los restos asignados al Orden de los Accipitriformes son 84 y pertenecen a dos de las tres familias que lo componen: Accipitridae y Falconidae. Se trata de las rapaces diurnas.

\section{FAMILIA ACCIPITRIDAE VIEILLOT, 1816}

En esta familia se incluyen los gavilanes, ratoneros, águilas, milanos, buitres y aguiluchos. En Praileaitz I están 


\begin{tabular}{|c|c|c|c|c|c|c|c|c|c|}
\hline \multirow[t]{2}{*}{ HÚMERO } & & \multicolumn{2}{|c|}{ GL } & \multicolumn{2}{|l|}{$\mathrm{Bp}$} & \multicolumn{2}{|c|}{ SC } & \multicolumn{2}{|c|}{ BD } \\
\hline & & Min - Máx. & Media & Min - Máx. & Media & Min - Máx. & Media & Min - Máx. & Media \\
\hline \multirow[t]{2}{*}{ Kraft 1972} & L. lagopus 17 + & $56,2-63,1$ & 58,4 & $14,7-16,6$ & 15,4 & $5,2-5,9$ & 5,4 & $11,0-12,0$ & 11,4 \\
\hline & L. lagopus $17 \hat{0}$ & $56,5-64,5$ & 61,2 & $15,0-17,3$ & 16,1 & $4,9-6,3$ & 5,8 & $11,1-12,4$ & 11,8 \\
\hline LARC \& LAZ & L. lagopus (Inglaterra) $30^{\wedge}$ & $61,9-65,1$ & 63,4 & $15,3-17,0$ & 16,3 & $5,9-6,5$ & 6,1 & $10,3-12,2$ & 11,2 \\
\hline \multirow[t]{3}{*}{ LAZ } & L. lagopus (Suecia) $10^{\lambda}$ & 61,7 & & 16,5 & & 6,1 & & 11,6 & \\
\hline & L. lagopus (Escocia) $1 \hat{0}$ & 63,7 & & 16,2 & & 5,9 & & 11,3 & \\
\hline & L. lagopus (Escocia) 1 + & 63,2 & & 16,5 & & 6,3 & & 12,2 & \\
\hline \multirow[t]{2}{*}{ Kraft 1972} & L. muta 179 & $54,3-59,8$ & 56,8 & $14,4-15,7$ & 15,0 & $4,6-5,5$ & 5,2 & $10,7-11,5$ & 11,1 \\
\hline & L. muta $11-130^{\lambda}$ & $52,9-59,2$ & 56,5 & $13,8-15,9$ & 14,9 & $4,5-5,4$ & 5,1 & $10,1-11,8$ & 11,1 \\
\hline LAZ & L. muta (Groenlandia) $2(1$ ふ) & 60,7 & & $16,2-16,3$ & 16,2 & $5,6-5,8$ & 5,7 & $11,1-11,1$ & 11,1 \\
\hline \multirow[t]{2}{*}{ Praileaitz I } & Lagopus lagopus (Solutrense) & 61,6 & & & & 5,6 & & 11,7 & \\
\hline & Lagopus sp (Epipaleolítico) & & & & & 5,3 & & 10,6 & \\
\hline & & \multirow{2}{*}{\multicolumn{2}{|c|}{ GL }} & \multirow{2}{*}{\multicolumn{2}{|c|}{$\mathrm{Bp}$}} & \multirow{2}{*}{\multicolumn{2}{|c|}{ sc }} & \multirow{2}{*}{\multicolumn{2}{|c|}{ Did }} \\
\hline \multirow{3}{*}{\begin{tabular}{|l|} 
ULNA \\
Kraft 1972 \\
\end{tabular}} & & & & & & & & & \\
\hline & L. lagopus 170 & $53,9-61,2$ & 56,1 & $7,3-8,3$ & 7,7 & $3,2-3,6$ & 3,4 & $7,3-7,9$ & 7,6 \\
\hline & L. lagopus $17 \hat{0}$ & $53,9-61,3$ & 58,1 & $7,3-8,8$ & 8,0 & $3,1-3,9$ & 3,6 & $7,4-8,5$ & 7,9 \\
\hline LARC \& LAZ & L. lagopus (Inglaterra) $30^{\wedge}$ & $58,4-61,9$ & 60,7 & & & $3,5-3,8$ & 3,6 & $7,6-8,0$ & 7,9 \\
\hline \multirow[t]{3}{*}{ LAZ } & L. lagopus (Suecia) $10^{\lambda}$ & 58,4 & & & & 3,8 & & 8,2 & \\
\hline & L. lagopus (Escocia) $1 \hat{0}$ & 61,7 & & & & 3,9 & & 8,2 & \\
\hline & L. lagopus (Escocia) 19 & 61,3 & & & & 3,7 & & 8,2 & \\
\hline \multirow[t]{2}{*}{ Kraft 1972} & L. muta 169 & $53,3-57,6$ & 54,9 & $7,1-7,7$ & 7,3 & $3,0-3,4$ & 3,2 & $7,0-7,9$ & 7,3 \\
\hline & L. muta $110^{\lambda}$ & $51,9-60,0$ & 56,2 & $6,7-8,2$ & 7,5 & $2,9-3,4$ & 3,2 & $6,8-8,1$ & 7,4 \\
\hline LAZ & L. muta (Groenlandia) 2 (1 $\left.\delta^{\lambda}\right)$ & $58,2-58,5$ & 58,3 & & & $3,4-3,6$ & 3,5 & $7,4-7,7$ & 7,6 \\
\hline \multirow{2}{*}{\begin{tabular}{|l|} 
Praileaitz I \\
\end{tabular}} & & & & & & & & & \\
\hline & Lagopus lagopus (Magd. inf) & & & & & 4,2 & & 7,9 & \\
\hline \multicolumn{2}{|l|}{ FEMUR } & \multicolumn{2}{|c|}{ GL } & $\mathrm{Bp}$ & & $\mathrm{Dp}$ & & Bd & \\
\hline Kraft 1972 & L. lagopus 21 ? & $56,5-62,7$ & 59,2 & $10,1-12,3$ & 11,2 & $6,8-7,6$ & 7,3 & $9,1-10,5$ & 9,7 \\
\hline & L. lagopus $17 \hat{0}$ & $58,6-64,5$ & 61,4 & $10,9-12,5$ & 11,8 & $7,1-8,6$ & 7,6 & $9,5-10,8$ & 10,1 \\
\hline LARC \& LAZ & L. lagopus (Inglaterra) $30^{\wedge}$ & $61,5-64,4$ & 62,9 & $10,6-12,9$ & 11,8 & $7,1-7,4$ & 7,3 & $9,8-11,0$ & 10,6 \\
\hline LAZ & L. lagopus (Suecia) $1 \delta^{\wedge}$ & 62,3 & & 11,4 & & 7,5 & & 10,7 & \\
\hline & L. lagopus (Escocia) 10 & 62,3 & & 10,4 & & 7,3 & & 10,3 & \\
\hline & L. lagopus (Escocia) 1 + & 63,9 & & 11,3 & & 7,3 & & 10,9 & \\
\hline Kraft 1972 & L. muta 180 & $51,7-56,3$ & 54,0 & $9,8-10,6$ & 10,2 & $6,8-7,9$ & 7,4 & $8,1-9,2$ & 8,8 \\
\hline & L. muta $110^{\lambda}$ & $52,1-56,0$ & 54,4 & $9,0-11,2$ & 10,4 & $6,8-8,2$ & 7,4 & $8,2-9,3$ & 8,8 \\
\hline LAZ & L. muta (Groenlandia) 2 (1 $\left.\partial^{\lambda}\right)$ & 56,1 & & $10,4-10,7$ & 10,5 & $6,8-7,3$ & 7,0 & $9,6-9,8$ & 9,7 \\
\hline Praileaitz I & Lagopus sp (Solutrense) & & & 10,9 & & 7,2 & & & \\
\hline TMT & & GL & & $B p$ & & $\mathrm{SC}$ & & BD & \\
\hline Kraft 1972 & L. lagopus 180 & $36,6-40,5$ & 38,1 & $7,6-8,7$ & 8,1 & $3,0-3,6$ & 3,3 & $7,0-8,3$ & 7,6 \\
\hline & L. lagopus $17 \delta^{1}$ & $37,2-42,6$ & 38,9 & $7,7-9,0$ & 8,4 & $3,2-3,7$ & 3,5 & $7,5-8,7$ & 8,0 \\
\hline Stewart 1999 & L. lagopus (Escandinavia) 11 & $37,0-42,1$ & 38,9 & & & $2,9-3,3$ & 3,2 & & \\
\hline & L. lagopus (Rusia) 6 & $38,1-42,8$ & 40,6 & & & $2,8-3,4$ & 3,2 & & \\
\hline & L. lagopus (Inglaterra) 19 & $38,6-43,6$ & 41,1 & & & $2,9-3,9$ & 3,2 & & \\
\hline & L. lagopus (Escocia) 9 & $38,4-44,1$ & 41,1 & & & $3,1-3,6$ & 3,4 & & \\
\hline & L. lagopus (Kazakhstan) 1 & 45,32 & & & & 3,6 & & & \\
\hline LARC \& LAZ & L. lagopus (Inglaterra) $3 \hat{\jmath}$ & $40,4-42,4$ & 41,3 & $7,99-8,8$ & 8,4 & $3,4-3,6$ & 3,5 & $8,5-9,2$ & 9,0 \\
\hline LAZ & L. lagopus (Suecia) $1 \hat{0}$ & 40,3 & & 8,2 & & 3,7 & & 9,1 & \\
\hline & L. lagopus (Escocia) $10^{\lambda}$ & 41,2 & & 8,4 & & 3,4 & & 8,9 & \\
\hline & L. lagopus (Escocia) 1 + & 41,2 & & 8,7 & & 3,6 & & 9,0 & \\
\hline & & & & & & & & & \\
\hline
\end{tabular}




\begin{tabular}{|l|l|c|c|c|c|c|c|c|c|}
\hline Kraft 1972 & L. muta 179 & $30,7-33,9$ & 32,2 & $6,9-7,7$ & 7,2 & $2,7-3,3$ & 2,9 & $6,3-7,4$ & 6,8 \\
\hline & L. muta 110 & $32,6-35,4$ & 33,5 & $6,9-8,0$ & 7,4 & $2,8-3,1$ & 2,9 & $6,5-7,6$ & 7,0 \\
\hline Stewart 1999 & L. muta (Escandinavia) 2 & $29,4-34,1$ & 31,8 & & & $2,6-2,7$ & 2,7 & & \\
\hline & L. muta (Escocia) 5 & $33,2-35,9$ & 34,7 & & & $2,9-3,1$ & 3,0 & & \\
\hline & L. muta (Alpes franceses) 16 & $31,8-35,7$ & 33,1 & & & $2,5-2,9$ & 2,7 & & \\
\hline & L. muta (Islandia) 2 & $30,2-34,8$ & 32,5 & & & $2,6-2,9$ & 2,7 & & \\
\hline LAZ & L. muta (Groenlandia) 2 (10^) & $31,8-34,2$ & 33,0 & $7,4-7,6$ & 7,5 & $2,9-2,9$ & 2,9 & $7,5-7,6$ & 7,5 \\
\hline & & & & & & & & & \\
\hline Praileaitz I & Lagopus lagopus (Solutrense) & $\mathbf{4 0 , 8 5}$ & & $\mathbf{7 , 5 3}$ & & $\mathbf{3 , 3 5}$ & & $\mathbf{8 , 0 6}$ & \\
\hline
\end{tabular}

Tabl. 5. Datos métricos de Lagopus lagopus y Lagopus muta actuales comparados con los restos recuperados en Praileaitz I. LARC (Laboratorio de Arqueociencias de Lisboa, Portugal); LAZ (Laboratorio de Arqueozoología de la UAM, Madrid). / Comparison of metrical data of modern Lagopus lagopus and Lagopus muta with remains from Praileaitz I. LARC (Laboratorio de Arqueociencias de Lisboa, Portugal); LAZ (Laboratorio de Arqueozoología de la UAM, Madrid).

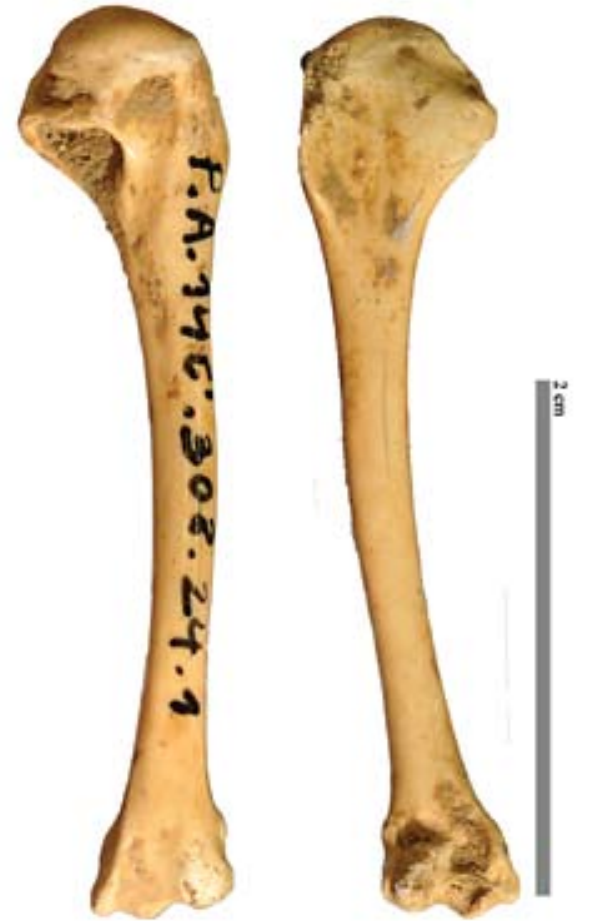

Fig. 2. Húmero derecho de Codorniz (Coturnix coturnix). P.A.14C'.308.24.1. Zona de tránsito entre vestíbulo y primera sala interior. Epipaleolítico. / Right humerus of Common Quail (Coturnix coturnix). P.A.14C'.308.24.1. Transit area between the hall and the first internal space. Epipalaeolithic.

presentes el Buitre Leonado (Gyps fulvus) y el Águila Real (Aquila chrysaetos). Registramos también un fragmento distal de tarsometatarso (P.A.10C.300.28; Fig.6) que por sus características morfológicas y métricas (Anexo 1) se encuentra muy próximo del Aguilucho Cenizo (cf. Circus pygargus).

El Buitre y el Águila Real constituyen las aves de mayores dimensiones recuperadas en el yacimiento.

Gyps fulvus (Hablizl, 1783)
El Buitre Leonado es una de las mayores rapaces que pueden encontrarse en la Península Ibérica. Está especialmente adaptado para alimentarse de carroña, sobre todo grandes ungulados. Las zonas que habita suelen ser montañosas, aunque también frecuenta llanuras con cortados fluviales de cierta entidad donde cualquier cantil vertical de más de 50 metros e inaccesible les sirve de buitrera o lugar de descanso.

Su presencia no es muy frecuente en yacimientos del País Vasco peninsular. Los registros publicados son en el Magdaleniense Superior de la cueva de Abauntz, Navarra (ALTUNA et al., 2001-2002) y el Preneolítico de la cueva de Santimamiñe, Bizkaia (ELORZA, 1990).

Se asigna a esta especie un fragmento distal de ulna (P.A.2G.255.342) localizado en el paquete con industria antigua de la galería noroeste. El estado de fragmentación de un húmero distal (P.A.4l.224.31; Fig.3) recuperado en el paquete superior de este mismo espacio de la cueva no pudo determinarse si pertenecía a Buitre leonado o Buitre negro (Tabl. 6).

\section{Aquila chrysaetos (Linnaeus, 1758)}

El Águila Real es una rapaz generalista y residente en la Península Ibérica. Su presencia se relaciona con los ambientes rupícolas, aunque ocupa una amplia variedad de hábitats, con preferencia por los paisajes abiertos, y evita las áreas forestales extensas (ARROYO, 2003). Actualmente es escasa en la franja costera del Cantábrico pero su presencia ya ha sido registrada en la cueva de Santimamiñe (ELORZA, 1990), el nivel Magdaleniense y Solutrense de Ermittia (ELORZA, 1993), el nivel Musteriense de cueva de Amalda (EASTHAM, 1989), cueva de Urtiaga (ELORZA, 1990) y también en el nivel Magdaleniense de Abauntz, Navarra (ALTUNA et al., 2001-2002).

Su dieta es muy variada (FERNÁNDEZ, PURROY, 1990), además de mamíferos incluye aves como palomas, patos, lagópodos e incluso otras rapaces diurnas de media y pequeña dimensión, por ejemplo el Cernícalo (Falco tinnunculus) o el Esmerejón (Falco columbarius). Al alimentarse también de carroña entra en conflicto con aves carroñeras como los cuervos (Corvus corax) y las urracas (Pica pica), aunque estas suelen apartarse y es- 


\begin{tabular}{|c|c|c|c|c|c|c|c|c|c|c|c|c|c|c|c|c|c|c|c|c|c|}
\hline \multirow{2}{*}{ EPIPALEOLÍTICO } & \multirow[b]{2}{*}{ TOTAL } & \multicolumn{2}{|c|}{ Craneal } & \multicolumn{6}{|c|}{ Axial } & \multicolumn{6}{|c|}{ Ala } & \multicolumn{6}{|c|}{ Pata } \\
\hline & & CR & MA & $\mathrm{VX}$ & FU & ST & $\cos$ & COR & ESC & $\mathrm{HU}$ & RA & UL & CMC & CUL & DIG & PEL & $\mathrm{FE}$ & TBT & FI & TMT & $\mathbf{F}$ \\
\hline \multicolumn{22}{|c|}{ 年 } \\
\hline Aquila chrysaetos & 2 & - & - & - & - & - & - & - & - & - & - & - & - & - & - & - & - & - & - & - & 2 \\
\hline Falco tinnunculus & 1 & - & - & - & - & - & - & - & - & - & - & - & - & - & - & - & - & - & - & 1 & - \\
\hline Accipitridae & 5 & - & - & - & - & - & - & - & - & - & - & - & - & - & - & - & - & - & - & - & 5 \\
\hline \multicolumn{22}{|l|}{ 2. GALERÍA NOROESTE } \\
\hline Accipitridae & 1 & - & - & - & - & - & - & - & - & - & - & - & - & - & - & - & - & - & - & - & 1 \\
\hline \multicolumn{22}{|l|}{ 4. $1^{\text {a }}$ SALA INTERIOR } \\
\hline Falco sp. & 1 & - & - & - & - & - & - & - & - & - & - & - & - & - & - & - & - & - & - & 1 & - \\
\hline \multicolumn{22}{|l|}{ 5. $2^{\mathrm{a}}$ SALA INTERIOR } \\
\hline Accipitridae & 1 & - & - & - & - & - & - & - & - & - & - & - & - & - & - & - & - & - & - & - & 1 \\
\hline Total restos & 11 & & & & & & & & & & & & & & & & & & & & \\
\hline & & & & & & & & & & & & & & & & & & & & & \\
\hline \multicolumn{22}{|l|}{$\begin{array}{l}\text { MAGDALENIENSE } \\
\text { SUPERIOR/FINAL }\end{array}$} \\
\hline 1. VESTÍBULO & & & & & & & & & & & & & & & & & & & & & \\
\hline Aquila chrysaetos & 4 & - & - & - & - & - & - & - & - & 1 & - & 1 & - & - & - & - & - & - & - & - & 2 \\
\hline Falco sp. & 2 & - & - & - & - & - & - & 1 & - & - & - & 1 & - & - & - & - & - & - & - & - & - \\
\hline Accipitridae & 1 & - & - & - & - & - & - & - & - & - & - & - & - & - & - & - & - & - & - & - & 1 \\
\hline Total restos & 7 & & & & & & & & & & & & & & & & & & & & \\
\hline & & & & & & & & & & & & & & & & & & & & & \\
\hline $\begin{array}{l}\text { MAGDALENIENSE } \\
\text { INFERIOR }\end{array}$ & & & & & & & & & & & & & & & & & & & & & \\
\hline 1. VESTÍBULO & & & & & & & & & & & & & & & & & & & & & \\
\hline Aquila chrysaetos & 9 & - & - & 1 & - & - & - & - & - & 1 & - & 1 & - & - & 2 & - & 1 & 1 & - & - & 2 \\
\hline cf. Circus pygargus & 1 & - & - & - & - & - & - & - & - & - & - & - & - & - & - & - & - & - & - & 1 & - \\
\hline Falco tinnunculus & 1 & - & - & - & - & - & - & - & - & - & - & 1 & - & - & - & - & - & - & - & - & - \\
\hline Accipitridae & 10 & - & - & - & - & - & - & - & - & - & - & - & - & - & 1 & - & - & - & - & - & 9 \\
\hline 3. TRÁNSITO & & & & & & & & & & & & & & & & & & & & & \\
\hline Falco tin./ F. columbarius & 1 & - & - & - & - & - & - & - & - & - & - & - & - & - & - & - & - & - & - & 1 & - \\
\hline Accipitridae & 1 & - & - & - & - & - & - & - & - & - & - & - & - & - & - & - & - & - & - & - & 1 \\
\hline 4. $1^{\text {a }}$ SALA INTERIOR & & & & & & & & & & & & & & & & & & & & & \\
\hline Aquila chrysaetos & 2 & - & - & - & - & - & - & - & - & - & - & - & - & - & 1 & - & - & - & - & - & 1 \\
\hline Accipitridae & 1 & - & - & - & - & - & - & - & - & - & - & - & - & - & - & - & - & - & - & - & 1 \\
\hline Total restos & 26 & & & & & & & & & & & & & & & & & & & & \\
\hline & & & & & & & & & & & & & & & & & & & & & \\
\hline SOLUTRENSE & & & & & & & & & & & & & & & & & & & & & \\
\hline 1. VESTíBULO & & & & & & & & & & & & & & & & & & & & & \\
\hline Aquila chrysaetos & 12 & - & - & - & - & - & - & 1 & - & 1 & 1 & 1 & 1 & 1 & 3 & - & - & 1 & - & - & 2 \\
\hline cf. Falco columbarius & 2 & - & - & - & - & - & - & 1 & - & - & - & - & - & - & - & - & - & - & - & 1 & - \\
\hline Falco tinnunculus & 4 & - & - & - & - & - & - & - & - & - & - & 2 & - & - & - & - & - & - & - & 2 & - \\
\hline Accipitridae & 13 & - & - & 2 & - & - & - & - & - & 1 & - & - & - & 1 & 1 & - & - & - & - & - & 8 \\
\hline 3. TRÁNSITO & & & & & & & & & & & & & & & & & & & & & \\
\hline Falco tinnunculus & 1 & - & - & - & - & - & - & - & - & - & - & - & - & - & - & - & - & - & - & 1 & - \\
\hline Total restos & 32 & & & & & & & & & & & & & & & & & & & & \\
\hline & & & & & & & & & & & & & & & & & & & & & \\
\hline SOLUTRENSE-GRAVE & & & & & & & & & & & & & & & & & & & & & \\
\hline 2. GALERÍA NOROESTE & & & & & & & & & & & & & & & & & & & & & \\
\hline Aquilla chrysaetos & 5 & - & - & - & - & - & - & - & - & 1 & - & 1 & - & - & - & - & - & - & - & 1 & 2 \\
\hline Gyps fulvus & 1 & - & - & - & - & - & - & - & - & - & - & 1 & - & - & - & - & - & - & - & - & - \\
\hline Gyps/Aegypius & 1 & - & - & - & - & - & - & - & - & 1 & - & - & - & - & - & - & - & - & - & - & - \\
\hline Accipitridae & 1 & - & - & - & - & - & - & - & - & 1 & - & - & - & - & - & - & - & - & - & - & - \\
\hline Total restos & 8 & & & & & & & & & & & & & & & & & & & & \\
\hline & & & & & & & & & & & & & & & & & & & & & \\
\hline TOTAL & 84 & - & - & 3 & - & - & - & 3 & - & 7 & 1 & 9 & 1 & 2 & 7 & - & 1 & 2 & - & 9 & 39 \\
\hline
\end{tabular}

Tabl. 6. Praileaitz I. Representación anatómica de los restos de Accipitriformes. Abreviaturas: CR: cráneo; MA: mandíbula; VX: vértebra; FU: fúrcula; ST: esternón; COS: costilla; COR: coracoides; SC: escápula; HU: húmero; RA: radio; UL: ulna; CMC: carpometacarpo; CUL: carpal-ulnar; DIG: dígito; PEL: pelvis; FE: fémur; TBT: tibiotarso; FI: fíbula; TMT: tarsometatarso; F: falange. / Praileaitz I. Anatomical representation of the Accipitriformes. Abbreviations: CR: skull; MA: mandible; VX: vertebra; FU: furcula; ST: sternum; COS: rib; COR: coracoid; SC: scapula; HU: humerus; RA: radius; UL: ulna; CMC: carpometacarpus; CUL: carpal-ulnar; DIG: digit; PEL: pelvis; FE: femur; TBT: tibiotarsus; FI: fibula; TMT: tarsometatarsus; F: phalange. 

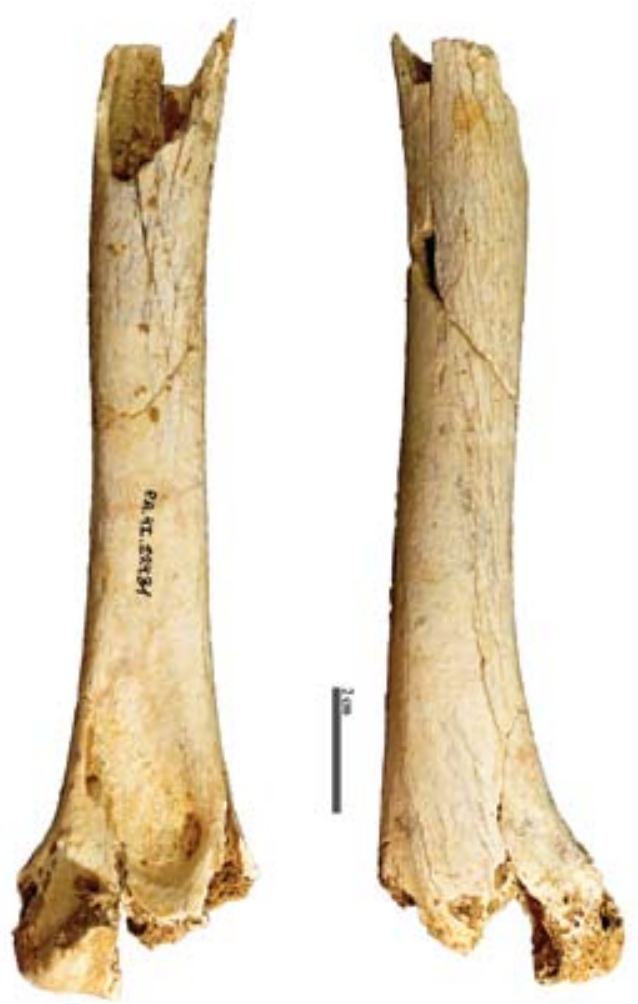

Fig. 3. Fragmento distal de húmero de Gyps/Aegypius. P.A.4l.224.31. Galería noroeste. Solutrense-Gravetiense. / Distal humerus of Gyps/Aegypius. P.A.4I.224.31. Northwest gallery. Solutrean-Gravettian.

perar para apropiarse de su presa. En definitiva, se le considera un depredador apex porque un individuo adulto prácticamente nunca es depredado por otro animal. Desde esta perspectiva, el espectro ornitofaunístico de Praileaitz I comprende muchas de las posibles presas del Águila Real, que pudo haber utilizado la cueva como un comedero o lugar de refugio.

Se recuperaron un total de 34 restos repartidos por toda la secuencia cronológica, pero que se localizan sobre todo en el vestíbulo. El húmero y la ulna son los elementos más frecuentes después de las falanges (Tabl. 6). En este sentido, hacemos notar que los huesos registrados como Accipitridae pertenecen todos a las partes terminales de las alas (dígitos) y las patas (falanges), que por prudencia hemos preferido no asignar a una especie concreta pero que dada la baja frecuencia de buitre y el mayor número de restos de Águila Real en el conjunto deben pertenecer a esta especie. En total el NMI asciende a cinco individuos, uno en cada nivel.

En ninguno de los huesos largos de los miembros (Figs. 4 y 5) ni en las falanges se observaron trazas de manipulación antrópica, por lo que no existe evidencia alguna de la selección humana de estos elementos con el fin de utilizarlos como materia prima en la elaboración de herramientas, utensilios o adornos. El aprovechamiento de las plumas es una cuestión difícil de demostrar si no hay marcas en los huesos de las alas (FINLAYSON et al., 2012; LAWSON, D'ERRICO 2002; MORIN, LAROULANDIE, 2012). Por esa razón, carecemos de elementos para demostrar que este fuera el propósito que originó la acumulación de varios huesos, probablemente pertenecientes al ala izquierda de un único individuo, localizada en el nivel Solutrense del vestíbulo (coracoides P.A.10A.314.34.1.2, húmero P.A.8A.347.58, radio P.A.8A.331.166, ulna P.A.14F.323.228, carpometacarpo P.A.8C.308.75, carpal-ulnar P.A.8A.335.59 y el primer dígito P.A.12B.316.261).

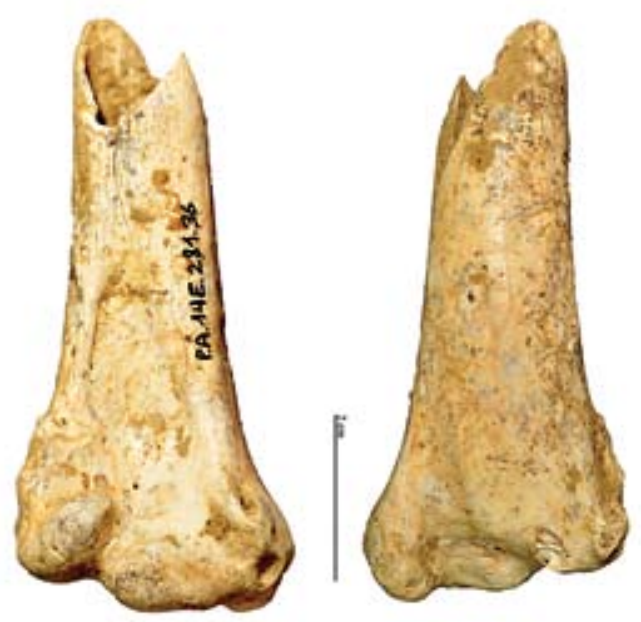

Fig. 4. Fragmento distal de húmero de Águila Real (Aquila chrysaetos). P.A.14E. 281.36. Vestíbulo. Magdaleniense Inferior. / Distal humerus of Golden Eagle (Aquila chrysaetos). P.A.14E. 281.36. Hall. Early Magdalenian.

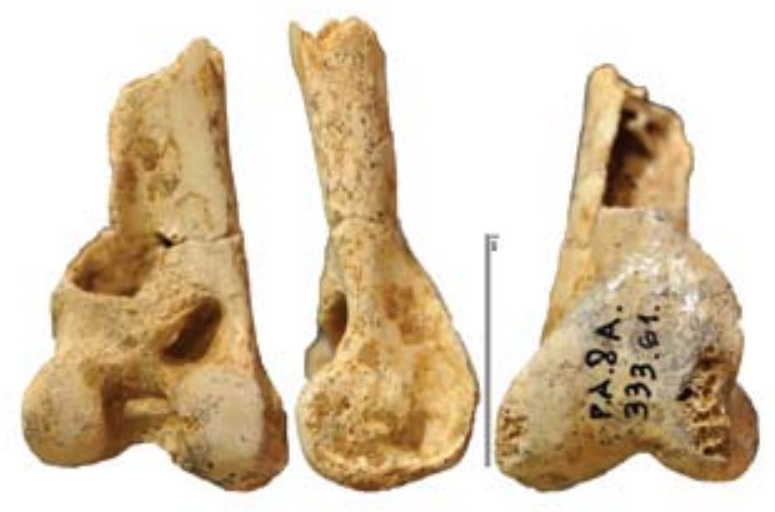

Fig. 5. Fragmento distal de tibiotarso de Águila Real (Aquila chrysaetos). P.A.8A.333.61. Vestíbulo. Solutrense. / Distal tibiotarsus of Golden Eagle (Aquila chrysaetos). P.A.8A.333.61. Hall. Solutrean.

\section{cf.Circus pygargus (Linnaeus, 1758)}

El Aguilucho Cenizo es una especie estival en la Península lbérica que no aparece en el registro arqueológico del País Vasco. La erosión que afecta al tarsometatar- 
so recuperado limita nuestra identificación como posible. Nos basamos en la comparación morfológica con los especímenes actuales de la colección de referencia de nuestro laboratorio y con los criterios métricos publicados para los Accipitridae (SCHMIDT-BURGER, 1982). Su anchura distal (P.A.10C.300.28; Fig.6) cae en el intervalo registrado para las hembras de la especie (Tabl. 7).

\begin{tabular}{|c|c|c|}
\hline \multirow{2}{*}{ TARSOMETATARSO } & \multicolumn{2}{|c|}{ Bd } \\
\hline & Min - Máx. & Media \\
\hline Milvus milvus 40 & $12,8-13,7$ & 13,18 \\
\hline Milvus milvus 5 우 & $13,0-14,2$ & 13,62 \\
\hline Milvus migrans $1{ }^{\wedge}$ & 12,0 & \\
\hline Milvus migrans 29 & $12,5-12,8$ & 12,65 \\
\hline Accipiter gentilis $15 \hat{0}^{\wedge}$ & $12,0-12,7$ & 12,39 \\
\hline Accipiter gentilis 11 운 & $15,0-15,9$ & 15,44 \\
\hline Buteo buteo $33 \hat{0}^{\wedge}$ & $12,6-14,5$ & 13,10 \\
\hline Buteo buteo 27 우 & $13,0-14,5$ & 13,93 \\
\hline Buteo lagopus $30^{\lambda}$ & $12,6-13,1$ & 12,83 \\
\hline Buteo lagopus $2+$ & $14,2-15,0$ & 14,60 \\
\hline Pernis apivorus $3 \hat{\jmath}$ & $12,3-13,0$ & 12,73 \\
\hline Pernis apivorus $4 q$ & $11,4-12,8$ & 12,28 \\
\hline Circus aeruginosus $7 \hat{\jmath}$ & $10,9-11,7$ & 11,36 \\
\hline Circus aeruginosus 59 & $12,3-13,0$ & 12,76 \\
\hline Circus cyaneus $3 \hat{0}$ & $8,6-8,8$ & 8,7 \\
\hline Circus cyaneus 11 + & $10,0-10,6$ & 10,24 \\
\hline Circus pygargus $20^{\wedge}$ & $7,5-7,8$ & 7,65 \\
\hline Circus pygargus $2 q$ & $8,0-8,4$ & 8,2 \\
\hline Praileaitz I cf. Circus pygargus & \multicolumn{2}{|c|}{8,26} \\
\hline
\end{tabular}

Tabl. 7. Datos métricos del tarsometatarso de cf. Circus pygargus recuperado en Praileaitz I comparado con otros Accipitridae (SCHMIDT-BURGER, 1982). / Comparison of the tarsometatarsus metrical data of cf. Circus pygargus recovered from Praileaitz I to other Accipitridae (SCHMIDT-BURGER, 1982).

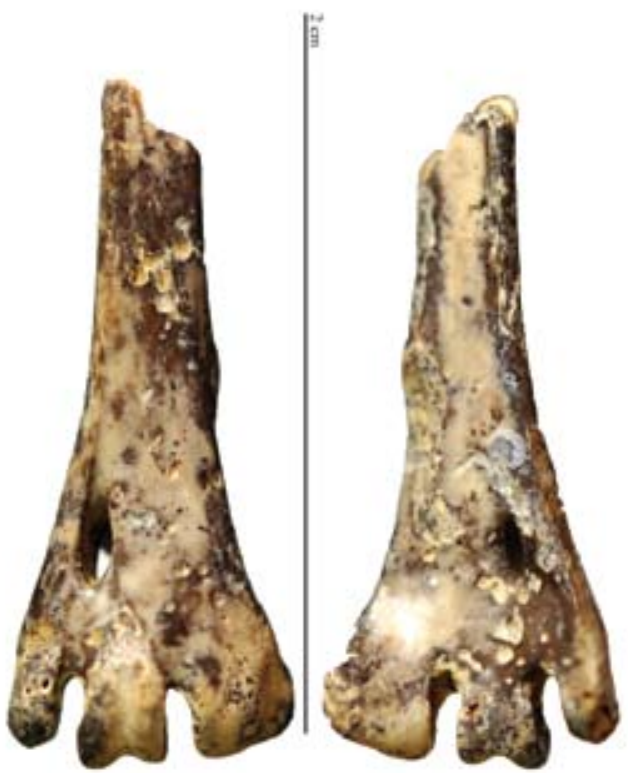

Fig. 6. Fragmento distal de tarsometatarso de posible Aguilucho Cenizo (cf. Circus pygargus). P.A.10C.300. Vestíbulo. Magdaleniense Inferior. / Distal tarsometatarsus of a probable Montagu's Harrier (cf. Circus pygargus). P.A.10C.300. Hall. Early Magdalenian.
FAMILIA FALCONIDAE VIEILLOT, 1816

Un total de 13 restos se asignan a esta familia, de los cuales 7 se identifican como pertenecientes a Cernícalo Vulgar (Falco tinnunculus) y 2 como probablemente a Esmerejón (cf. Falco columbarius). De nuevo, el nivel Solutrense del vestíbulo muestra la mayor concentración con 6 restos y es además donde se registraron los dos posibles taxones. El hueso más abundante es el tarsometatarso (NME: 7) seguido de la ulna (NME: 4) (Tabl. 6). Todos los restos excepto tres, que pertenecían a individuos juveniles (Falco sp.), resultaron mensurables (Anexo 1). Dado que los huesos de las varias especies de pequeños Falconidae son muy semejantes, recurrimos a la biometría con el objetivo de conseguir su determinación específica (SOLTI, 1996).

\section{Falco tinnunculus (Linnaeus, 1758)}

El Cernícalo Vulgar es una especie residente en nuestro territorio al que llega un número de invernantes procedentes del centro y norte de Europa. Habita regiones abiertas o poco arboladas y es poco exigente a la hora de ubicar el nido. Elorza (1990) señala su existencia en la cueva de Santimamiñe y en todos los niveles (del Magdaleniense Final al Auriñaciense) de la cueva de Aitzbitarte IV. Por su parte, Eastham (1989) lo identificó en el nivel Perigordiense de cueva de Amalda y el Magdaleniense Final de cueva de Erralla (EASTHAM, 1985).

El NMl se calculó a partir de los tarsometatarsos izquierdos (Fig. 7). En la secuencia estratigráfica hay 5 individuos que se distribuyen: tres en el nivel Solutrense (dos en el vestíbulo y uno en el pasillo), uno en el Magdaleniense Inferior (vestíbulo) y otro en el Epipaleolítico (vestíbulo). La comparación de los datos métricos de estos especímenes con los publicados por Solti (1996) y los ejemplares presentes en la colección de nuestro laboratorio permiten concluir con alguna confianza que pertenecieron a hembras (Tabl. 8), excepto el fragmento recuperado en el Magdaleniense Inferior que podría tratarse de un macho o incluso pertenecer a Falco columbarius. En la Fig. 8 se observa que la anchura de la diáfisis es el criterio que mejor discrimina entre machos y hembras de Cernícalo Vulgar actuales. Mientras los machos se sitúan en la parte inferior del gráfico, las hembras lo hacen por encima. Los ejemplares de Praileaitz I ocupan la parte superior del conjunto de las hembras. Además es evidente que los tarsometatarsos del Esmerejón son más pequeños y gráciles, situándose los ejemplares actuales en el canto inferior izquierdo.

Por último, referimos que la fractura de una de las ulnas recuperadas del nivel Solutrense del vestíbulo permitió observar la deposición de hueso medular en su interior, lo que sugiere su pertenencia a una hembra en época de cría (DRIVER, 1982). La existencia de tres ejemplares juveniles apoya también la posibilidad de que la cueva pudo haber sido aprovechada por los cernícalos como lugar de reproducción. 


\begin{tabular}{|c|c|c|c|c|c|c|c|c|c|}
\hline \multirow[t]{2}{*}{ CORACOIDES } & & \multicolumn{2}{|l|}{ GL } & \multicolumn{2}{|l|}{$\mathrm{Lm}$} & \multicolumn{2}{|l|}{$\mathrm{Bb}$} & \multicolumn{2}{|l|}{$\mathrm{Bf}$} \\
\hline & & Min - Máx. & Media & Min - Máx. & Media & Min - Máx. & Media & Min - Máx. & Media \\
\hline \multirow[t]{2}{*}{ Solti 1996} & Falco tinnunculus $21{ }^{\lambda}$ & $27,7-31,4$ & 29,50 & $25,5-29,0$ & 27,00 & $10,4-12,9$ & 11,42 & $10,4-13,3$ & 11,49 \\
\hline & Falco tinnunculus $27 \%$ & $27,5-32,4$ & 30,30 & $24,9-29,5$ & 27,67 & $11,0-12,9$ & 11,78 & $10,8-13,0$ & 11,79 \\
\hline \multirow[t]{2}{*}{ CSIC } & Falco tinnunculus $11 \hat{o}^{\lambda}$ & $\begin{array}{c}24,50- \\
28,19\end{array}$ & 26,67 & $\begin{array}{c}23,19 \\
-26,22\end{array}$ & 24,89 & & & $9,76-11,30$ & 10,33 \\
\hline & Falco tinnunculus 109 & $\begin{array}{c}26,32- \\
30,78\end{array}$ & 27,93 & $\begin{array}{c}24,90- \\
28,59\end{array}$ & 26,00 & & & $10,23-12,40$ & 11,00 \\
\hline \multirow[t]{2}{*}{ Solti 1996} & Falco columbarius $150^{\AA}$ & $29,1-30,8$ & 29,87 & $26,9-28,8$ & 27,94 & $10,0-10,9$ & 10,36 & $9,6-10,6$ & 10,17 \\
\hline & Falco columbarius 209 & $30,6-35,1$ & 32,97 & $28,5-33,1$ & 30,82 & $11,0-12,5$ & 11,49 & $10,6-12,1$ & 11,21 \\
\hline \multirow[t]{2}{*}{ CSIC } & Falco columbarius $1{ }^{\lambda}$ & 29,45 & & 27,48 & & & & 9,71 & \\
\hline & Falco columbarius 1 + & 33,28 & & 31,24 & & & & 11,21 & \\
\hline Praileaitz I & cf. Falco columbarius (Solutrense) $q$ & 32,29 & & 29,30 & & 11,61 & & 11,56 & \\
\hline ULNA & & \multicolumn{2}{|l|}{ GL } & \multicolumn{2}{|l|}{$\mathrm{Bp}$} & \multicolumn{2}{|l|}{ sc } & \multicolumn{2}{|l|}{ Did } \\
\hline \multirow[t]{2}{*}{ Solti 1996} & Falco tinnunculus $17 \hat{0}$ & $56,5-64,7$ & 60,12 & $6,2-6,9$ & 6,63 & $3,3-3,7$ & 3,58 & $6,1-6,5$ & 6,31 \\
\hline & Falco tinnunculus 259 & $59,1-67,0$ & 62,43 & $6,5-7,4$ & 6,93 & $3,4-4,1$ & 3,74 & $6,3-7,2$ & 6,66 \\
\hline \multirow[t]{2}{*}{ CSIC } & Falco tinnunculus $110^{\lambda}$ & $51,2-59,2$ & 55,00 & $5,9-6,7$ & 6,25 & $3,2-3,7$ & 3,41 & $5,5-6,4$ & 5,84 \\
\hline & Falco tinnunculus $10 \%$ & $54,9-65,3$ & 58,03 & $6,3-7,3$ & 6,63 & $3,3-3,8$ & 3,55 & $6,0-6,9$ & 6,27 \\
\hline \multirow[t]{2}{*}{ Solti 1996} & Falco columbarius $15{ }^{\lambda}$ & $49,3-54,3$ & 51,74 & $6,0-6,4$ & 6,24 & $3,2-3,5$ & 3,40 & $5,8-6,2$ & 6,06 \\
\hline & Falco columbarius 21 ? & $53,8-60,4$ & 56,77 & $6,5-7,2$ & 6,86 & $3,4-3,9$ & 3,68 & $6,2-6,9$ & 6,65 \\
\hline \multirow[t]{3}{*}{ Praileaitz I } & Falco tinnunculus (Magd. Inf.) $q$ & - & & 7,36 & & - & & - & \\
\hline & Falco tinnunculus (Solutrense) $q$ & 65,52 & & - & & - & & - & \\
\hline & Falco tinnunculus (Solutrense) & 64,65 & & - & & - & & - & \\
\hline TARSOMETATARSO & & \multicolumn{2}{|l|}{ GL } & \multicolumn{2}{|l|}{$\mathrm{Bp}$} & \multicolumn{2}{|l|}{ sc } & \multicolumn{2}{|l|}{$\mathrm{Bd}$} \\
\hline \multirow[t]{2}{*}{ Solti 1996} & Falco tinnunculus $13 \hat{0}$ & $37,5-43,7$ & 40,16 & $6,6-7,6$ & 7,18 & $2,6-3,2$ & 2,95 & $6,4-7,3$ & 6,85 \\
\hline & Falco tinnunculus 239 & $38,4-42,7$ & 40,53 & $6,8-8,0$ & 7,48 & $2,8-3,4$ & 3,09 & $6,4-8,0$ & 7,15 \\
\hline \multirow[t]{2}{*}{ CSIC } & Falco tinnunculus $11 \hat{0}$ & $37,1-41,1$ & 40,07 & $6,5-7,1$ & 6,81 & $2,7-3,2$ & 2,91 & $6,5-7,3$ & 7,01 \\
\hline & Falco tinnunculus $10 q$ & $38,9-42,1$ & 40,36 & $6,7-7,7$ & 7,19 & $3,0-3,3$ & 3,18 & $7,1-7,6$ & 7,40 \\
\hline \multirow[t]{2}{*}{ Solti 1996} & Falco columbarius $17 \hat{0}$ & $34,6-37,7$ & 36,34 & $6,3-7,0$ & 6,76 & $2,2-2,7$ & 2,46 & $6,0-6,7$ & 6,28 \\
\hline & Falco columbarius 209 & $36,6-40,7$ & 38,02 & $6,9-7,9$ & 7,40 & $2,4-2,9$ & 2,69 & $6,5-7,4$ & 6,94 \\
\hline \multirow[t]{2}{*}{ CSIC } & Falco columbarius $10^{\wedge}$ & 36,4 & & 6,5 & & 2,5 & & 6,3 & \\
\hline & Falco columbarius 1 iq & 37,8 & & 7,5 & & 2,9 & & 7,3 & \\
\hline \multirow[t]{6}{*}{ Praileaitz I } & Falco tinnunculus (Epipaleolítico) o & 39,11 & & 7,41 & & 3,25 & & 7,55 & \\
\hline & Falco tinnunculus (Solutrense) $q$ & - & & - & & - & & 7,30 & \\
\hline & Falco tinnunculus (Solutrense) $q$ & 40,32 & & 7,85 & & 3,59 & & - & \\
\hline & Falco tinnunculus (Solutrense) $q$ & - & & - & & - & & 7,89 & \\
\hline & Falco tin. ¿̊? / F. col. (Magd. Inf.) & 38,20 & & 6,61 & & 3,20 & & 6,77 & \\
\hline & cf. F. columbarius (Solutrense) o & 38,46 & & - & & - & & - & \\
\hline
\end{tabular}

Tabl. 8. Datos métricos de Falco tinnunculus y Falco columbarius actuales comparados con los restos recuperados en Praileaitz I. / Comparison of metrical data of modern Falco tinnunculus and Falco columbarius to remains recovered from Praileaitz I. 

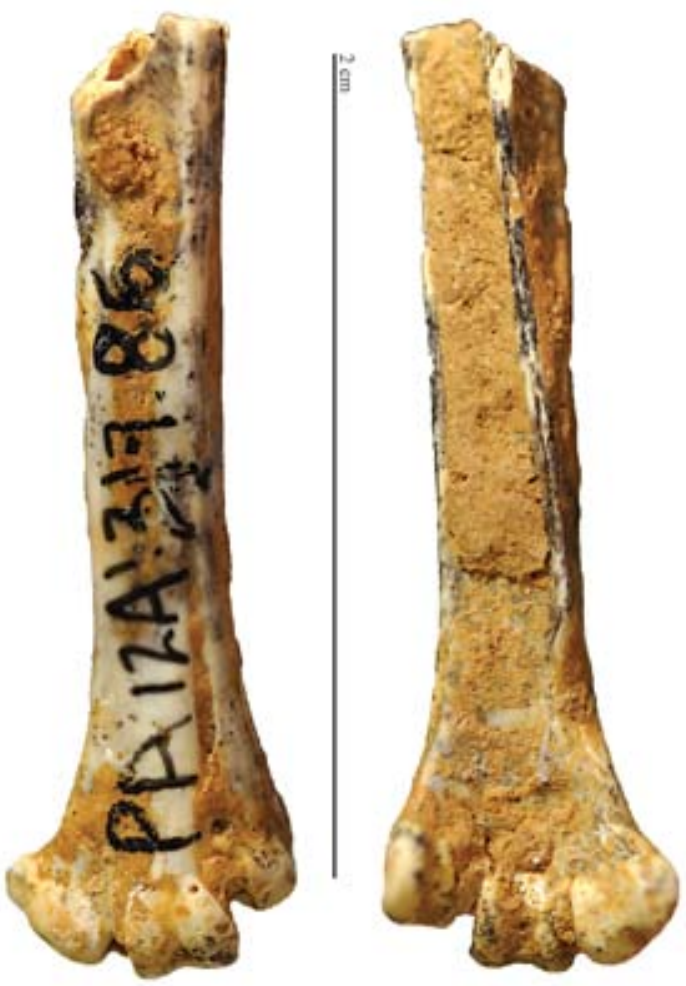

Fig. 7. Tarsometatarso de Cernícalo Vulgar (Falco tinnunculus). P.A.-12A'.317.85. Tránsito entre vestíbulo y primera sala interior. Solutrense. / Tarsometatarsus of Common Kestrel (Falco tinnunculus). P.A.12A'.317.85. Transit area between the hall and the first internal space. Solutrean.

\section{cf. Falco columbarius (Linnaeus, 1758)}

El Esmerejón es el falcónido más pequeño de la fauna europea. Llega a la Península lbérica como invernante desde Escandinavia. Las principales vías de entrada se localizan en ambos extremos de la cordillera pirenaica y se instala en áreas abiertas y llanas, principalmente en la Meseta norte. También se ha registrado su preferencia por zonas húmedas naturales y embalses con pocos cambios de nivel, que resultan atrayentes para las presas que forman parte de su dieta. Es una especie ornitófaga, especialista en el consumo de pequeñas y medianas aves, menores de $50 \mathrm{gr}$, como jilgueros, bisbitas, limícolas y otros pequeños paseriformes, aunque las hembras con su mayor envergadura pueden cazar aves del tamaño de una urraca (SUNYER, VIÑUELA, 1990).

Los dos restos asignados (con reservas) a esta especie son un coracoides (P.A.8E.299.209.7) y un tarsometatarso (P.A.8E.299.209.11) recuperados en el nivel solutrense del vestíbulo. Los datos métricos no resultan concluyentes a la hora de llegar a una determinación específica, pues existe solapamiento en algunas medidas con el Cernícalo (Tabl. 8). La comparación con los ejemplares de la colección de referencia nos inclina a identificarlos como posible Esmerejón.

\section{ORden CHARADRIIIFORMES HuXLEY, 1867}

Las familias comprendidas en este orden de aves se encuentran relacionadas con medios acuáticos. En el caso de Praileaitz I aparecen representadas Alcidae, Laridae y Sternidae. Todas ellas incluyen aves marinas que frecuentan la costa cantábrica. No fue posible rea-

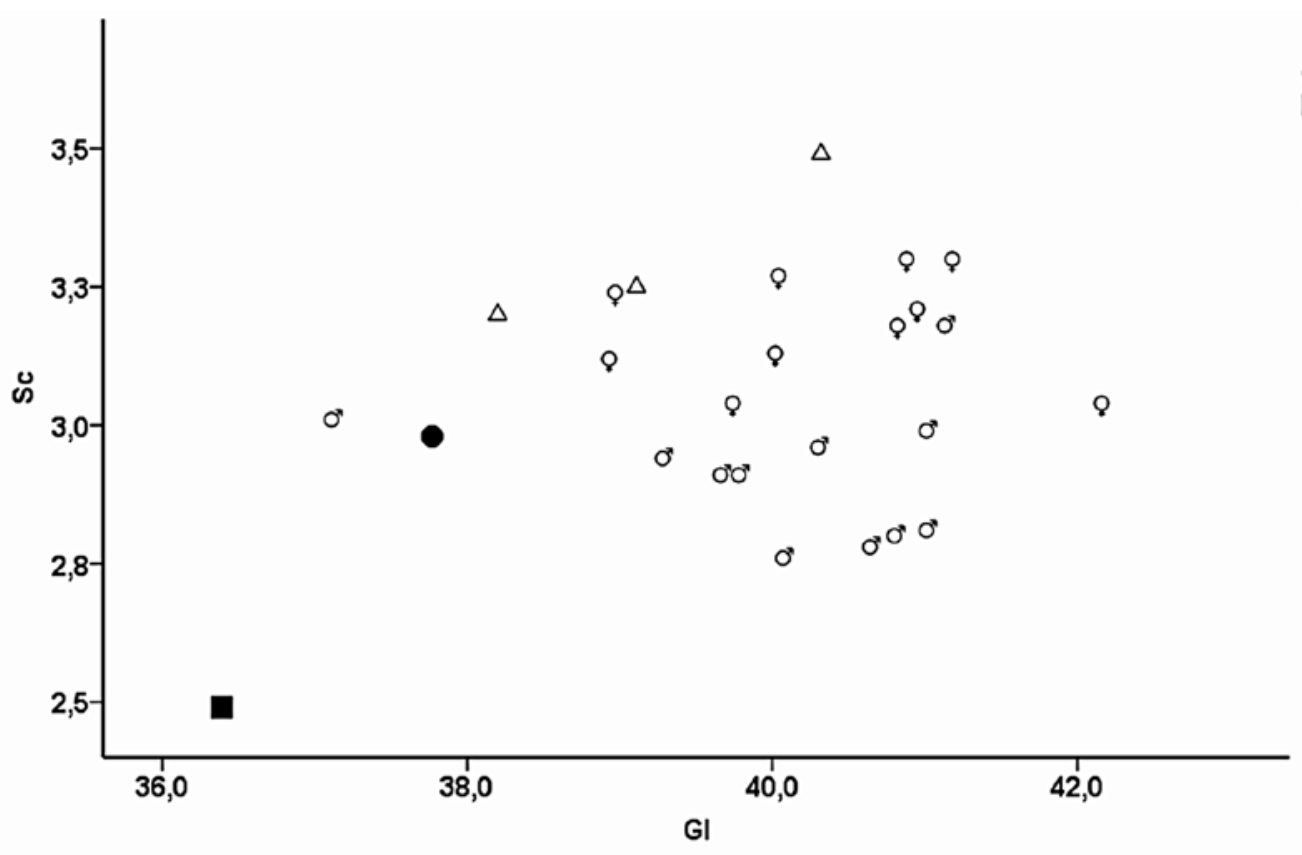

OF. COLUMBARIUS HEMBRA
G. COLUMBARIUS MACHO
OF. TINNUNCULUS HEMBRA
O'F. TINNUNCULUS MACHO $\triangle$ PRAILEAITZ

Fig. 8. Gráfico de dispersión. Anchura vs. longitud máxima de la diáfisis del tarsometarso de Cernícalo Vulgar (Falco tinnunculus) y Esmerejón (Falco columbarius) actuales y ejemplares recuperados en Praileaitz I. / Scattergram. Width vs greatest length of tarsometatarsus of modern Common Kestrel (Falco tinnunculus), Merlin (Falco columbarius) and samples recovered in Praileaitz I. 


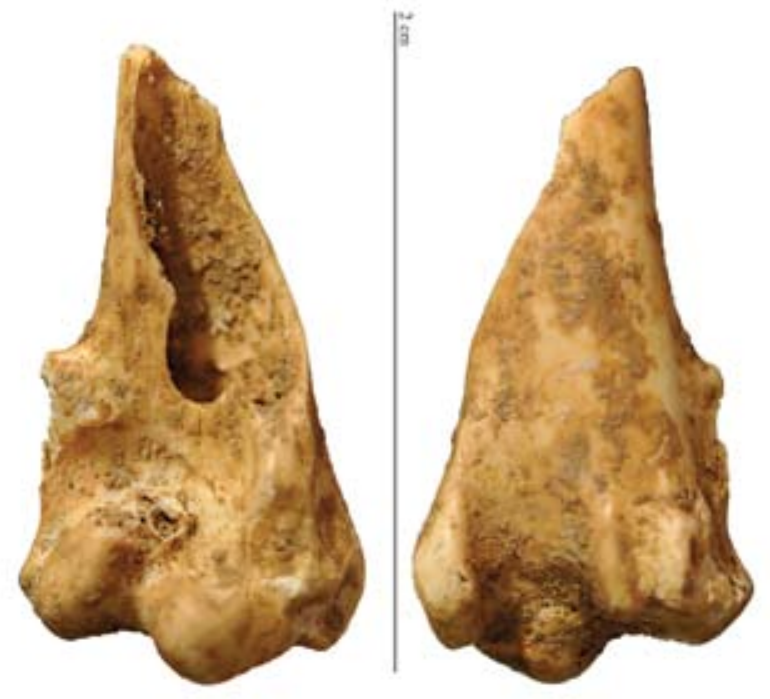

Fig. 9. Fragmento distal de húmero de Laridae. Probable Gaviota reidora (Chroicocephalus ridibundus). P.A.12A'.281.56. Tránsito entre vestíbulo y primera sala interior. Magdaleniense Inferior. I. / Distal humerus of Laridae. Probably Black-headed Gull (Chroicocephalus ridibundus). P.A.12A'.281.56. Transit between hall and first internal space. Early Magdalenian.

lizar identificaciones taxonómicas a nivel de género o especie, aunque los dos restos de Laridae (un coracoides P.A.12A'.285.13 y un húmero P.A.12A'.281.56; Fig. 9 , ambos del lado derecho) recuperados en el nivel del
Magdaleniense Inferior de la zona de tránsito entre el vestíbulo y la primera sala interior se aproximan mucho a la Gaviota reidora (Chroicocephalus ridibundus). Los Alcidae aparecen en los niveles del Magdaleniense Superior/Final y del Epipaleolítico.

\section{Orden COLUMBIFORMES Latham, 1790 \\ Familia COLUMBIDAE Illiger, 1811 \\ Columba livia (Gmelin, 1789)/ Columba oenas (Linaeus, 1758)}

Los Columbiformes con un total de 215 fragmentos suponen el $5 \%$ de la avifauna de Praileaitz I y están presentes en todos los niveles y espacios de la cueva. La mayor concentración de restos e individuos se constata en el nivel Epipaleolítico, al que le sigue el Magdaleniense Inferior, Magdaleniense Superior, Solutrense y por último el nivel SolutrenseGravetiense, en el que apenas se recuperó un individuo (Tabl. 9).

Las semejanzas osteológicas y métricas entre la Paloma Bravía (Columba livia) y la Paloma Zurita (Columba oenas) nos llevan a considerar la existencia de ambas especies (Anexo 1). Las dimensiones de los huesos identificados se ubican en el rango de las medidas registradas por Fick (1974) para ambos taxones (Tabl. 10). En todos los casos son más pequeñas que las de la Paloma Torcaz (Columba palumbus), especie de mayor tamaño. La Paloma Bravía cría en cuevas y en acan-

\begin{tabular}{|c|c|c|c|c|c|c|c|c|c|c|c|c|c|c|c|}
\hline \multirow[t]{2}{*}{$\begin{array}{l}\text { HUESO } \\
\text { (NMI) }\end{array}$} & \multicolumn{3}{|c|}{$\begin{array}{c}\text { EPIPALEOLÍTICO } \\
\text { (8) }\end{array}$} & \multicolumn{3}{|c|}{$\begin{array}{c}\text { MAGD. SUP } \\
\text { (4) }\end{array}$} & \multicolumn{3}{|c|}{$\begin{array}{l}\text { MAGD. INF } \\
\text { (5) }\end{array}$} & \multicolumn{3}{|c|}{$\begin{array}{l}\text { SOLUTRENSE } \\
\text { (5) }\end{array}$} & \multicolumn{3}{|c|}{$\begin{array}{l}\text { SOLUTRENSE- } \\
\text { GRAVETIENSE } \\
\text { (1) }\end{array}$} \\
\hline & NR & NME & $\% \mathrm{C}$ & NR & NME & $\%$ C & NR & NME & $\%$ C & NR & NME & $\%$ C & NR & NME & $\%$ C \\
\hline $\begin{array}{l}\text { Coracoides } \\
\%\end{array}$ & $\begin{array}{l}16 \\
18 \\
\end{array}$ & $\begin{array}{c}8 \\
18 \\
\end{array}$ & 50 & $\begin{array}{c}9 \\
23 \\
\end{array}$ & $\begin{array}{c}4 \\
19 \\
\end{array}$ & 50 & $\begin{array}{c}8 \\
16 \\
\end{array}$ & $\begin{array}{c}5 \\
17 \\
\end{array}$ & 50 & $\begin{array}{c}7 \\
20\end{array}$ & $\begin{array}{c}4 \\
20\end{array}$ & 40 & 1 & 1 & 50 \\
\hline $\begin{array}{l}\text { Escápula } \\
\%\end{array}$ & $\begin{array}{l}4 \\
5\end{array}$ & $\begin{array}{l}3 \\
7 \\
\end{array}$ & 19 & $\begin{array}{l}2 \\
5 \\
\end{array}$ & $\begin{array}{l}1 \\
5 \\
\end{array}$ & 12 & $\begin{array}{c}6 \\
12 \\
\end{array}$ & $\begin{array}{c}4 \\
13 \\
\end{array}$ & 40 & $\begin{array}{l}2 \\
6 \\
\end{array}$ & $\begin{array}{l}1 \\
5 \\
\end{array}$ & 10 & 1 & 1 & 50 \\
\hline $\begin{array}{l}\text { Húmero } \\
\%\end{array}$ & $\begin{array}{l}16 \\
18 \\
\end{array}$ & $\begin{array}{c}7 \\
15 \\
\end{array}$ & 44 & $\begin{array}{c}5 \\
13 \\
\end{array}$ & $\begin{array}{c}3 \\
14 \\
\end{array}$ & 37 & $\begin{array}{c}5 \\
10 \\
\end{array}$ & $\begin{array}{c}3 \\
10 \\
\end{array}$ & 30 & $\begin{array}{c}4 \\
11 \\
\end{array}$ & $\begin{array}{c}2 \\
10 \\
\end{array}$ & 20 & 1 & 1 & 50 \\
\hline $\begin{array}{l}\text { Ulna } \\
\%\end{array}$ & $\begin{array}{l}19 \\
22\end{array}$ & $\begin{array}{c}7 \\
15 \\
\end{array}$ & 44 & $\begin{array}{c}6 \\
15\end{array}$ & $\begin{array}{c}3 \\
14\end{array}$ & 37 & $\begin{array}{l}12 \\
24\end{array}$ & $\begin{array}{c}5 \\
17 \\
\end{array}$ & 50 & $\begin{array}{l}10 \\
29\end{array}$ & $\begin{array}{c}5 \\
25 \\
\end{array}$ & 50 & 1 & 1 & 50 \\
\hline $\begin{array}{l}\text { Radio } \\
\%\end{array}$ & $\begin{array}{l}5 \\
6 \\
\end{array}$ & $\begin{array}{l}3 \\
7 \\
\end{array}$ & 19 & $\begin{array}{l}3 \\
8 \\
\end{array}$ & $\begin{array}{l}2 \\
9\end{array}$ & 25 & $\begin{array}{c}5 \\
10 \\
\end{array}$ & $\begin{array}{c}3 \\
10\end{array}$ & 30 & $\begin{array}{l}2 \\
6 \\
\end{array}$ & $\begin{array}{c}2 \\
10 \\
\end{array}$ & 20 & - & - & - \\
\hline $\begin{array}{l}\text { Carpometacarpo } \\
\%\end{array}$ & $\begin{array}{l}12 \\
14 \\
\end{array}$ & $\begin{array}{c}7 \\
15 \\
\end{array}$ & 44 & $\begin{array}{c}4 \\
10 \\
\end{array}$ & $\begin{array}{l}2 \\
9 \\
\end{array}$ & 25 & $\begin{array}{c}7 \\
14 \\
\end{array}$ & $\begin{array}{c}5 \\
17 \\
\end{array}$ & 50 & $\begin{array}{l}2 \\
6 \\
\end{array}$ & $\begin{array}{l}1 \\
5 \\
\end{array}$ & 10 & 1 & 1 & 50 \\
\hline $\begin{array}{l}\text { Fémur } \\
\%\end{array}$ & $\begin{array}{l}2 \\
2 \\
\end{array}$ & $\begin{array}{l}2 \\
4 \\
\end{array}$ & 13 & $\begin{array}{l}1 \\
3 \\
\end{array}$ & $\begin{array}{l}1 \\
5 \\
\end{array}$ & 12 & $\begin{array}{l}1 \\
2 \\
\end{array}$ & $\begin{array}{l}1 \\
3 \\
\end{array}$ & 10 & $\begin{array}{l}3 \\
8 \\
\end{array}$ & $\begin{array}{c}2 \\
10 \\
\end{array}$ & 20 & - & - & - \\
\hline $\begin{array}{l}\text { Tibiotarso } \\
\%\end{array}$ & $\begin{array}{l}4 \\
5\end{array}$ & $\begin{array}{l}3 \\
7 \\
\end{array}$ & 19 & $\begin{array}{c}4 \\
10 \\
\end{array}$ & $\begin{array}{l}2 \\
9\end{array}$ & 25 & $\begin{array}{l}1 \\
2 \\
\end{array}$ & $\begin{array}{l}1 \\
3 \\
\end{array}$ & 10 & $\begin{array}{l}3 \\
8 \\
\end{array}$ & $\begin{array}{c}2 \\
10 \\
\end{array}$ & 20 & - & - & - \\
\hline $\begin{array}{l}\text { Tarsometatarso } \\
\%\end{array}$ & $\begin{array}{c}9 \\
10\end{array}$ & $\begin{array}{c}5 \\
11 \\
\end{array}$ & 31 & $\begin{array}{c}5 \\
13\end{array}$ & $\begin{array}{c}3 \\
14\end{array}$ & 37 & $\begin{array}{l}4 \\
8\end{array}$ & $\begin{array}{c}3 \\
10\end{array}$ & 30 & $\begin{array}{l}2 \\
6\end{array}$ & $\begin{array}{l}1 \\
5\end{array}$ & 10 & - & - & - \\
\hline $\begin{array}{l}\text { Total } \\
\%\end{array}$ & $\begin{array}{c}87 \\
100 \\
\end{array}$ & $\begin{array}{c}45 \\
100 \\
\end{array}$ & & $\begin{array}{c}39 \\
100 \\
\end{array}$ & $\begin{array}{c}21 \\
100 \\
\end{array}$ & & $\begin{array}{c}49 \\
100 \\
\end{array}$ & $\begin{array}{c}30 \\
100 \\
\end{array}$ & & $\begin{array}{c}35 \\
100 \\
\end{array}$ & $\begin{array}{c}20 \\
100 \\
\end{array}$ & & 5 & 5 & \\
\hline
\end{tabular}

Tabl. 9. Praileaitz I. Perfil anatómico de Paloma Bravía/Zurita (Columba livia/Columba oenas). Número de restos (NR), Número Mínimo de Elementos (NME) y porcentaje de huesos conservados (\% C). / Praileaitz I. Anatomical representation of Rock dove/Stock dove (Columba livia/Columba oenas). Number of remains (NR), Minimum Number of Elements (NME) and frequency of preserved bones (\% C). 
tilados, principalmente en costas marinas mientras que la Paloma Zurita prefiere zonas arboladas y linderos de bosques, aunque localmente también anida en costas rocosas, en salientes o en cavidades (SVENSSON et al., 2009).
Únicamente se determinaron los principales huesos de las alas y las patas, así como la escápula y el coracoides del esqueleto axial (Fig. 10). El perfil anatómico cuantificado a partir del número de restos (NR) ofrece valores mayores que el calculado a través del NME. En el primer

\begin{tabular}{|c|c|c|c|c|c|c|c|c|c|}
\hline \multirow[t]{2}{*}{ CORACOIDES } & & \multicolumn{2}{|c|}{ GL } & \multicolumn{2}{|c|}{$\mathrm{Lm}$} & \multicolumn{2}{|c|}{$\mathrm{Bb}$} & \multicolumn{2}{|c|}{$\mathrm{Bf}$} \\
\hline & & Min - Máx. & Media & Min - Máx. & Media & Min - Máx. & Media & Min - Máx. & Media \\
\hline \multirow[t]{3}{*}{ Fick 1974} & Columba palumbus (38) & $39,2-44,3$ & 42,0 & $37,4-42,2$ & 39,9 & $16,2-18,3$ & 17,0 & $9,5-13,0$ & 11,6 \\
\hline & Columba oenas (20) & $33,0-37,0$ & 34,7 & $31,5-35,4$ & 33,0 & $12,6-15,3$ & 13,6 & $8,8-10,3$ & 9,5 \\
\hline & Columba livia (8) & $32,2-35,4$ & 34,1 & $29,7-33,4$ & 32,2 & $12,7-14,1$ & 13,6 & $9,2-9,8$ & 9,5 \\
\hline Praileaitz I & & $32,13-35,87$ & $34,08(15)$ & $30,16-35,19$ & $32,72(21)$ & $9,48-14,40$ & $11,36(5)$ & $8,36-10,09$ & $8,98(11)$ \\
\hline HUMERO & & \multicolumn{2}{|c|}{ GL } & \multicolumn{2}{|c|}{ Dip } & \multicolumn{2}{|c|}{ SC } & \multicolumn{2}{|c|}{$B d$} \\
\hline \multirow[t]{3}{*}{ Fick 1974} & Columba palumbus (29) & $49,8-56,9$ & 54,2 & $19,8-22,2$ & 21,1 & $5,8-6,8$ & 6,2 & $11,8-13,6$ & 12,9 \\
\hline & Columba oenas (18) & $42,9-48,4$ & 45,8 & $16,5-18,5$ & 17,5 & $4,8-5,5$ & 5,2 & $10,0-11,2$ & 10,6 \\
\hline & Columba livia (8) & $40,7-46,4$ & 45,0 & $15,5-18,4$ & 17,4 & $5,0-5,2$ & 5,0 & $9,8-10,5$ & 10,2 \\
\hline Praileaitz I & & $43,75-45,98$ & $44,83(9)$ & $15,09-17,12$ & $15,95(8)$ & $4,94-5,64$ & $5,22(14)$ & $9,56-11,23$ & $10,36(22)$ \\
\hline ULNA & & \multicolumn{2}{|c|}{ GL } & \multicolumn{2}{|c|}{$\mathrm{Bp}$} & \multicolumn{2}{|c|}{ SC } & \multicolumn{2}{|c|}{ Did } \\
\hline \multirow[t]{3}{*}{ Fick 1974} & Columba palumbus (23) & $58,8-63,7$ & 61,4 & $7,7-8,8$ & 8,5 & $3,8-4,6$ & 4,1 & $6,4-7,2$ & 6,8 \\
\hline & Columba oenas (18) & $50,7-54,7$ & 52,5 & $6,5-7,4$ & 6,9 & $3,1-3,8$ & 3,4 & $5,0-6,0$ & 5,5 \\
\hline & Columba livia (8) & $49,4-53,3$ & 52,0 & $6,1-7,4$ & 6,9 & $3,2-3,5$ & 3,4 & $5,3-6,0$ & 5,8 \\
\hline Praileaitz I & & $49,01-54,66$ & $51,53(12)$ & $5,85-7,45$ & $6,71(17)$ & $3,46-4,28$ & $3,76(13)$ & $5,99-7,27$ & $6,82(29)$ \\
\hline CARPOMETACARPO & & \multicolumn{2}{|c|}{ GL } & & & & & & \\
\hline \multirow[t]{3}{*}{ Fick 1974} & Columba palumbus (24) & $36,1-40,3$ & 38,5 & & & & & & \\
\hline & Columba oenas (18) & $31,8-35,3$ & 33,8 & & & & & & \\
\hline & Columba livia (8) & $30,8-33,0$ & 32,0 & & & & & & \\
\hline Praileaitz I & & $31,38-34,63$ & $32,87(14)$ & & & & & & \\
\hline TIBIOTARSO & & & & & & & & \multicolumn{2}{|c|}{$\mathrm{Bd}$} \\
\hline \multirow[t]{3}{*}{ Fick 1974} & Columba palumbus (23) & & & & & & & $6,8-7,9$ & 7,3 \\
\hline & Columba oenas (18) & & & & & & & $5,5-6,6$ & 6,1 \\
\hline & Columba livia (8) & & & & & & & $6,0-7,2$ & 6,5 \\
\hline Praileaitz I & & & & & & & & $6,14-6,85$ & $6,41(10)$ \\
\hline TARSOMETATARSO & & \multicolumn{2}{|c|}{ GL } & \multicolumn{2}{|c|}{$\mathrm{Bp}$} & \multicolumn{2}{|c|}{ SC } & \multicolumn{2}{|c|}{$\mathrm{Bd}$} \\
\hline \multirow[t]{3}{*}{ Fick 1974} & Columba palumbus (21) & $30,4-32,8$ & 31,9 & $7,4-8,8$ & 8,3 & $3,2-3,8$ & 3,5 & $7,7-9,0$ & 8,5 \\
\hline & Columba oenas (18) & $27,8-30,5$ & 29,4 & $6,6-8,4$ & 7,0 & $2,6-3,3$ & 2,9 & $6,6-7,6$ & 7,2 \\
\hline & Columba livia (8) & $27,2-31,0$ & 29,4 & $6,8-7,6$ & 7,3 & $2,8-3,0$ & 2,9 & $6,9-8,2$ & 7,5 \\
\hline Praileaitz | & & 28,39 - 31,82 & 30,43 (12) & $6,39-7,34$ & 6,82 (11) & $2,80-3,29$ & $3,02(10)$ & $6,62-8,20$ & 7,35 (12) \\
\hline
\end{tabular}

Tabl. 10. Datos métricos de palomas (FICK 1974) actuales comparados con los restos recuperados en Praileaitz I. Número de la muestra entre paréntesis. / Comparison of modern pigeons' metrical data (FICK 1974) with remains from Praileaitz I. Sample number in brackets.

caso, la ulna es casi siempre el elemento mejor representado, mientras que en el segundo lo es el coracoides, salvo en el Solutrense donde la ulna se confirma como el elemento más frecuente (Tabl. 9). En el otro extremo se encuentran los fémures, las escápulas y los tibiotarsos. Este patrón difiere del que Mourer-Chauviré (1983) atribuye a acumulaciones de origen antrópico, ya comentado en relación a los anátidos, y se encuentra próximo del generado por rapaces, dominados por coracoides y tarsometatarsos (BOCHENSKI, 2005).
Laroulandie (2002) en el análisis tafonómico realizado sobre restos de palomas en egagrópilas de Búho Real y restos no ingeridos de alimentación de Halcón Peregrino observa que mientras los huesos de las patas, en particular los tarsometatarsos, están muy bien representados en las egagrópilas, no ocurre lo mismo en los restos no consumidos por la rapaz diurna (vide Tabl. 1 en LAROULANDIE, 2002). Las muestras de Praileaitz I se encuentran en una posición intermedia entre estas dos situaciones lo que nos hace considerar la existencia de 


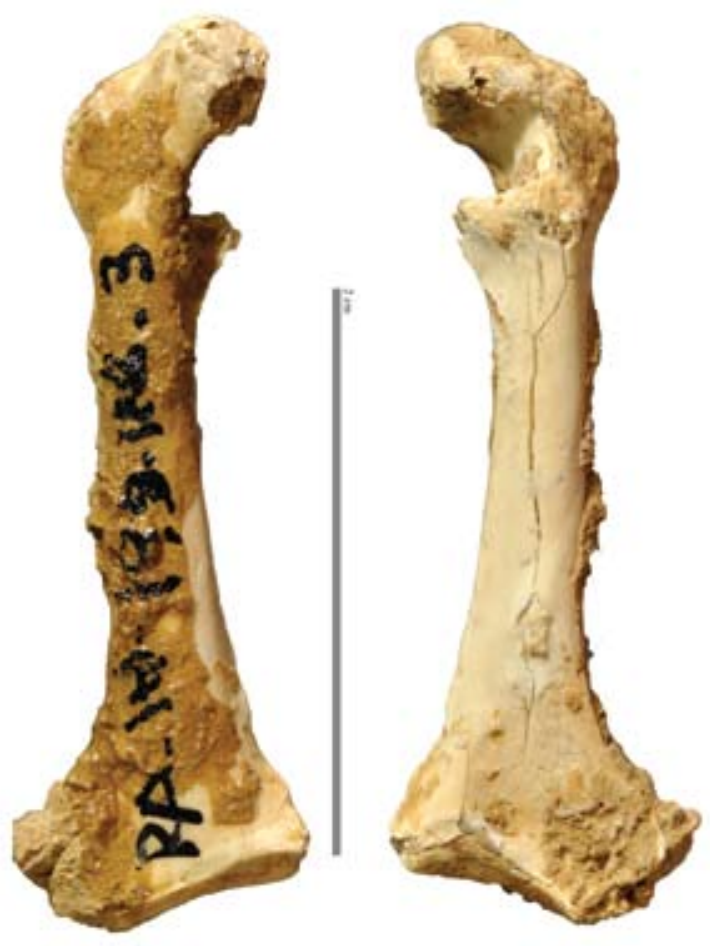

Fig. 10. Coracoides de Paloma Bravía/Paloma Zurita (Columba livia/Columba oenas). P.A.1H.198.188.3. Galería noroeste. Epipaleolítico-Magdaleniense Inferior. / Coracoid of Rock dove/ Stock dove (Columba livia/Columba oenas). P.A.1H.198.188.3. Northwest gallery. Epipalaeolithic-Early Magdalenian.

factores como por ejemplo, la erosión y otros procesos postdeposicionales, que pudieron influir en la conservación diferencial de los huesos y afectar a la formación de la tafocenosis recuperada. Con el objetivo de confirmar esta hipótesis procedemos al análisis del estado de fragmentación.
A partir de diversos estudios actualísticos, Bochenski (2005) distingue tres categorías de fragmentación: alta, intermedia y baja, en los huesos de las presas de aves rapaces diurnas y nocturnas. Los restos regurgitados en egagrópilas de rapaces diurnas aparecen siempre muy fragmentados, siendo la frecuencia de huesos completos inferior a $30 \%$. En el nivel intermedio estos ocurren entre $30 \%$ y $60 \%$, circunstancia que se observa en los materiales procedentes de acumulaciones mixtas derivadas de egagrópilas y restos no consumidos de rapaces nocturnas. La incidencia más alta de huesos completos se registra entre los restos no consumidos de rapaces diurnas, con valores superiores a $60 \%$. Por otro lado, la mayor o menor fragmentación del coracoides permite distinguir restos no consumidos de aquellos derivados de egagrópilas. Las rapaces diurnas rasgan la carne de sus víctimas, pero dejan intacta la articulación de la zona pectoral (esternón - coracoides - húmero) de manera que el coracoides permanece completo. La frecuencia media de huesos completos de palomas en Praileaitz I oscila entre 37\% - 44\% (Tabl. 11), es decir se sitúa en la categoría intermedia. Escápula, fémur y tibiotarso son los elementos más afectados, mientras carpometacarpo, coracoides y tarsometatarso están mejor conservados. No se observaron trazas de digestión o perforaciones producidas por el impacto de picos y garras (LAROULANDIE, 2002). Desde esta perspectiva, las evidencias apuntan a que parte de las palomas acumuladas en esta cueva derivan de esqueletos no consumidos y que sobre los elementos más frágiles actuaron factores bioestratinómicos y diagenéticos que alteraron la acumulación original (BOCHENSKI, TOMEK, 1997).

Otro criterio que también apoya esta hipótesis es el cálculo de la ratio del número total de huesos de alas en relación al de patas (ERICSON, 1987). En las egagrópilas de las rapaces esta ratio es normalmente 1:1 (50\%)

\begin{tabular}{|c|c|c|c|c|c|c|c|c|c|c|c|c|c|c|c|}
\hline \multirow[t]{2}{*}{$\begin{array}{l}\text { PERIODO } \\
\text { (NR) }\end{array}$} & \multicolumn{3}{|c|}{$\begin{array}{c}\text { EPIPALEOLÍTICO } \\
\text { (87) }\end{array}$} & \multicolumn{3}{|c|}{$\begin{array}{l}\text { MAGD. SUP/FIN } \\
\text { (39) }\end{array}$} & \multicolumn{3}{|c|}{$\begin{array}{l}\text { MAGD. INF } \\
\text { (49) }\end{array}$} & \multicolumn{3}{|c|}{$\begin{array}{c}\text { SOLUTRENSE } \\
\text { (35) }\end{array}$} & \multicolumn{3}{|c|}{$\begin{array}{c}\text { SOLUTRENSE- } \\
\text { GRAVETIENSE } \\
\text { (5) }\end{array}$} \\
\hline & C & $\mathbf{F}$ & $\% \mathrm{C}$ & C & $\mathbf{F}$ & $\% \mathrm{C}$ & C & $\mathbf{F}$ & $\% \mathrm{C}$ & C & $\mathbf{F}$ & $\% \mathrm{C}$ & C & $\mathbf{F}$ & $\% \mathrm{C}$ \\
\hline \multicolumn{16}{|l|}{ HUESO } \\
\hline Coracoides & 10 & 6 & 62,5 & 5 & 4 & 56 & 6 & 2 & 75 & 4 & 3 & 57 & - & 1 & - \\
\hline Escápula & - & 4 & - & - & 2 & - & - & 6 & - & - & 2 & - & - & 1 & - \\
\hline Húmero & 6 & 10 & 37,5 & 3 & 2 & 60 & 1 & 4 & 20 & 1 & 3 & 25 & - & 1 & - \\
\hline Ulna & 5 & 14 & 26 & - & 6 & - & 5 & 7 & 42 & 4 & 6 & 40 & - & 1 & - \\
\hline Radio & 2 & 3 & 40 & - & 3 & - & 3 & 2 & 60 & 1 & 1 & 50 & - & - & - \\
\hline Carpometacarpo & 6 & 6 & 50 & 4 & - & 100 & 3 & 4 & 43 & 1 & 1 & 50 & - & 1 & - \\
\hline Fémur & - & 2 & - & 1 & - & 100 & - & 1 & - & - & 3 & - & - & - & - \\
\hline Tibiotarso & 1 & 3 & 25 & - & 4 & - & - & 1 & - & 1 & 2 & 33 & - & - & - \\
\hline Tarsometatarso & 6 & 3 & 67 & 4 & 1 & 80 & 1 & 3 & 25 & 1 & 1 & 50 & - & - & - \\
\hline $\mathrm{N} / \%$ medio C & 36 & 51 & 41 & 17 & 22 & 44 & 19 & 30 & 39 & 13 & 22 & 37 & - & 5 & - \\
\hline
\end{tabular}

Tabl. 11. Praileaitz I. Porcentaje de huesos completos (C) de palomas (Columba livia/Columba oenas). (NR= número de restos). / Praileaitz I. Frequency of complete bones $(\mathrm{C})$ of pigeons (Columba livia/Columba oenas). (NR= number of remains). 
mientras la frecuencia de huesos del ala es bastante superior entre los restos no consumidos (BOCHENSKI, 2005: 34). Además, se ha demostrado que la abundancia de alas no se debe únicamente a factores de conservación (BOVY, 2002). Esta ratio oscila entre $60 \%$ y $80 \%$ en Praileaitz I (Tabl. 12).

\begin{tabular}{|l|c|}
\hline & PALOMAS \\
\hline & Ratio (\%) \\
\hline Epipaleolítico & 76 \\
\hline Magdaleniense Superior/Final & 60 \\
\hline Magdaleniense Inferior & 80 \\
\hline Solutrense & 67 \\
\hline
\end{tabular}

Tabl. 12. Ratio de alas vs. patas en las palomas recuperadas en Praileaitz I. / Ratio of wings vs. legs in the pigeon remains from Praileaitz I.

En conclusión, las características descritas indican que gran parte de las palomas recuperadas no derivan de las regurgitaciones de aves rapaces, sino que se asocian a restos no consumidos. Ante esta circunstancia, con las reservas que impone lo reducido de la muestra y su estado de conservación, resulta imposible discernir entre lo que pudieron ser acumulaciones naturales de aquellas derivadas de carcasas no consumidas por rapaces. Ambas situaciones son compatibles con las evidencias obtenidas.

\section{ORDEN STRIGIFORMES WAGLER, 1830 \\ FAMILIA STRIGIDAE VIGORS, 1825}

Esta familia comprende las rapaces nocturnas. Su representación en la cueva es residual $(\mathrm{NR}=6)$. Se identificó apenas Búho Real (Bubo bubo). Los restos no determinados pertenecen a una Strigidae de menores dimensiones (Tabl. 3).

\section{Bubo bubo (Linnaeus, 1758)}

Se trata de la mayor rapaz nocturna europea. Habita zonas muy variadas desde bosques cerrados a semidesiertos, acantilados costeros y tundras. En la Península Ibérica, su alimentación se basa fundamentalmente en el conejo, aunque también captura una amplia variedad de vertebrados, desde córvidos y aves acuáticas a pollos de otras rapaces diurnas y nocturnas (MARTÍNEZ-CLIMENT, ZUBEROGOITIA ARROYO, 2003). Su presencia ya ha sido registrada en la cueva de Lumentxa (ELORZA, 1990), cueva de Laminak II (HERNÁNDEZ CARRASQUILLA, 1993) y cueva de Amalda (EASTHAM, 1989).

\section{Orden APODIFORMES Peters, 1940}

FAMILIA APODIDAE HARTERT, 1897

Apus apus (Linnaeus, 1758)

Los dos restos de Vencejo Común, un coracoides (P.A.1E.213.131.6) y un carpometacarpo (P.A.6F.199.290) izquierdos, proceden del nivel Epipaleolítico del Vestíbulo. Solo resultó mensurable el segundo (Anexo 1). El Ven- cejo es una especie estival y en origen rupícola, que cría en cuevas, acantilados y cavidades rocosas (CASAUX RIVAS, 2003).

\section{ORdEN PASSERIFORMES LINNAEUS, 1758 \\ FAMILIA CORVIDAE VIGORS, 1825}

Los córvidos constituyen la familia dominante de la asociación arqueornitológica recuperada en Praileaitz I con más de 3500 restos repartidos por toda la secuencia estratigráfica de la cueva (Tabl. 3). Son particularmente abundantes en el Solutrense $(\mathrm{NR}=1431)$ y el Magdaleniense Inferior $(\mathrm{NR}=1118)$. Fue posible identificar cuatro especies: Cuervo (Corvus corax), Chova Piquigualda (Pyrrhocorax graculus), Chova Piquirroja (Pyrrhocorax pyrrhocorax) y Urraca (Pica pica). La presencia de todas ellas es habitual en los yacimientos pleistocénicos en cueva del País Vasco (Tabl. 13). La distribución espacial y temporal del número mínimo de individuos se resume en la Tabla 14. Los resultados obtenidos confirman que la mayor acumulación de carcasas ocurrió en el vestíbulo (NMl=121) y en especial, durante el Solutrense (NMI=50).

\section{Corvus corax (Linnaeus, 1758)}

Es el paseriforme de mayores dimensiones. Aunque es un ave residente en toda la geografía peninsular las mayores densidades de población se alcanzan en áreas abruptas y montañosas, al igual que en ciertas zonas acantiladas de las costas. Su distribución está condicionada por la disponibilidad de cortados rocosos donde nidifica, sin que importe tanto la altitud a la que estos lugares se encuentren (MOLINA VILLARINO, 2003).

Los 18 restos recuperados en Praileaitz I pertenecen a huesos del esqueleto apendicular (alas y patas, Tabl. 15). En cada uno de los niveles se identificó al menos un individuo (Tabl. 14).

\section{Pyrrhocorax graculus (Linnaeus, 1766) y Pyrrhocorax} pyrrhocorax (Linnaeus, 1758)

Estas dos especies son las que dominan toda la secuencia cronológica de Praileaitz I. Ambas habitan en zonas de alta montaña donde abundan grandes paredes verticales que utilizan como dormidero y lugar de cría. Mientras la Chova Piquigualda se alimenta en prados alpinos y subalpinos, en general por encima del límite del arbolado, la Chova Piquirroja también aprovecha zonas de vegetación baja mediterránea, de ahí que la distribución actual de esta especie en la Península lbérica sea más amplia que la de la primera (BLANCO, 2003; SÁNCHEZ-ALONSO, 2003).

A pesar de que la Chova Piquirroja es un poco mayor que la Chova Piquigualda el criterio del tamaño de los huesos no siempre discrimina entre ambas especies, por lo que un número significativo de restos han sido atribuidos a Pyrrhocorax sp. (Tabl. 3). Aplicando los parámetros osteométricos señalados por Tomek, Bochenski (2000) conseguimos identificar específicamente parte de la muestra, pero como se resume en el Anexo 2, en casi 


\begin{tabular}{|c|c|c|c|c|c|}
\hline & & Corvus corax & $\begin{array}{c}\text { Pyrrhocorax } \\
\text { graculus }\end{array}$ & P. pyrrhocorax & Pica pica \\
\hline \multirow[t]{2}{*}{$\begin{array}{l}\text { Cueva de Santimamiñe } \\
\text { (ELORZA. 1990) }\end{array}$} & $\begin{array}{l}\text { Aziliense, } \\
\text { Magdaleniense VI } \\
\text { y V, Solutrense, } \\
\text { Auriñaciense }\end{array}$ & $x$ & $x$ & $x$ & $x$ \\
\hline & Tardiglacial & $x$ & $x$ & $x$ & $x$ \\
\hline $\begin{array}{l}\text { Cueva de Lumentxa } \\
\text { (ELORZA. 1990) }\end{array}$ & $\begin{array}{l}\text { Aziliense- } \\
\text { Magdaleniense }\end{array}$ & & & $x$ & \\
\hline $\begin{array}{l}\text { Cueva de Arenaza } \\
\text { (ELORZA. 1990) }\end{array}$ & Tardiglacial & & $x$ & & \\
\hline $\begin{array}{l}\text { Cueva de Ermittia } \\
\text { (ELORZA. 1990) }\end{array}$ & $\begin{array}{l}\text { Solutrense- } \\
\text { Magdaleniense }\end{array}$ & & $x$ & $x$ & \\
\hline \multirow[t]{2}{*}{$\begin{array}{l}\text { Cueva de Ekain } \\
\text { (EASTHAM, 1985) }\end{array}$} & $\begin{array}{l}\text { Auriñaco-Perigordiense } \\
\text { (nivel IX-X) }\end{array}$ & & $x$ & & \\
\hline & $\begin{array}{l}\text { Magdaleniense (nivel } \\
\mathrm{VI} \mathrm{a} / \mathrm{b} \text { ) }\end{array}$ & & $x$ & & \\
\hline \multirow[t]{4}{*}{$\begin{array}{l}\text { Cueva de Amalda } \\
\text { (EASTHAM, 1985) }\end{array}$} & Musteriense (nivel VII) & & & $x$ & \\
\hline & Perigordiense (nivel VI) & $x$ & & $x$ & \\
\hline & Magdaleniense (nivel V) & & & $x$ & $x$ \\
\hline & Solutrense (nivel IV) & $x$ & & $x$ & $x$ \\
\hline \multirow[t]{2}{*}{$\begin{array}{l}\text { Cueva de Erralla } \\
\text { (EASTHAM, 1985) }\end{array}$} & Magdaleniense Inferior & & $x$ & & \\
\hline & Magdaleniense Final & & $x$ & & \\
\hline $\begin{array}{l}\text { Cueva de Lezetxiki } \\
\text { (ELORZA. 1990) }\end{array}$ & Musteriense & & $x$ & $x$ & \\
\hline \multirow[t]{2}{*}{$\begin{array}{l}\text { Cueva de Urtiaga } \\
\text { (ELORZA. 1990) }\end{array}$} & Würm III & & $x$ & $x$ & \\
\hline & Magdaleniense VI y V & $x$ & $x$ & $x$ & \\
\hline \multirow[t]{3}{*}{$\begin{array}{l}\text { Cueva de Aitzbitarte IV } \\
\text { (ELORZA. 1990) }\end{array}$} & Auriñaciense & & $x$ & & \\
\hline & Solutrense & $x$ & $x$ & $x$ & $x$ \\
\hline & Magdaleniense & $x$ & $x$ & $x$ & \\
\hline $\begin{array}{l}\text { Cueva de Urratxa III } \\
\text { (ELORZA, 1997) }\end{array}$ & $\begin{array}{l}\text { Magdaleniense Final- } \\
\text { Aziliense }\end{array}$ & & $x$ & & \\
\hline
\end{tabular}

Tabl. 13. Presencia de córvidos en yacimientos pleistocénicos del País Vasco (HERNÁNDEZ CARRASQUILLA, 1993). / Corvid remains in Pleistocene archaeological sites from the Basque Country (HERNÁNDEZ CARRASQUILLA, 1993). 


\begin{tabular}{|c|c|c|c|c|c|c|c|}
\hline & & 1 & 2 & 3 & 4 & 5 & 6 \\
\hline \multirow[t]{4}{*}{ 1. VESTÍBULO } & Corvus corax & 1 & 1 & 1 & - & 1 & - \\
\hline & Pyrrhocorax pyrrhocorax & 7 & 7 & 15 & - & 13 & - \\
\hline & Pyrrhocorax graculus & 8 & 5 & 21 & - & 35 & - \\
\hline & Pica pica & 1 & - & 4 & - & 1 & - \\
\hline TOTAL NMI: 121 & TOTAL & 17 & 13 & 41 & - & 50 & - \\
\hline \multirow[t]{4}{*}{ 2. GALERÍA NOROESTE } & Corvus corax & - & - & - & - & - & 1 \\
\hline & Pyrrhocorax pyrrhocorax & - & - & - & 8 & - & 5 \\
\hline & Pyrrhocorax graculus & - & - & - & 6 & - & 8 \\
\hline & Pica pica & - & - & - & - & - & - \\
\hline TOTAL NMI: 28 & TOTAL & - & - & - & 14 & - & 14 \\
\hline \multirow[t]{4}{*}{ 3. TRÁNSITO } & Corvus corax & - & - & - & - & - & - \\
\hline & Pyrrhocorax pyrrhocorax & 3 & 3 & 5 & - & 1 & - \\
\hline & Pyrrhocorax graculus & 3 & 1 & 3 & - & 4 & - \\
\hline & Pica pica & - & - & 1 & - & - & - \\
\hline TOTAL NMI: 24 & TOTAL & 6 & 4 & 9 & - & 5 & - \\
\hline \multirow[t]{4}{*}{ 4. $1^{\text {a }}$ SALA INTERIOR } & Corvus corax & - & - & - & - & - & - \\
\hline & Pyrrhocorax pyrrhocorax & 1 & - & - & - & - & - \\
\hline & Pyrrhocorax graculus & 1 & - & - & - & - & - \\
\hline & Pica pica & - & - & - & - & - & - \\
\hline TOTAL NMI: 2 & TOTAL & 2 & - & - & - & - & - \\
\hline \multirow[t]{4}{*}{ 5. $2^{\mathrm{a}}$ SALA INTERIOR } & Corvus corax & - & - & - & - & - & - \\
\hline & Pyrrhocorax pyrrhocorax & 2 & - & - & - & - & - \\
\hline & Pyrrhocorax graculus & 2 & - & - & - & - & - \\
\hline & Pica pica & - & - & - & - & - & - \\
\hline TOTAL NMI: 4 & TOTAL & 4 & - & - & - & - & - \\
\hline
\end{tabular}

Tabl. 14. Praileaitz I. Distribución espacial y temporal del NMI de las especies de córvidos (1. Epipaleolítico; 2. Magdaleniense Superior/ Final; 3. Magdaleniense Inferior; 4. Epipaleolítico- Magdaleniense Inferior; 5. Solutrense; 6. Solutrense-Gravetiense). / Praileaitz I. Spatial and temporal distribution of the corvid species MNI (1. Epipaleolithic; 2. Upper/Late Magdalenian; 3. Early Magdalenian; 4. Epipaleolithic- Early Magdalenian; 5. Solutrean; 6. Solutrean-Gravettian).

todas las medidas existe solapamiento entre los especimenes mayores de la primera y los menores de la segunda. Por ejemplo, la relación entre la longitud máxima (a) y la anchura de la articulación proximal (b) en el tarsometatarso (Fig. 11) y la relación entre la longitud máxima (a) y la anchura de la diáfisis (g) en el húmero (Fig.12) permiten determinar el grupo inferior en la esquina izquierda como perteneciente a $P$. graculus mientras los $P$. pyrrhocorax se dispersan hacia la parte superior derecha.

Tras realizar una cuantificación de los restos a lo largo de la secuencia cronológica, se observa que la mayor concentración de chovas ocurre en los niveles Solutrense y Magdaleniense Inferior. Además, el $P$. graculus es más abundante en los niveles inferiores de manera que durante el Magdaleniense Superior/Final y el Epipaleolítico domina el $P$. pyrrhocorax (Tabls. 3 y 14). No son taxones que funcionen como buenos indicadores ambientales o ecológicos pero como hipótesis de trabajo planteamos que el cambio en la frecuencia de una y otra podría estar reflejando la existencia de diferentes tipos de cobertura vegetal en los alrededores de la cueva a partir del Magdaleniense Superior/Final.

Con el objetivo de caracterizar la tafocenosis de estas especies se procedió al análisis en conjunto (sin hacer discriminación entre $P$. graculus y $P$. pyrrhocorax e incluyéndose los restos identificados a nivel de género) de la representación anatómica y los patrones de fragmentación. El primer resultado es un incremento considerable en el NMI, según refleja la Tabla 16, en comparación con los datos presentados en la Tabla 14. En general, destaca la alta contribución del esqueleto apendicular frente al cranial y parte del axial, representado casi exclusivamente por coracoides y escápulas, elementos que se asocian también a las alas (Tabl. 15). Entre la fracción de indeterminados se registró un alto número de vértebras y costillas, que por carecer de rasgos diagnósticos tan claros como los de los huesos del esqueleto apendicular resultan difíciles de identificar y cuantificar, pero su presencia indica que las acumulaciones originales derivan de carcasas completas. 


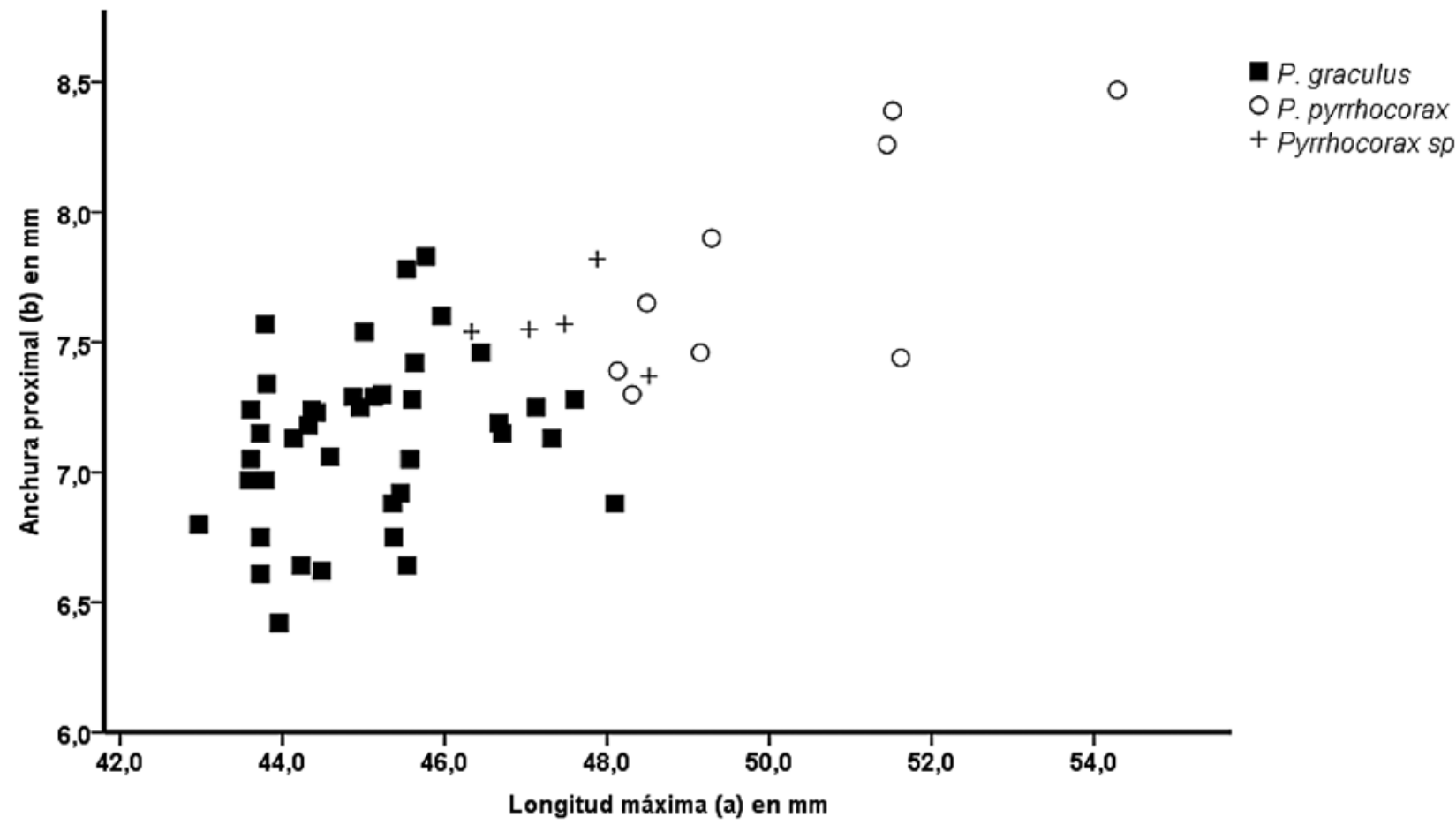

Fig. 11. Gráfico de dispersión. Longitud máxima del tarsometatarso (a) vs. anchura máxima de la articulación proximal (b) de los ejemplares de Chova Piquigualda (Pyrrhocorax graculus) y Chova Piquirroja (Pyrrhocorax pyrrhocorax) recuperados en Praileaitz I. / Scattergram. Greatest length of tarsometatarsus (a) vs. greatest width of proximal articulation (b) of Alpine chough (Pyrrhocorax graculus) and Red-billed chough (Pyrrhocorax pyrrhocorax) specimens recovered in Praileaitz I.

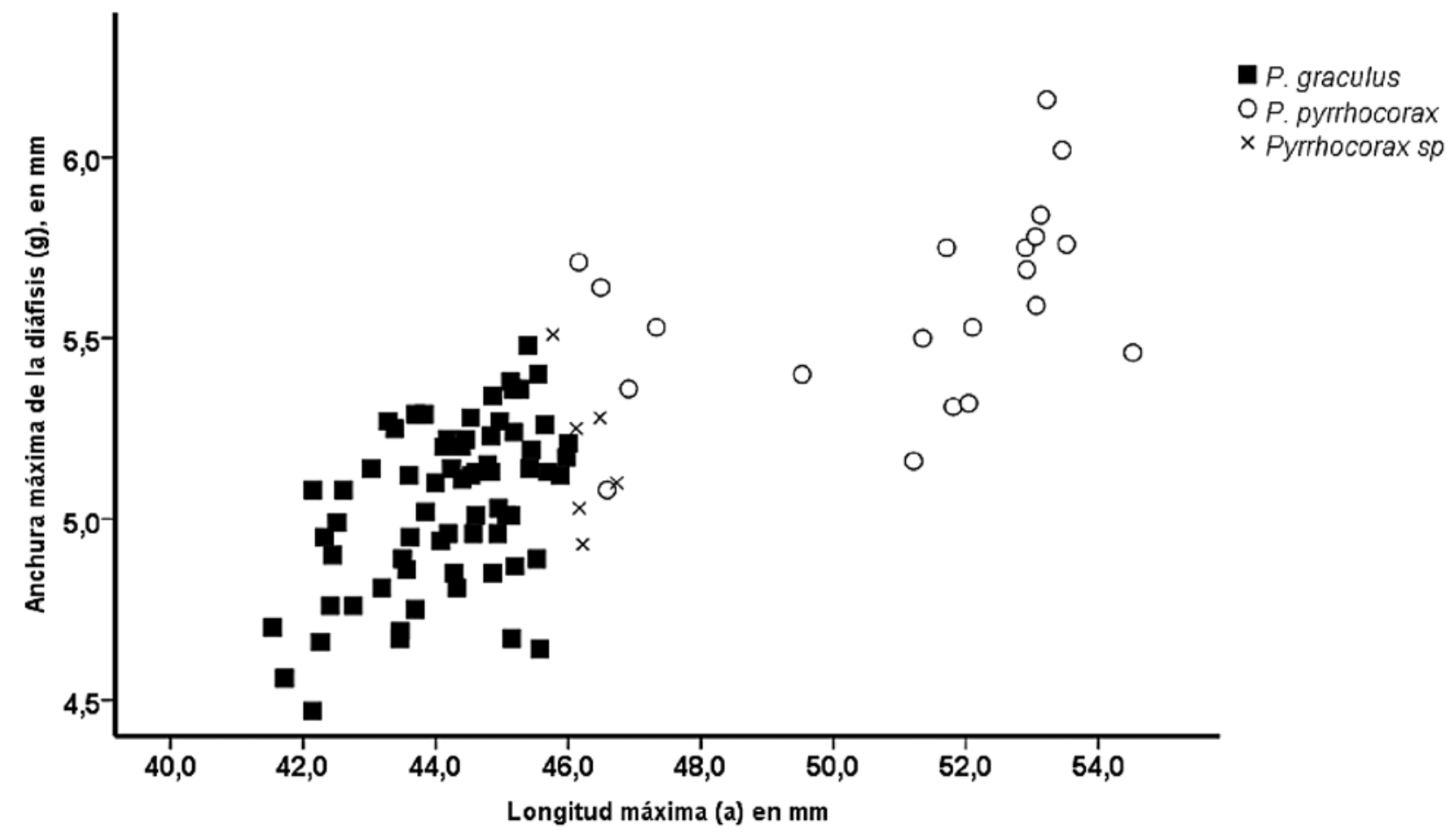

Fig. 12. Gráfico de dispersión. Longitud máxima del húmero (a) vs. anchura máxima de la diáfisis (g) de los ejemplares de Pyrrhocorax graculus y Pyrrhocorax pyrrhocorax recuperados en Praileaitz I. / Scattergram. Greatest length of humerus (a) vs. greatest width of diaphysis (b) of Pyrrhocorax graculus and Pyrrhocorax pyrrhocorax specimens recovered in Praileaitz I. 


\begin{tabular}{|c|c|c|c|c|c|c|c|c|c|c|c|c|c|c|c|c|c|c|c|c|c|}
\hline \multirow{2}{*}{ EPIPALEOLÍTICO } & \multirow[b]{2}{*}{ TOTAL } & \multicolumn{2}{|c|}{ Craneal } & \multicolumn{6}{|c|}{ Axial } & \multicolumn{6}{|c|}{ Ala } & \multicolumn{6}{|c|}{ Pata } \\
\hline & & CR & MA & VX & FU & ST & $\cos$ & COR & ESC & $\mathrm{HU}$ & RA & UL & CMC & CUL & DIG & PEL & FE & TBT & FI & TMT & $F$ \\
\hline \multicolumn{22}{|l|}{ 1. VESTíBULO } \\
\hline Corvus corax & 7 & - & - & - & - & - & - & - & - & 1 & 1 & 1 & 2 & - & - & - & 1 & - & - & 1 & - \\
\hline Pyrrhocorax pyrrhocorax & 75 & - & 2 & - & - & - & - & 13 & 3 & 10 & - & 16 & 6 & - & - & - & 7 & 9 & - & 9 & - \\
\hline Pyrrhocorax graculus & 43 & - & - & - & - & - & - & 6 & - & 7 & - & 8 & 3 & - & - & - & 1 & 11 & - & 7 & - \\
\hline Pyrrhocorax sp. & 111 & 1 & - & - & - & - & - & 12 & 6 & 11 & 1 & 37 & 17 & - & - & - & 10 & 7 & - & 9 & - \\
\hline Pica pica & 1 & - & - & - & - & - & - & - & - & - & - & - & - & - & - & - & - & 1 & - & - & - \\
\hline Corvidae no det. & 45 & 1 & 1 & - & - & 1 & - & 4 & 1 & 6 & 9 & 4 & 6 & - & - & - & 3 & 3 & - & 6 & - \\
\hline \multicolumn{22}{|l|}{ 3. TRÁNSITO } \\
\hline Pyrrhocorax pyrrhocorax & 7 & - & - & - & - & - & - & - & - & 1 & - & 3 & - & - & - & - & 3 & - & - & - & - \\
\hline Pyrrhocorax graculus & 7 & - & - & - & - & - & - & 3 & - & - & - & 2 & 1 & - & - & - & - & 1 & - & - & - \\
\hline Pyrrhocorax sp. & 31 & - & - & - & - & - & - & 4 & 1 & 3 & - & 11 & 4 & - & - & - & 3 & 2 & - & 3 & - \\
\hline Corvidae no det. & 10 & - & - & - & - & - & - & 2 & 3 & 2 & - & 1 & 2 & - & - & - & - & - & - & - & - \\
\hline \multicolumn{22}{|l|}{ 4. $1^{\text {a }}$ SALA INTERIOR } \\
\hline Pyrrhocorax pyrrhocorax & 1 & - & - & - & - & - & - & - & - & - & - & - & - & - & - & - & 1 & - & - & - & - \\
\hline Pyrrhocorax graculus & 3 & - & - & - & - & - & - & - & 1 & 1 & - & - & - & - & - & - & - & - & - & 1 & - \\
\hline Pyrrhocorax sp. & 8 & - & - & - & - & - & - & - & 1 & 4 & - & 3 & - & - & - & - & - & - & - & - & - \\
\hline Corvidae no det. & 4 & - & - & - & 1 & - & - & 3 & - & - & - & - & - & - & - & - & - & - & - & - & - \\
\hline \multicolumn{22}{|l|}{ 5. $2^{\mathrm{a}}$ SALA INTERIOR } \\
\hline Pyrrhocorax pyrrhocorax & 4 & - & - & - & - & - & - & - & - & - & - & 2 & 1 & - & - & - & 1 & - & - & - & - \\
\hline Pyrrhocorax graculus & 6 & - & - & - & - & - & - & - & - & 2 & - & 3 & 1 & - & - & - & - & - & - & - & - \\
\hline Pyrrhocorax sp. & 9 & - & - & - & - & - & - & 1 & - & 2 & - & 5 & - & - & - & - & - & 1 & - & - & - \\
\hline Corvidae no det. & 5 & - & - & - & - & - & - & - & - & - & - & 1 & 1 & - & - & - & - & 1 & - & 2 & - \\
\hline Total restos & 377 & 2 & 3 & - & 1 & 1 & - & 48 & 16 & 50 & 11 & 97 & 44 & - & - & - & 30 & 36 & - & 38 & - \\
\hline & & & & & & & & & & & & & & & & & & & & & \\
\hline \multicolumn{22}{|l|}{$\begin{array}{l}\text { EPIPALEOLÍTICO- } \\
\text { MAGDALENIENSE }\end{array}$} \\
\hline \multicolumn{22}{|l|}{ 2. GALERÍA NOROESTE } \\
\hline Pyrrhocorax pyrrhocorax & 42 & - & 1 & - & - & - & - & 5 & 1 & 11 & - & 6 & 7 & - & - & - & 7 & 3 & - & 1 & - \\
\hline Pyrrhocorax graculus & 27 & - & - & - & - & - & - & 4 & - & 3 & - & 6 & 3 & - & - & - & - & 8 & - & 3 & - \\
\hline Pyrrhocorax sp. & 71 & - & - & - & - & - & - & 3 & 2 & 17 & 1 & 27 & 8 & - & 2 & - & 6 & 1 & - & 4 & - \\
\hline Corvidae no det. & 30 & - & 1 & - & - & - & - & 4 & 1 & 7 & - & 3 & 5 & - & - & - & - & 1 & - & 5 & 3 \\
\hline Total restos & 170 & - & 2 & - & - & - & - & 16 & 4 & 38 & 1 & 42 & 23 & - & 2 & - & 13 & 13 & - & 13 & 3 \\
\hline \multicolumn{22}{|l|}{$\begin{array}{l}\text { MAGDALENIENSE } \\
\text { SUPERIOR/FINAL }\end{array}$} \\
\hline \multicolumn{22}{|l|}{ 1. VESTíBULO } \\
\hline Corvus corax & 2 & - & - & - & - & - & - & - & - & 1 & - & - & - & - & - & - & - & - & - & 1 & - \\
\hline Pyrrhocorax pyrrhocorax & 66 & - & 2 & - & - & - & - & 11 & 4 & 8 & - & 11 & 6 & - & - & - & 7 & 11 & - & 6 & - \\
\hline Pyrrhocorax graculus & 36 & - & 1 & - & - & - & - & 3 & 1 & 6 & - & 7 & 6 & - & - & - & 2 & 5 & - & 5 & - \\
\hline Pyrrhocorax sp. & 97 & - & - & - & - & - & - & 6 & 9 & 19 & - & 18 & 12 & - & - & - & 9 & 7 & - & 17 & - \\
\hline Corvidae no det. & 53 & 3 & 7 & - & - & 2 & - & 3 & 2 & 5 & 3 & 4 & 4 & - & - & - & 7 & 5 & - & 8 & - \\
\hline 3. TRÁNSITO & & & & & & & & & & & & & & & & & & & & & \\
\hline Pyrrhocorax pyrrhocorax & 8 & - & - & - & - & - & - & 1 & - & 1 & - & 3 & - & - & - & - & 1 & 1 & - & 1 & - \\
\hline Pyrrhocorax graculus & 1 & - & - & - & - & - & - & - & - & - & - & - & - & - & - & - & - & 1 & - & - & - \\
\hline Pyrrhocorax sp. & 3 & - & - & - & - & - & - & - & - & 2 & - & 1 & - & - & - & - & - & - & - & - & - \\
\hline Corvidae no det. & 3 & - & 1 & - & - & - & - & 2 & - & - & - & - & - & - & - & - & - & - & - & - & - \\
\hline Total restos & 269 & 3 & 11 & - & - & 2 & - & 26 & 16 & 42 & 3 & 44 & 28 & - & - & - & 26 & 30 & - & 38 & - \\
\hline $\begin{array}{l}\text { MAGDALENIENSE } \\
\text { INFERIOR }\end{array}$ & & & & & & & & & & & & & & & & & & & & & \\
\hline 1. VESTÍBULO & & & & & & & & & & & & & & & & & & & & & \\
\hline Corvus corax & 4 & - & - & - & - & - & - & - & - & 2 & - & 1 & - & - & - & - & - & 1 & - & - & - \\
\hline
\end{tabular}




\begin{tabular}{|c|c|c|c|c|c|c|c|c|c|c|c|c|c|c|c|c|c|c|c|c|c|}
\hline Pyrrhocorax pyrrhocorax & 138 & - & 3 & - & - & - & - & 24 & 7 & 20 & - & 23 & 17 & - & - & - & 23 & 7 & - & 14 & - \\
\hline Pyrrhocorax graculus & 180 & - & 2 & - & - & - & - & 37 & 2 & 18 & 2 & 42 & 23 & - & 2 & - & 6 & 26 & - & 20 & - \\
\hline Pyrrhocorax sp. & 488 & - & 6 & - & - & - & - & 56 & 38 & 75 & 5 & 119 & 48 & - & 4 & - & 59 & 43 & - & 35 & - \\
\hline Pica pica & 6 & - & - & - & - & - & - & - & - & - & - & - & 1 & - & - & - & - & 5 & - & - & - \\
\hline Corvidae no det. & 172 & 1 & 1 & - & 2 & 1 & - & 20 & 13 & 25 & 8 & 21 & 24 & - & - & - & 16 & 13 & - & 27 & - \\
\hline \multicolumn{22}{|l|}{ 3. TRÁNSITO } \\
\hline Pyrrhocorax pyrrhocorax & 44 & - & - & - & - & - & - & 2 & 3 & 9 & - & 11 & 5 & - & - & - & 6 & 5 & - & 3 & - \\
\hline Pyrrhocorax graculus & 21 & - & - & - & - & - & - & 3 & 1 & 5 & - & 3 & 3 & - & - & - & 1 & 3 & - & 2 & - \\
\hline Pyrrhocorax sp. & 41 & - & - & - & - & - & - & 3 & 3 & 7 & - & 10 & 6 & - & - & - & 4 & 5 & - & 3 & - \\
\hline Pica pica & 1 & - & - & - & - & - & - & - & - & - & - & - & 1 & - & - & - & - & - & - & - & - \\
\hline Corvidae no det. & 23 & - & - & - & - & - & - & 2 & - & 5 & 3 & 1 & 4 & - & 1 & - & 4 & 2 & - & 1 & - \\
\hline Total restos & 1118 & 1 & 12 & - & 2 & 1 & - & 147 & 67 & 166 & 18 & 231 & 132 & - & 7 & - & 119 & 110 & - & 105 & - \\
\hline \multicolumn{22}{|l|}{ SOLUTRENSE } \\
\hline \multicolumn{22}{|l|}{ 1. VESTíBULO } \\
\hline Corvus corax & 1 & - & - & - & - & - & - & - & - & - & - & 1 & - & - & - & - & - & - & - & - & - \\
\hline Pyrrhocorax pyrrhocorax & 97 & - & - & - & - & - & - & 17 & 4 & 11 & - & 15 & 14 & - & - & - & 20 & 9 & - & 7 & - \\
\hline Pyrrhocorax graculus & 353 & - & 2 & - & - & - & - & 59 & 7 & 51 & 5 & 56 & 45 & - & - & - & 10 & 53 & - & 65 & - \\
\hline Pyrrhocorax sp. & 639 & - & 1 & - & - & - & - & 64 & 63 & 93 & 9 & 195 & 56 & - & 2 & - & 65 & 35 & - & 56 & - \\
\hline Pica pica & 3 & - & - & - & - & - & - & - & - & - & - & - & 1 & - & - & - & - & 2 & - & - & - \\
\hline Corvidae no det. & 259 & - & 9 & - & 3 & & & 28 & 12 & 26 & 19 & 22 & 42 & - & 4 & - & 36 & 28 & - & 30 & - \\
\hline \multicolumn{22}{|l|}{ 3. TRÁNSITO } \\
\hline Pyrrhocorax pyrrhocorax & 5 & - & - & - & - & - & - & 1 & - & - & - & 2 & - & - & - & - & - & 2 & - & - & - \\
\hline Pyrrhocorax graculus & 22 & - & 1 & - & - & - & - & 6 & - & 3 & - & 8 & 1 & - & - & - & 1 & 1 & - & 1 & - \\
\hline Pyrrhocorax sp. & 33 & - & - & - & - & - & - & 3 & - & 5 & - & 17 & 3 & - & - & - & 1 & - & - & 4 & - \\
\hline Corvidae no det. & 19 & - & 1 & - & - & - & - & 2 & 2 & 4 & - & 2 & 2 & - & - & - & 3 & 2 & - & 1 & - \\
\hline Total restos & 1431 & - & 14 & - & 3 & - & - & 180 & 88 & 193 & 33 & 318 & 164 & - & 6 & - & 136 & 132 & - & 164 & - \\
\hline \multicolumn{22}{|l|}{$\begin{array}{l}\text { SOLUTRENSE- } \\
\text { GRAVETIENSE }\end{array}$} \\
\hline \multicolumn{22}{|l|}{ 2. GALERÍA NOROESTE } \\
\hline Corvus corax & 4 & - & - & - & - & - & - & 1 & - & 1 & - & - & 1 & - & - & - & 1 & - & - & - & - \\
\hline Pyrrhocorax pyrrhocorax & 41 & - & 2 & - & - & - & - & 5 & - & 7 & 1 & 10 & 2 & - & - & - & 4 & 7 & - & 3 & - \\
\hline Pyrrhocorax graculus & 79 & - & - & - & - & - & - & 9 & 1 & 19 & - & 16 & 10 & - & - & - & 9 & 10 & - & 5 & - \\
\hline Pyrrhocorax sp. & 69 & - & 1 & - & - & - & - & 3 & - & 18 & 1 & 25 & 6 & - & - & - & 3 & 9 & - & 3 & - \\
\hline Corvidae no det. & 23 & - & - & 1 & - & - & - & 1 & - & 2 & 3 & 4 & 5 & - & - & - & 4 & 2 & - & 1 & - \\
\hline Total restos & 216 & - & 3 & 1 & - & - & - & 19 & 1 & 47 & 5 & 55 & 24 & - & - & - & 21 & 28 & - & 12 & - \\
\hline TOTAL & 3581 & 6 & 45 & 1 & 6 & 4 & - & 436 & 192 & 536 & 71 & 787 & 415 & - & 15 & - & 345 & 349 & - & 370 & 3 \\
\hline
\end{tabular}

Tabl. 15. Praileaitz I. Representación anatómica de los Corvidae. Abreviaturas: CR: cráneo; MA: mandíbula; VX: vértebra; FU: fúrcula; ST: esternón; COS: costilla; COR: coracoides; SC: escápula; HU: húmero; RA: radio; UL: ulna; CMC: carpometacarpo; CUL: carpal-ulnar; DIG: dígito; PEL: pelvis; FE: fémur; TBT: tibiotarso; FI: fíbula; TMT: tarsometatarso; F: falange. / Praileaitz I. Anatomical representation of Corvidae. Abbreviations: CR: skull; MA: mandible; VX: vertebra; FU: furcula; ST: sternum; COS: rib; COR: coracoid; SC: scapula; HU: humerus; RA: radius; UL: ulna; CMC: carpometacarpus; CUL: carpal-ulnar; DIG: digit; PEL: pelvis; FE: femur; TBT: tibiotarsus; FI: fibula; TMT: tarsometatarsus; F: phalange.

El perfil anatómico obtenido a partir de los principales huesos de las alas y las patas demuestra que las alas siempre son más abundantes que las patas (Tabl. 16). En especial, sobresale el alto número de ulnas en los niveles Solutrense y Magdaleniense Inferior, seguido de cerca por el húmero. El cálculo de la ratio entre alas y patas oscila entre 58\% (en la muestra del Magdaleniense Superior) y $72 \%$ (en el nivel Epipaleolítico-Magdaleniense de la galería noroeste) (Tabl. 17). Los resultados están muy próximos a los registrados por Laroulandie (2010) con muestras de la Chova Piquigualda en cuevas francesas fechadas desde el Musteriense al Magdaleniense Superior/Final y que fueron interpretados por esta autora como evidencia de la descomposición natural de las carcasas. De igual forma, se aproximan a las ratio obtenidas a partir de los restos no ingeridos por rapaces diurnas (BOCHENSKI, 2005). Esta misma conclusión se deriva si se tiene en cuenta el porcentaje de huesos comple- 
tos (Tabl. 18), en particular la abundancia de coracoides, que como ya fue señalado en el caso de las palomas, es un criterio discriminante para identificar si los restos proceden de egagrópilas o de desechos no ingeridos. La mayor fragmentación de escápulas y tibiotarsos frente a carpometacarpos se debe a diferentes procesos diagenéticos postdeposicionales que afectaron en mayor grado a los elementos más frágiles. Por último, la ratio de elementos proximales (escápula, coracoides, húmero, fémur y tibiotarso) y distales (ulna, radio, carpometacarpo y tarsometatarso) (Tabl. 19) muestra una ligera tendencia a favor de las partes proximales, tal como se ha descrito en estudios actualísticos con conjuntos derivados de desechos no ingeridos de rapaces diurnas (BOCHENSKI, 2005).

\begin{tabular}{|c|c|c|c|c|c|c|c|c|c|c|c|c|c|c|c|c|c|c|}
\hline \multirow[t]{2}{*}{$\begin{array}{l}\text { PERIODO } \\
\text { (NMI) }\end{array}$} & \multicolumn{3}{|c|}{$\begin{array}{l}\text { EPIPALEOLÍTICO } \\
\text { (33) }\end{array}$} & \multicolumn{3}{|c|}{$\begin{array}{l}\text { EPIPAL-MAG. } \\
\text { (16) }\end{array}$} & \multicolumn{3}{|c|}{$\begin{array}{l}\text { MAGD. SUP } \\
\text { (18) }\end{array}$} & \multicolumn{3}{|c|}{$\begin{array}{l}\text { MAGD. INF } \\
\text { (75) }\end{array}$} & \multicolumn{3}{|c|}{$\begin{array}{l}\text { SOLUTRENSE } \\
\text { (92) }\end{array}$} & \multicolumn{3}{|c|}{$\begin{array}{c}\text { SOLUTRENSE- } \\
\text { GRAVETIENSE (20) }\end{array}$} \\
\hline & NR & NME & $\% \mathrm{~S}$ & NR & NME & $\% S$ & NR & NME & $\% S$ & NR & NME & $\% S$ & NR & NME & $\% S$ & NR & NME & $\% S$ \\
\hline $\begin{array}{l}\text { Coracoides } \\
\%\end{array}$ & $\begin{array}{l}39 \\
13\end{array}$ & $\begin{array}{l}31 \\
13\end{array}$ & 47 & $\begin{array}{c}12 \\
9\end{array}$ & $\begin{array}{l}6 \\
6\end{array}$ & 19 & $\begin{array}{l}21 \\
10\end{array}$ & $\begin{array}{l}19 \\
11\end{array}$ & 53 & $\begin{array}{c}125 \\
14\end{array}$ & \begin{tabular}{|c|}
103 \\
15 \\
\end{tabular} & 69 & $\begin{array}{c}150 \\
13\end{array}$ & $\begin{array}{c}122 \\
14\end{array}$ & 66 & $\begin{array}{c}17 \\
9\end{array}$ & $\begin{array}{c}13 \\
9\end{array}$ & 32 \\
\hline $\begin{array}{l}\text { Escápula } \\
\%\end{array}$ & $\begin{array}{c}12 \\
4\end{array}$ & $\begin{array}{c}12 \\
5\end{array}$ & 18 & $\begin{array}{l}3 \\
2\end{array}$ & $\begin{array}{l}2 \\
2\end{array}$ & 6 & $\begin{array}{c}14 \\
7\end{array}$ & $\begin{array}{l}14 \\
8\end{array}$ & 39 & $\begin{array}{c}54 \\
6\end{array}$ & $\begin{array}{c}54 \\
8\end{array}$ & 36 & $\begin{array}{c}74 \\
6\end{array}$ & $\begin{array}{c}73 \\
8\end{array}$ & 40 & $\begin{array}{c}1 \\
<1\end{array}$ & $\begin{array}{c}1 \\
<1\end{array}$ & 2 \\
\hline $\begin{array}{l}\text { Húmero } \\
\%\end{array}$ & $\begin{array}{l}41 \\
13 \\
\end{array}$ & $\begin{array}{l}37 \\
16 \\
\end{array}$ & 56 & $\begin{array}{l}31 \\
23 \\
\end{array}$ & $\begin{array}{l}26 \\
27 \\
\end{array}$ & 81 & $\begin{array}{l}36 \\
17 \\
\end{array}$ & $\begin{array}{l}24 \\
14 \\
\end{array}$ & 67 & $\begin{array}{c}134 \\
15 \\
\end{array}$ & $\begin{array}{c}105 \\
15 \\
\end{array}$ & 70 & $\begin{array}{c}163 \\
14 \\
\end{array}$ & $\begin{array}{c}122 \\
14 \\
\end{array}$ & 66 & $\begin{array}{l}44 \\
24 \\
\end{array}$ & $\begin{array}{l}34 \\
23 \\
\end{array}$ & 85 \\
\hline $\begin{array}{l}\text { Ulna } \\
\%\end{array}$ & $\begin{array}{l}90 \\
30\end{array}$ & $\begin{array}{l}65 \\
28\end{array}$ & 98 & $\begin{array}{l}39 \\
28\end{array}$ & $\begin{array}{l}27 \\
28\end{array}$ & 84 & $\begin{array}{l}40 \\
19\end{array}$ & $\begin{array}{l}29 \\
17\end{array}$ & 80 & $\begin{array}{c}208 \\
23\end{array}$ & $\begin{array}{c}143 \\
21\end{array}$ & 95 & $\begin{array}{c}292 \\
25\end{array}$ & $\begin{array}{c}179 \\
21\end{array}$ & 97 & $\begin{array}{l}51 \\
27\end{array}$ & $\begin{array}{l}36 \\
25\end{array}$ & 90 \\
\hline $\begin{array}{l}\text { Radio } \\
\%\end{array}$ & $\begin{array}{c}1 \\
<1\end{array}$ & $\begin{array}{c}1 \\
<1\end{array}$ & 1 & $\begin{array}{c}1 \\
<1 \\
\end{array}$ & $\begin{array}{c}1 \\
<1\end{array}$ & 3 & - & - & - & $\begin{array}{l}7 \\
1 \\
\end{array}$ & $\begin{array}{c}4 \\
<1\end{array}$ & 3 & $\begin{array}{c}14 \\
1 \\
\end{array}$ & $\begin{array}{c}11 \\
1 \\
\end{array}$ & 6 & $\begin{array}{l}2 \\
1 \\
\end{array}$ & $\begin{array}{l}2 \\
1 \\
\end{array}$ & 5 \\
\hline $\begin{array}{l}\text { Carpometacarpo } \\
\%\end{array}$ & $\begin{array}{l}33 \\
11 \\
\end{array}$ & $\begin{array}{l}26 \\
11 \\
\end{array}$ & 39 & $\begin{array}{l}18 \\
13 \\
\end{array}$ & $\begin{array}{l}12 \\
12 \\
\end{array}$ & 37 & $\begin{array}{l}24 \\
12 \\
\end{array}$ & $\begin{array}{l}23 \\
13 \\
\end{array}$ & 64 & $\begin{array}{l}102 \\
11 \\
\end{array}$ & $\begin{array}{l}90 \\
13 \\
\end{array}$ & 60 & $\begin{array}{c}119 \\
10 \\
\end{array}$ & $\begin{array}{c}111 \\
13 \\
\end{array}$ & 60 & $\begin{array}{l}18 \\
10 \\
\end{array}$ & $\begin{array}{l}15 \\
10 \\
\end{array}$ & 37 \\
\hline $\begin{array}{l}\text { Fémur } \\
\%\end{array}$ & $\begin{array}{c}26 \\
9\end{array}$ & $\begin{array}{c}18 \\
8\end{array}$ & 27 & $\begin{array}{c}13 \\
9\end{array}$ & $\begin{array}{l}8 \\
8\end{array}$ & 25 & $\begin{array}{c}19 \\
9\end{array}$ & $\begin{array}{c}16 \\
9\end{array}$ & 44 & $\begin{array}{l}99 \\
11\end{array}$ & $\begin{array}{l}78 \\
11 \\
\end{array}$ & 52 & $\begin{array}{c}97 \\
8\end{array}$ & $\begin{array}{c}64 \\
7\end{array}$ & 35 & $\begin{array}{c}16 \\
9\end{array}$ & $\begin{array}{c}13 \\
9\end{array}$ & 32 \\
\hline $\begin{array}{l}\text { Tibiotarso } \\
\%\end{array}$ & $\begin{array}{l}31 \\
10 \\
\end{array}$ & $\begin{array}{l}26 \\
11 \\
\end{array}$ & 39 & $\begin{array}{c}12 \\
9\end{array}$ & $\begin{array}{l}11 \\
11 \\
\end{array}$ & 34 & $\begin{array}{l}25 \\
12 \\
\end{array}$ & $\begin{array}{l}24 \\
14 \\
\end{array}$ & 67 & $\begin{array}{l}89 \\
10 \\
\end{array}$ & $\begin{array}{l}67 \\
10 \\
\end{array}$ & 45 & $\begin{array}{c}100 \\
9 \\
\end{array}$ & $\begin{array}{l}82 \\
10 \\
\end{array}$ & 44 & $\begin{array}{l}26 \\
14 \\
\end{array}$ & $\begin{array}{l}21 \\
14 \\
\end{array}$ & 52 \\
\hline $\begin{array}{l}\text { Tarsometatarso } \\
\%\end{array}$ & $\begin{array}{l}29 \\
10 \\
\end{array}$ & $\begin{array}{c}19 \\
8\end{array}$ & 29 & $\begin{array}{l}8 \\
6 \\
\end{array}$ & $\begin{array}{l}5 \\
5 \\
\end{array}$ & 16 & $\begin{array}{l}28 \\
13 \\
\end{array}$ & $\begin{array}{l}21 \\
12 \\
\end{array}$ & 58 & $\begin{array}{c}77 \\
9\end{array}$ & $\begin{array}{c}52 \\
7\end{array}$ & 35 & \begin{tabular}{c|}
133 \\
12 \\
\end{tabular} & $\begin{array}{l}94 \\
11\end{array}$ & 51 & $\begin{array}{c}11 \\
6\end{array}$ & $\begin{array}{c}10 \\
7\end{array}$ & 25 \\
\hline $\begin{array}{l}\text { Total } \\
\%\end{array}$ & $\begin{array}{l}302 \\
100\end{array}$ & $\begin{array}{l}235 \\
100 \\
\end{array}$ & & $\begin{array}{l}137 \\
100 \\
\end{array}$ & $\begin{array}{c}98 \\
100\end{array}$ & & $\begin{array}{l}207 \\
100 \\
\end{array}$ & $\begin{array}{l}170 \\
100\end{array}$ & & $\begin{array}{l}895 \\
100 \\
\end{array}$ & $\begin{array}{l}696 \\
100 \\
\end{array}$ & & $\begin{array}{c}1142 \\
100 \\
\end{array}$ & $\begin{array}{l}858 \\
100\end{array}$ & & $\begin{array}{l}186 \\
100\end{array}$ & $\begin{array}{l}145 \\
100 \\
\end{array}$ & \\
\hline
\end{tabular}

Tabl. 16. Praileaitz I. Perfil anatómico de las chovas (Pyrrhocorax pyrrhocorax + Pyrrhocorax graculus + Pyrrhocorax sp) Número de restos (NR), Número Mínimo de Elementos (NME) y porcentaje de supervivencia (\% S). / Praileaitz I. Anatomical representation of choughs (Pyrrhocorax pyrrhocorax + Pyrrhocorax graculus + Pyrrhocorax sp). Number of remains (NR), Minimum Number of Elements (NME) and survival percentage (\% S).

\begin{tabular}{|l|c|}
\hline & CHOVAS \\
\hline & Ratio (\%) \\
\hline Epipaleolítico & 65 \\
\hline Epipaleolítico- Magdaleniense Superior & 72 \\
\hline Magdaleniense Superior/Final & 58 \\
\hline Magdaleniense Inferior & 62 \\
\hline Solutrense & 63 \\
\hline Solutrense-Gravetiense & 68 \\
\hline
\end{tabular}

Tabl. 17. Ratio de alas vs. patas en las chovas recuperadas en Praileaitz I. / Ratio of wings vs. legs among choughs from Praileaitz I.

Otro aspecto que interesa comentar es la presencia de individuos juveniles. Al no estar totalmente formados los huesos carecemos de los criterios diagnósticos que permiten una identificación específica, por ello un porcentaje considerable se asigna a la familia o incluso se registra entre la fracción no determinada. Este es el caso de las dos especies de chovas. Muy probablemente los restos incluidos en la familia Corvidae e incluso no de- terminados correspondan a ellas. Los resultados obtenidos demuestran que a lo largo de toda la secuencia de ocupación de la cueva los individuos juveniles están presentes. En especial durante el Solutrense se observa la contribución más alta, lo que no deja duda sobre la utilización de este espacio como lugar de reproducción (Tabl. 20). Además la presencia de un tibiotarso patológico de P. graculus (P.A. 8B.285.67.10-67.7) demuestra que animales seniles o enfermos también encontraron allí refugio (Fig. 13).

En conclusión, los patrones de representación anatómica y fragmentación son compatibles con una acumulación natural de carcasas y también de restos no ingeridos por rapaces diurnas. Probablemente las variaciones observadas entre periodos se deban a la mayor o menor incidencia de uno u otro fenómeno, a los que debemos añadir la actuación diferencial de procesos tafonómicos postdeposicionales en los varios espacios de la cueva.

La relación de estas acumulaciones con actividad antrópica, tal como se ha demostrado en cuevas de nuestro entorno europeo, por ejemplo, en el yacimiento Mag- 


\begin{tabular}{|c|c|c|c|c|c|c|c|c|c|c|c|c|c|c|c|c|c|c|}
\hline \multirow[t]{2}{*}{$\begin{array}{l}\text { PERIODO } \\
\text { (NR) }\end{array}$} & \multicolumn{3}{|c|}{$\begin{array}{l}\text { EPIPALEOLÍTICO } \\
(302)\end{array}$} & \multicolumn{3}{|c|}{$\begin{array}{l}\text { MAGD. SUP/FIN } \\
\text { (207) }\end{array}$} & \multicolumn{3}{|c|}{$\begin{array}{c}\text { EPIPAL-MAG. } \\
\text { (137) }\end{array}$} & \multicolumn{3}{|c|}{$\begin{array}{l}\text { MAGD. INF } \\
\text { (895) }\end{array}$} & \multicolumn{3}{|c|}{$\begin{array}{c}\text { SOLUTRENSE } \\
\text { (1142) }\end{array}$} & \multicolumn{3}{|c|}{$\begin{array}{c}\text { SOLUTRENSE- } \\
\text { GRAVETIENSE } \\
\text { (186) }\end{array}$} \\
\hline & C & $\mathbf{F}$ & $\% \mathrm{C}$ & C & $\mathbf{F}$ & $\% \mathrm{C}$ & C & $\mathbf{F}$ & $\% \mathrm{C}$ & $C$ & $\mathbf{F}$ & $\% \mathrm{C}$ & C & $\mathbf{F}$ & $\% \mathrm{C}$ & C & $\mathbf{F}$ & $\% \mathrm{C}$ \\
\hline \multicolumn{19}{|l|}{ HUESO } \\
\hline Coracoides & 17 & 22 & 44 & 14 & 7 & 67 & 5 & 7 & 42 & 62 & 63 & 50 & 93 & 57 & 62 & 10 & 7 & 59 \\
\hline Escápula & - & 12 & 0 & 1 & 13 & 7 & - & 3 & 0 & 1 & 53 & 2 & 9 & 65 & 12 & - & 1 & 0 \\
\hline Húmero & 18 & 23 & 44 & 12 & 24 & 33 & 10 & 21 & 32 & 35 & 99 & 26 & 52 & 111 & 32 & 17 & 27 & 39 \\
\hline Ulna & 14 & 76 & 16 & 15 & 25 & 37,5 & 8 & 31 & 20,5 & 38 & 170 & 18 & 44 & 248 & 15 & 19 & 32 & 37 \\
\hline Radio & - & 1 & 0 & - & - & - & - & 1 & 0 & 1 & 6 & 14 & 5 & 9 & 36 & 1 & 1 & 50 \\
\hline Carpometacarpo & 18 & 15 & 54 & 15 & 9 & 62,5 & 9 & 9 & 50 & 55 & 47 & 54 & 88 & 31 & 74 & 12 & 6 & 67 \\
\hline Fémur & 9 & 17 & 35 & 11 & 8 & 58 & 3 & 10 & 23 & 33 & 66 & 33 & 23 & 74 & 24 & 8 & 8 & 50 \\
\hline Tibiotarso & 3 & 28 & 10 & 3 & 22 & 12 & 2 & 10 & 17 & 4 & 85 & 4 & 4 & 96 & 4 & 3 & 23 & 11,5 \\
\hline Tarsometatarso & 6 & 23 & 21 & 6 & 22 & 21 & 1 & 7 & 12,5 & 19 & 58 & 25 & 36 & 97 & 27 & 3 & 8 & 27 \\
\hline $\mathrm{N} / \%$ medio C & 85 & 217 & 28 & 77 & 130 & 37 & 38 & 99 & 28 & 248 & 647 & 28 & 354 & 788 & 31 & 73 & 113 & 39 \\
\hline
\end{tabular}

Tabl. 18. Praileaitz I. Porcentaje de huesos completos (C) de chovas (NR= número de restos). / Praileaitz I. Frequency of choughs complete bones (C) (NR= number of remains).

\begin{tabular}{|l|c|c|c|c|}
\hline & \multicolumn{2}{|c|}{ PROXIMALES } & \multicolumn{2}{c|}{ DISTALES } \\
\hline & $\mathrm{N}$ & $\%$ & $\mathrm{~N}$ & $\%$ \\
\hline Epipaleolítico & 149 & 49 & 153 & 51 \\
\hline Epipaleolítico- Magdaleniense Superior & 71 & 52 & 66 & 48 \\
\hline Magdaleniense Superior/Final & 115 & 56 & 92 & 44 \\
\hline Magdaleniense Inferior & 501 & 56 & 394 & 44 \\
\hline Solutrense & 584 & 51 & 558 & 49 \\
\hline Solutrense-Gravetiense & 104 & 56 & 82 & 44 \\
\hline
\end{tabular}

Tabl. 19. Praileaitz I. Chovas. Frecuencia de elementos proximales $P$ (escápula, coracoides, húmero, fémur y tibiotarso) y distales $D$ (ulna, radio, carpometacarpo y tarsometatarso) según el NR. / Praileaitz I. Choughs. Frequency of proximal P (scapula, coracoid, humerus, femur and tibiotarsus) and distal $\mathrm{D}$ elements (ulna, radius, carpometacarpus and tarsometatarsus) according to NR.

\begin{tabular}{|l|c|c|c|c|c|c|c|c|c|c|}
\hline & \multicolumn{2}{|c|}{$\mathbf{1}$} & \multicolumn{2}{|c|}{$\mathbf{2}$} & \multicolumn{3}{|c|}{$\mathbf{3}$} & \multicolumn{4}{|c|}{$\mathbf{4}$} & \multicolumn{2}{|c|}{$\mathbf{5}$} \\
\hline & NR & \%JUV & NR & \%JUV & NR & \%JUV & NR & \%JUV & NR & \%JUV \\
\hline Chovas & 302 & 4 & 207 & 4 & 895 & 4 & 1142 & 6 & 186 & 2 \\
\hline Corvidae & 64 & 11 & 56 & 12,5 & 195 & 18 & 278 & 25,5 & 23 & 17 \\
\hline Chovas + Corvidae & 366 & $\mathbf{5}$ & 263 & $\mathbf{6}$ & 1090 & $\mathbf{6}$ & 1420 & $\mathbf{1 0}$ & 209 & $\mathbf{3}$ \\
\hline & & & & & & & & & & \\
\hline No determinados & 208 & 7 & 113 & 11 & 434 & 9 & 494 & 17 & 69 & 9 \\
\hline & & & & & & & & & & \\
\hline TOTAL & 574 & $6 \%$ & 376 & $7 \%$ & 1524 & $7 \%$ & 1914 & $12 \%$ & 278 & $5 \%$ \\
\hline
\end{tabular}

Tabl. 20. Praileaitz I. Frecuencia de juveniles en la secuencia cronológica (1. Epipaleolítico; 2. Magdaleniense Superior/Final; 3. Magdaleniense Inferior; 4. Solutrense; 5. Solutrense-Gravetiense). / Praileaitz I. Frequency of juveniles in the chronological sequence (1. Epipaleolithic; 2. Upper/Final Magdalenian; 3. Early Magdalenian; 4. Solutrean; 5. Solutrean-Gravettian).

daleniense de La Vache, Ariège, Francia (LAROULANDIE, 2000) y en los niveles Auriñacienses y Gravetienses de Grotta Paglicci en Italia (TAGLIACOZZO, GALA, 2004) no se ha documentado. En estos yacimientos las marcas de corte visibles en gran parte de la muestra y la termoalteración de los restos fueron interpretados como resultado del consumo de Chova Piquigualda. A este respecto, notamos que la frecuencia de huesos quemados en Praileaitz I es reducidísima y parece concentrarse en torno de los cuadros $12 \mathrm{E}$ y $12 \mathrm{~F}$ del vestíbulo, en los niveles Solutrense y Magdaleniense Inferior. Sobre el total de la muestra recuperada en estos horizontes cronológicos los restos termoalterados representan menos del $1 \%$.

\section{Pica pica (LINNAEUS, 1758)}

La Urraca es el córvido más abundante y extendido en la Península Ibérica. Es posible encontrarlo en cual- 


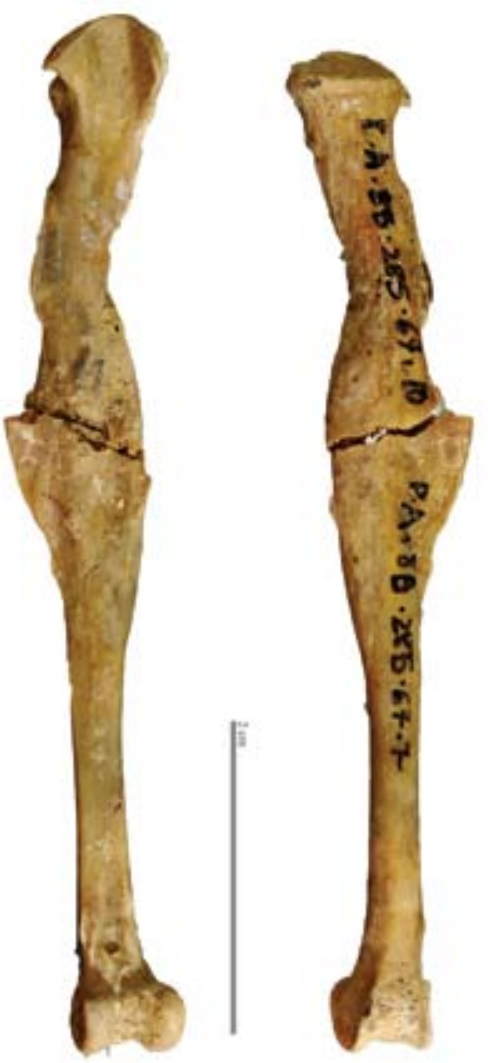

Fig. 13. Tibiotarso patológico de Chova Piquigualda (Pyrrhocorax graculus). P.A.8B.285.67.10-67.7. Vestíbulo. Magdaleniense Inferior. / Pathological tibiotarsus of Alpine chough (Pyrrhocorax graculus). P.A.8B.285.67.10-67.7. Hall. Early Magdalenian.

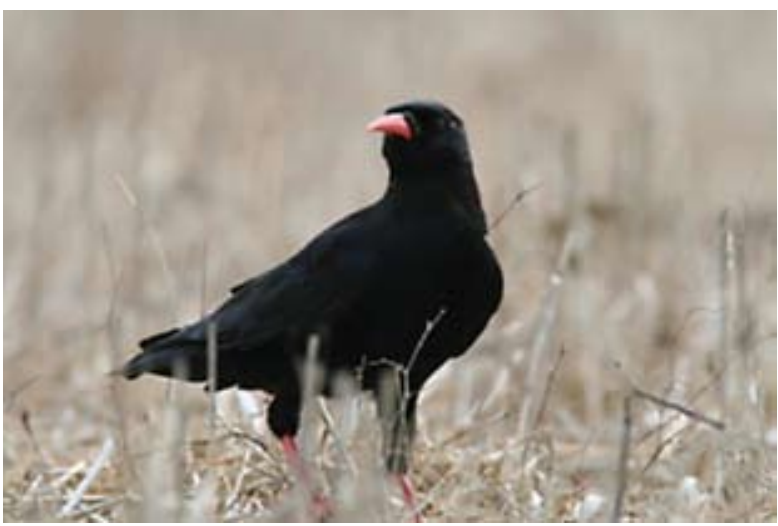

Los 11 restos identificados corresponden en su mayoría a tibiotarsos. Los datos osteométricos se resumen en el Anexo 1.

FAMILIA TURDIDAE VIGORS, 1825

El espectro faunístico identificado se completa con cuatro restos de tordo recuperados en los niveles Solutrense y Epipaleolítico. Debido a sus pequeñas dimensiones y la erosión no fue posible llegar a una identificación específica.

El registro de los Passeriformes incluye además cien restos no identificados pertenecientes a aves de pequeño tamaño.

\section{4.- DISCUSIÓN Y CONCLUSIÓN}

El conjunto de aves recuperado en la cueva de Praileaitz I constituye uno de los mayores hasta ahora analizado en el País Vasco. A pesar del elevado número de huesos que están presentes, la variedad de especies es limitada. Los taxones dominantes en toda la secuencia son la Chova Piquigualda y la Chova Piquirroja, cuyo nicho ecológico se encuentra en estas áreas de roquedo, que también les sirven como espacios de cría. A ellas se suman las palomas y algunas rapaces diurnas entre las que destaca el Águila Real y el Cernícalo, igualmente frecuentadoras de este tipo de ambientes rupícolas. Completan el espectro anátidos, lagópodos y otras pequeñas aves que vivirían en el entorno de la cueva y que constituyeron seguramente las presas consumidas por las rapaces identificadas, ya que en ningún resto fue posible ob-

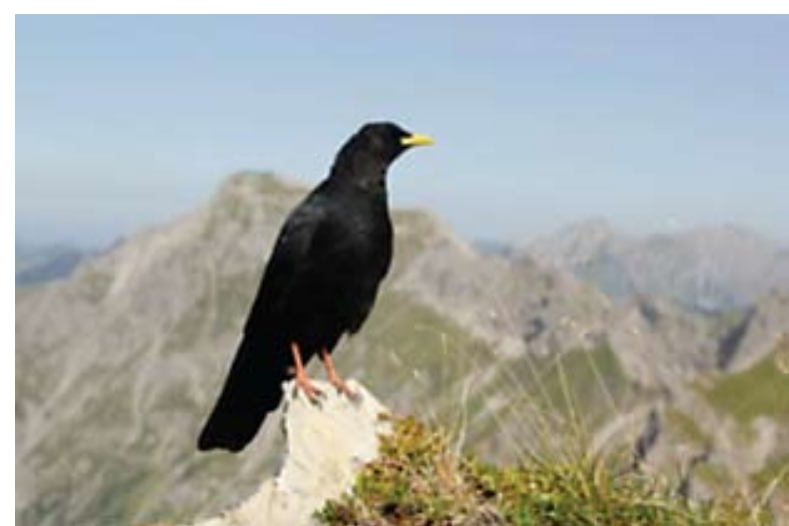

Fig. 14-15. Imágenes actuales de Pyrrhocorax pyrrhocorax (izquierda) y Pyrrhocorax graculus (derecha). / Present day images of Pyrrhocorax pyrrhocorax (left) and Pyrrhocorax graculus (right).

quier hábitat, exceptuando bosques densos y parajes situados a más de 1500 metros de altura. Es muy sedentaria, pues rara vez realiza movimientos superiores a los $50 \mathrm{~km}$ de radio (MARTíNEZ et al., 2003). Gran parte de su éxito radica en la falta de especialización de su dieta que, dependiendo de la época del año, puede incluir invertebrados, granos, frutas o carroña. servar trazas de manipulación humana. Muchas de estas especies son actualmente nidificantes en el País Vasco. La presencia del Lagópodo Escandinavo en el Solutrense constituye una clara evidencia de condiciones ambientales más frías que las actuales. En este sentido, llamamos la atención sobre los dos restos identificados como posible Esmerejón, también en este nivel, para el que no exis- 
te constancia en el registro arqueozoológico de la zona y que tratándose de un ave invernante que llega a la Península Ibérica desde Escandinavia reafirma la existencia de temperaturas más rigurosas en el Solutrense.

Por otra parte, destacamos el importante número de datos biométricos recopilados sobre la Chova Piguigualda y la Chova Piquirroja, que permitirán desarrollar en breve trabajos de osteometría comparada con el fin de mejorar nuestro conocimiento sobre la caracterización osteológica de estas dos especies en el pasado y comprender como evolucionaron.

Gracias al volumen de material se ha realizado el estudio de los patrones de representatividad anatómica y estado de fragmentación de los taxones más representativos (chovas y palomas), tomando por base los resultados publicados en estudios actualísticos con rapaces diurnas y nocturnas. Esta aproximación metodológica ha puesto de manifiesto que es posible caracterizar restos derivados de egagrópilas y desechos no ingeridos. La información obtenida a partir de la muestra de Praileaitz indica que gran parte de las aves recuperadas no proceden de regurgitaciones y por tanto no fueron consumidas. No obstante, como señala Laroulandie (2010), en el registro arqueológico procedente de cuevas pleistocénicas no es fácil diferenciar entre acumulaciones de aves muertas de manera natural y restos no ingeridos de las presas capturadas por rapaces, ya que la frecuencia de determinados elementos anatómicos puede verse afectada por factores tafonómicos postdeposicionales. Los huesos más frágiles, al sufrir una mayor fragmentación, son los peor conservados y se produce un sesgo en los perfiles anatómicos que nada tiene que ver con los hábitos de alimentación de las rapaces. Por esta razón, es conveniente no limitar el estudio al análisis de un único criterio. En este sentido, se cuantificó la frecuencia de individuos juveniles entre la muestra de chovas, lo que permitió confirmar que la cueva de Praileaitz I sirvió como lugar de cría. Incluso entre los cernícalos también se registraron dos huesos de juveniles y la presencia mayoritaria de hembras.

En definitiva, el estudio realizado demuestra el carácter mixto del conjunto recuperado, consistente en acumulaciones sucesivas de carcasas de aves muertas de forma natural junto a aportaciones puntuales realizadas por rapaces diurnas, sin que exista ninguna evidencia de intervención humana.

\section{5.- BIBLIOGRAFÍA}

ALTUNA, J., MARIEZKURRENA, K., ELORZA, M.

2001-2002 Arqueozoología de los niveles paleolíticos de la cueva de Abauntz (Arraiz, Navarra). Saldvie II, 1-26.

ÁlVAREZ, J., BEA, A., FAUS, J.M., CASTIEN, E. MENDIOLA, I.

1985 Atlas de los Vertebrados Continentales de Álava, Vizcaya y Guipúzcoa (excepto Chiroptera). Gobierno Vasco. Vitoria-Gasteiz.
ARROYO, B

2003 Águila Real, Aquila chrysaetos, en MARTí. R. \& DEL MORAL, J.C. (eds.) Atlas de las aves reproductoras de ESpaña. 188-189. Dirección General de Conservación de la Naturaleza, Sociedad Española de Ornitología. Madrid.

BLANCO, G.

2003 Chova Piquirroja, Pyrrhocorax pyrrhocorax, en MARTí. R. \& DEL MORAL, J.C. (eds.) Atlas de las aves reproductoras de España. 546-547. Dirección General de Conservación de la Naturaleza, Sociedad Española de Ornitología. Madrid.

\section{BOCHENSKI, Z.}

1985 Osteological differentiation in Willow grouse. Fortschritte der Zoologie 30, 69-72.

BOCHENSKI, Z.M.

2005 Owls, diurnal raptors and humans: signatures on avian bones, en O'CONNOR, T. (ed.) Biosphere to Lithosphere New studies in vertebrate taphonomy. 31-45. Oxbow Books. Oxford.

BOCHENSKI, Z.M., KOROVIN, V.A., NEKRASOV, A.E. TOMEK, T.

1997 Fragmentation of bird bones in food remains of Imperial Eagles (Aquila heliaca). International Journal of Osteoarchaeology 7, 165-171.

BOCHENSKI, Z.M., TOMEK, T.

1997 Preservation of bird bones: erosion versus digestion by owls. International Journal of Osteoarchaeology 7, 372387.

BOCHENSKI, Z.M., TOMEK, T., TORNBERG, R. WERTZ, K.

2009 Distinguishing nonhuman predation on birds: pattern of damage done by the white-tailed eagle Haliaetus albicilla, with comments on the punctures made by the golden eagle Aquila chrysaetos. Journal of Archaeological Science 36, 122-129.

BOV, K.M.

2002 Differential avian skeletal part distribution: explaining the abundance of wings. Journal of Archaeological Science 29, 965-978.

BRAIN, C.K.

1981 The hunters or the hunted? University of Chicago Press. Chicago.

CANUT, J., GARCÍA, D., PARELLADA, X. LORENTE, L.

2003 Lagópodo Alpino, Lagopus mutus, en MARTí. R. \& DEL MORAL, J.C. (eds.) Atlas de las aves reproductoras de España. 208-209. Dirección General de Conservación de la Naturaleza-Sociedad Española de Ornitología. Madrid. 
CASAUX RIVAS, E.

2003 Vencejo Común, Apus apus, en MARTí. R. \& DEL MORAL, J.C. (eds.) Atlas de las aves reproductoras de España. 334-335. Dirección de Conservación de la Naturaleza, SEO. Madrid.

CRAMP, S. SIMMONS, K.E.L.

1980 The Birds of the Western Palearctic. Volume II. Oxford University Press. Oxford, New York.

DRIESCH, A. VON DEN

1976 A guide to the measurement of animal bones from archaeological sites. Peabody Museum Bulletin. Harvard.

DRIVER, J.C.

1982 Medullary bone as an indicator of sex in bird remains from archaeological sites, en WILSON, B., GRIGSON, C. \& PAYNE, S. (eds.) Ageing and sexing animal bones from archaeological sites. 251-254. Oxford. BAR British Series; 109).

EASTHAM, A.

1984 The avifauna of the Cave of Ekain, en ALTUNA, J. \& MERINO J. M. (eds.) El yacimiento prehistórico de la Cueva de Ekain (Deva, Guipúzcoa). 331-344. Eusko Ikaskuntza, Sociedad de Estudios Vascos. Donostia.

1985 The Magdalenian avifauna at Erralla cave. Munibe 37, 5980.

1989 The bird bones in the Cave of Amalda, en ALTUNA, J., BALDEÓN, A. \& MARIEZKURRENA, K. (eds.) La Cueva de Amalda (Zestoa, País Vasco) Ocupaciones paleoliticas y postpaleoliticas. 239-253. Fundación Barandiaran, Eusko lkaskuntza.

\section{ELORZA, M.}

1990 Restos de aves en los yacimientos prehistóricos vascos. Estudios realizados. Munibe (Antropologia - Arkeologia) 42, 263-267.

1993 Revisión de la avifauna de Ermittia (Gipuzkoa). Munibe (Antropologia - Arkeologia) 45, 175-177.

1997 La avifauna del yacimiento de Urratxa III (Orozko, Bizkaia), en MUÑOZ SALVATIERRA, M. \& BERGANZA, E. (eds.) El yacimiento de la cueva de Urratxa III (Orozko, Bizkaia). 191-206. Universidad de Deusto. Deusto.

ERICSON, P.G.P.

1987 Interpretation of archaeological bird remains: a taphonomic approach. Journal of Archaeological Science 14, 65-75.

FERNÁNDEZ, C. PURROY, F.

1990 Tendencias geográficas en la alimentación del Águila Real (Aquila chrysaetos L.) en Navarra. Ardeola 37(2), 197-206.

FICK, O.K.W.

1974 Vergleichend morphologische Untersuchungen an Einzelknochen europäischer Taubenarten. Ludwig-Maximilians-Universität München. München.
FINLAYSON, C., BROWN, K., BLASCO, R., ROSELL, J., NEGRO, J.J., BORTOLOTII, G.R., FINLAYSON, G., SÁNCHEZ MARCO, A., GILES PACHECO, F., RODRÍGUEZ VIDAL, J. et al.

2012 Birds of a feather: Neanderthal exploitation of raptors and corvids. Plos One 7(9), e45927.

HERNÁNDEZ CARRASQUILLA, F.

1993 Catálogo provisional de los yacimientos con aves del Cuaternario de la Península lbérica. Archaeofauna 2, 231 275.

HÖRNELL-WILLEBRAND, M.

2005 Temporal and spatial dynamics of Willow Grouse Lagopus lagopus. University of Umea. Umea.

KRAFT, E.

1972 Vergleichend morphologische Untersuchungen an Einzelknochen nord- und mitteleuropäischer kleinerer Hühnenvögel. Universität München. München.

\section{LAROULANDIE, V.}

2000 Taphonomie et Archéozoologie des oiseaux en grotte: applications aux sites paléolithiques du Bois-Ragot (Vienne), de Combe Saunière (Dordogne) et de La Vache (Ariège) [Tesis Doctoral]. Bordeaux: L'Universite Bordeaux I. 396 p.

2002 Damage to Pigeon long bones in pellets of the Eagle OWl Bubo bubo and food remains of Peregrine Falcon Falco peregrinus: zooarchaeological implications. Acta Zoologica Cracoviensia 45 (special issue), 331-339.

2005 Bird exploitation pattern: the case of Ptarmigan Lagopus $\mathrm{sp}$. in the Upper Magdalenian site of La Vache (Ariège, France), en GRUPE, G. \& PETERS, J. (eds.) Feathers, grit and symbolism Birds and humans in the ancient Old and New Worlds. Verlag 165-178. Marie Leidorf, GmbH. Rahden/Westf.

2010 Alpine chough Pyrrhocorax graculus from Pleistocene sites between Pyrenees and Alps : natural versus cultural assemblages, en PRUMMEL, W., ZEILER, J. \& BRINKHUIZEN, D.C. (eds.) Birds in archaeology. 219-232. Groningen. Proceedings of the 6th Meeting of the ICAZ Bird Working Group in Groningen.

LAWSON, G., D'ERRICO, F.

2002 Microscopic, experimental and theoretical re-assessment of Upper Palaeolithic bird-bone pipes from Isturitz, France: ergonomics of design, systems of notation and the origins of musical traditions, en HICKMANN, E., KILMER, A.D. \& EICHMANN, R. (eds.) The Archaeology of Sound: Origin and Organisation. 119-142. Verlag Marie Leidorf GmbH. Rahden/Westf

LIVINGSTON, S.D.

1989 The taphonomic interpretation of avian skeletal part frequencies. Journal of Archaeological Science 16, 537-547. 
MARTíNEZ-CLIMENT, J.A. ZUBEROGOITIA ARROYO, I. 2003 Búho Real, Bubo bubo, en MARTí. R. \& DEL MORAl, J.C. (eds.) Atlas de las aves reproductoras de España. 316-317. Dirección de Conservación de la Naturaleza, SEO. Madrid.

MARTíNEZ, J.G., SOLER, M., SOLER, J.J.

2003 Urraca, Pica pica, en MARTí. R. \& DEL MORAL, J.C. (eds.) Atlas de las aves reproductoras de España. 542-543. Dirección de Conservación de la Naturaleza, SEO. Madrid.

MOLINA VILLARINO, B.

2003 Cuervo, Corvus corax, en MARTÍ. R. \& DEL MORAL, J.C. (eds.) Atlas de las aves reproductoras de España. 554-555. Dirección de Conservación de la Naturaleza, SEO. Madrid.

\section{MORIN, E., LAROULANDIE, V.}

2012 Presumed symbolic use of diurnal raptors by Neanderthals. Plos One 7(3), e32856.

\section{MOURER-CHAUVIRÉ, C.}

1983 Les oiseaux dans les habitats paléolithiques: gibier des hommes ou proies des rapaces?, en GRIGSON, C. \& CLUTTONBROCK, J. (eds.) Animals and Archaeology 2 Shell middens, fishes and birds. 111-124. Oxford. BAR International Series; 183.

1993 The Pleistocene avifaunas of Europe. Archaeofauna 2, 53-66.

\section{SÁNCHEZ-ALONSO, C.}

2003 Chova Piquigualda, Pyrrhocorax graculus, en MARTí. R. \& DEL MORAL, J.C. (eds.) Atlas de las aves reproductoras de España. 544-545. Dirección General de Conservación de la Naturaleza, Sociedad Española de Ornitología. Madrid.

\section{SCHMIDT-BURGER, P}

1982 Vergleichend morphologische Untersuchungen an Einzelknochen in Zentraleuropa vorkommender mittelgrosser Accipitridae. II. Becken und Hinterextremität. Ludwig-Maximilians-Universität München. München.

SOLTI, B.

1996 The comparative osteomorphological study of the European small-statured falcons (Aves: Falconidae). Folia Historico-Naturalia Musei Matraensis 21, 5-282

STEWART, J.R.

1999 Intraspecific variation in modern and Quaternary European Lagopus. Smithsonian Contributions to Paleobiology 89, 159168

SUNYER, C., VIÑUELA, J.

1990 Migración e invernada del Esmerejón en España. Ardeola 37(2), 279-290

SVENSSON, L., MULLARNEY, K. ZEITERSTRÖM, D.

2009 Guía de aves. España, Europa y región mediterránea. Ediciones Omega. Barcelona.

TAGLIACOZZO, A. GALA. M.

2004 L' avifauna dei livelli 24-23 (Aurignaziana e Gravettiano antico) di Grotta Paglicci: I'aspetto amibiente e quello de economico, en PALMA DU CESNOLA, A. (ed.) Paglicci L' Aurignaziano e il Gravettiano antico. 71-90. Claudio Grenzi. Foggia.

TOMEK, T., BOCHENSKI, Z. M.

2000 The comparative osteology of European corvids (Aves: Corvidae), with a key to the identification of their skeletal elements. Polish Academy of Sciences. Kraków. 


\section{ANEXO 1}

\section{Praileaitz I. Datos métricos, en mm (según von den Driesch, 1976)}

Praileaitz I. Metrical data, in mm (after von den Driesch, 1976)

\begin{tabular}{|c|c|c|c|c|c|c|c|c|c|c|}
\hline PERIODO & ESPACIO & INVENTARIO & TAXA & HUESO & GL & $\mathrm{Lm}$ & $\mathrm{Bb}$ & BF & & \\
\hline Solutrense & Vestíbulo & $A 10.314 .34 .1 .2$ & Aquila chrysaetos & COR & 80,13 & 72,53 & - & - & & \\
\hline Solutrense & Vestíbulo & E8.299.209.7 & cf. Falco columbarius & COR & 32,29 & 29,30 & 11,61 & 11,56 & & \\
\hline Epipal-Magd & Galería NO & 1H.198.188.3 & Columba livia/oenas & $\mathrm{COR}$ & 32,40 & 30,87 & 11,22 & 9,90 & & \\
\hline Solutrense & Vestíbulo & A8.311.34.3 & Columba livia/oenas & COR & 32,13 & 30,97 & - & 8,49 & & \\
\hline Solutrense & Vestíbulo & A8.311.34.2 & Columba livia/oenas & $\mathrm{COR}$ & - & 31,63 & - & - & & \\
\hline Magd. Sup/fin & Vestíbulo & E2.219. & Columba livia/oenas & COR & 32,48 & 31,61 & - & 8,42 & & \\
\hline Magd. Sup/fin & Vestíbulo & E2.219. & Columba livia/oenas & COR & - & - & - & 8,46 & & \\
\hline Magd. Inf. & Vestíbulo & E2.236. & Columba livia/oenas & COR & 34,75 & - & - & 8,36 & & \\
\hline Magd. Inf. & Vestíbulo & F2.236.34.2 & Columba livia/oenas & $\mathrm{COR}$ & 32,90 & 32,02 & 10,54 & 9,26 & & \\
\hline Magd. Sup/fin & Vestíbulo & F2.228.95.4 & Columba livia/oenas & COR & 34,64 & 33,50 & - & 8,91 & & \\
\hline Epipaleolítico & Vestíbulo & 6A. 41.2 & Columba livia/oenas & $\mathrm{COR}$ & 33,66 & 32,57 & - & - & & \\
\hline Magd. Inf. & Pasillo & $8 A^{\prime} .309 .91 .3$ & Columba livia/oenas & COR & - & 33,64 & - & - & & \\
\hline Magd. Inf. & Vestíbulo & 12E 317.247 .2 & Columba livia/oenas & COR & 34,10 & 33,15 & - & - & & \\
\hline Magd. Inf. & Vestíbulo & 12E.324.386.15.16 & Columba livia/oenas & COR & 34,96 & 33,40 & - & - & & \\
\hline Magd. Inf. & Vestíbulo & 12E.304.119.4.1 & Columba livia/oenas & COR & 34,97 & 33,29 & - & - & & \\
\hline Epipaleolítico & Pasillo & $8 B^{\prime} .289 .35 .4$ & Columba livia/oenas & COR & 35,09 & 33,92 & 11,18 & 10,09 & & \\
\hline Solutrense & Vestíbulo & 14D.328.104.1 & Columba livia/oenas & COR & 34,28 & 33,15 & 9,48 & 8,63 & & \\
\hline Epipaleolítico & Vestíbulo & 2D.222.6.10 & Columba livia/oenas & $\mathrm{COR}$ & 35,32 & 33,86 & 14,40 & 9,04 & & \\
\hline Epipaleolítico & Vestíbulo & 2D.222.6.28 & Columba livia/oenas & $\mathrm{COR}$ & 32,72 & 31,72 & - & 9,28 & & \\
\hline Epipaleolítico & Vestíbulo & 2D.222.6.30 & Columba livia/oenas & $\mathrm{COR}$ & 34,41 & - & - & - & & \\
\hline Epipaleolítico & Vestíbulo & 2D.222.6.37 & Columba livia/oenas & COR & 35,01 & 33,61 & - & - & & \\
\hline Epipaleolítico & Vestíbulo & 2D.222.6.14 & Columba livia/oenas & COR & - & 32,17 & - & - & & \\
\hline Epipaleolítico & Vestíbulo & 2D.222.6.11 & Columba livia/oenas & COR & - & 32,77 & - & - & & \\
\hline Epipaleolítico & Vestíbulo & 2D.222.6.31 & Columba livia/oenas & COR & 35,65 & 33,81 & - & - & & \\
\hline Magd. Sup/fin & Vestíbulo & 2D.231.26.10 & Columba livia/oenas & COR & - & 33,95 & - & - & & \\
\hline Epipaleolítico & Vestíbulo & 6F.199.290.16 & Columba livia/oenas & COR & - & 30,16 & - & - & & \\
\hline Magd. Sup/fin & Vestíbulo & 10E.253.188.3 & Columba livia/oenas & COR & 35,87 & 35,19 & - & - & & \\
\hline PERIODO & ESPACIO & INVENTARIO & TAXA & HUESO & GL & Bp/Dip & SC & BD & Sexo & \\
\hline Epipaleolítico & Vestíbulo & 6F.214.54 & Anser sp. & $\mathrm{HU}$ & - & 33,29 & - & - & & \\
\hline Epipaleolítico & Vestíbulo & 12D.231.8.1.2 & A. platyrhynchos & $\mathrm{HU}$ & 98,59 & 21,32 & 7,59 & - & & \\
\hline $\begin{array}{l}\text { Solutrense- } \\
\text { Gravetiense }\end{array}$ & Galería NO & $4 \mathrm{H} .233 .262$ & A. platyrhynchos & $\mathrm{HU}$ & - & - & - & 14,83 & & \\
\hline $\begin{array}{l}\text { Solutrense- } \\
\text { Gravetiense }\end{array}$ & Galería NO & 41.233 .86 & A. platyrhynchos & $\mathrm{HU}$ & - & 21,35 & - & - & & \\
\hline Epipaleolítico & Vestíbulo & $6 F .188 . .22 .1$ & Lagopus sp & $\mathrm{HU}$ & - & - & 5,27 & 10,56 & & \\
\hline Solutrense & Vestíbulo & 10C.326.194.3.9 & Lagopus lagopus & $\mathrm{HU}$ & 61,60 & - & 5,59 & 11,70 & & \\
\hline Epipaleolítico & Vestíbulo & 6F.290.21 & Coturnix coturnix & $\mathrm{HU}$ & 34,89 & - & 2,69 & 5,33 & & \\
\hline Epipaleolítico & Pasillo & 14C'.308.24.1 & Coturnix coturnix & $\mathrm{HU}$ & 34,74 & 7,64 & 2,46 & 5,30 & & \\
\hline Magd. Inf. & Vestíbulo & 14E.281.36 & Aquila chrysaetos & $\mathrm{HU}$ & - & - & - & 31,99 & $\mathrm{H}$ & \\
\hline Epipal-Magd & Galería NO & $3 \mathrm{H} .204 .6$ & Columba livia/oenas & $\mathrm{HU}$ & - & 15,31 & 5,16 & - & & \\
\hline Epipal-Magd & Galería NO & $2 \mathrm{H} .205 .273$ & Columba livia/oenas & $\mathrm{HU}$ & 43,75 & - & 5,25 & 9,88 & & \\
\hline Epipaleolítico & Vestíbulo & E1.208.142 & Columba livia/oenas & $\mathrm{HU}$ & - & - & - & 10,34 & & \\
\hline Epipaleolítico & Vestíbulo & 2C.209.4 & Columba livia/oenas & $\mathrm{HU}$ & - & - & 4,94 & 10,18 & & \\
\hline Epipaleolítico & Vestíbulo & 2C.209.3 & Columba livia/oenas & $\mathrm{HU}$ & 45,85 & 15,39 & - & 11,02 & & \\
\hline Epipaleolítico & Vestíbulo & 2D.209.5.11 & Columba livia/oenas & $\mathrm{HU}$ & - & - & - & 10,90 & & \\
\hline Epipaleolítico & Vestíbulo & 2D.222.6.4 & Columba livia/oenas & $\mathrm{HU}$ & 45,98 & 16,52 & 5,64 & 11,03 & & \\
\hline Epipaleolítico & Vestíbulo & 2D.222.6.2 & Columba livia/oenas & $\mathrm{HU}$ & 44,33 & 16,14 & 4,98 & 10,35 & & \\
\hline
\end{tabular}




\begin{tabular}{|c|c|c|c|c|c|c|c|c|c|c|}
\hline Epipaleolítico & Vestíbulo & 2D.222.6.5 & Columba livia/oenas & $\mathrm{HU}$ & - & 16,00 & - & - & & \\
\hline Epipaleolítico & Vestíbulo & 2D.222.6.3 & Columba livia/oenas & $\mathrm{HU}$ & - & - & 5,25 & 10,38 & & \\
\hline Epipaleolítico & Vestíbulo & 2D.222.6.8 & Columba livia/oenas & $\mathrm{HU}$ & - & - & 5,25 & 9,85 & & \\
\hline Epipaleolítico & Vestíbulo & 2D.209.5.10 & Columba livia/oenas & $\mathrm{HU}$ & - & - & 5,19 & 10,26 & & \\
\hline Epipaleolítico & Vestíbulo & 10A.239.8 & Columba livia/oenas & $\mathrm{HU}$ & 44,62 & 17,12 & 5,33 & 10,53 & & \\
\hline Magd. Sup/fin & Vestíbulo & $2 \mathrm{E} .230 .138 .1$ & Columba livia/oenas & $\mathrm{HU}$ & 44,33 & - & 5,04 & 9,83 & & \\
\hline Magd. Sup/fin & Vestíbulo & 10C.244.220.2 & Columba livia/oenas & $\mathrm{HU}$ & - & - & - & 9,56 & & \\
\hline Magd. Sup/fin & Vestíbulo & 10C.256.222.1 & Columba livia/oenas & $\mathrm{HU}$ & 45,63 & 15,09 & 5,22 & 10,43 & & \\
\hline Magd. Sup/fin & Vestíbulo & 2D.231.26.4 & Columba livia/oenas & $\mathrm{HU}$ & 43,89 & - & 5,32 & 10,06 & & \\
\hline Magd. Inf. & Vestíbulo & 2D.239. & Columba livia/oenas & $\mathrm{HU}$ & - & - & - & 10,79 & & \\
\hline Magd. Inf. & Vestíbulo & E2.236.123 & Columba livia/oenas & $\mathrm{HU}$ & - & - & - & 10,08 & & \\
\hline Magd. Inf. & Pasillo & A8'.298.17.22 & Columba livia/oenas & $\mathrm{HU}$ & - & - & - & 11,23 & & \\
\hline Magd. Inf. & Pasillo & 12A'.295.35.1 & Columba livia/oenas & $\mathrm{HU}$ & 44,08 & 15,31 & 5,37 & 10,29 & & \\
\hline Magd. Inf. & Vestíbulo & 12E.317.247.1 & Columba livia/oenas & $\mathrm{HU}$ & - & - & - & 10,27 & & \\
\hline Solutrense & Vestíbulo & 8A.337.152.3 & Columba livia/oenas & $\mathrm{HU}$ & 44,90 & 16,11 & 5,18 & 10,81 & & \\
\hline Solutrense & Vestíbulo & 12A.309.85.8 & Columba livia/oenas & $\mathrm{HU}$ & - & - & - & 10,12 & & \\
\hline Solutrense & Vestíbulo & 12B.311.236.1 & Columba livia/oenas & $\mathrm{HU}$ & - & - & - & 9,99 & & \\
\hline PERIODO & ESPACIO & INVENTARIO & TAXA & HUESO & GL & $\mathrm{Bp}$ & SC & $\mathrm{Bd}$ & & \\
\hline Solutrense & Vestíbulo & A8.331.166 & Aquila chrysaetos & RA & 202,56 & - & 6,13 & 14,66 & & \\
\hline Magd. Inf. & Vestíbulo & 8 A.300.41.1 & Columba livia/oenas & RA & 47,98 & - & - & - & & \\
\hline Magd. Inf. & Vestíbulo & $2 F .234 .98$ & Columba livia/oenas & RA & 45,76 & - & 2,15 & 4,45 & & \\
\hline Solutrense & Vestíbulo & 12E.317.285.1 & Columba livia/oenas & RA & 46,71 & - & - & - & & \\
\hline PERIODO & ESPACIO & INVENTARIO & TAXA & HUESO & GL & $\mathrm{Bp}$ & Dip & SC & Did & Sexo \\
\hline Magd. Inf. & Vestíbulo & 12A.288.174.8 & Lagopus lagopus & UL & - & - & - & 4,28 & 7,98 & \\
\hline Magd. Inf. & Vestíbulo & 12F.314.263 & Aquila chrysaetos & UL & - & 22,40 & - & - & - & \\
\hline Magd. Sup/fin & Vestíbulo & $8 \mathrm{H} .238 .10$ & Aquila chrysaetos & UL & - & - & - & - & 18,40 & \\
\hline Solutrense & Vestíbulo & 14F.323.228 & Aquila chrysaetos & UL & - & - & - & - & 17,15 & \\
\hline Magd. Inf. & Vestíbulo & 12G.288.75.3 & Falco tinnunculus & UL & - & 7,36 & - & - & - & \\
\hline Solutrense & Vestíbulo & 12D.305.296.2 & Falco tinnunculus & UL & 65,52 & - & - & - & - & $\mathrm{H}$ \\
\hline Solutrense & Vestíbulo & 12D.315.308.8/2 & Falco tinnunculus & UL & 64,65 & - & - & - & - & $\mathrm{H}$ \\
\hline- & Sala NO & G1.218.70.1 & Columba livia/oenas & UL & - & - & - & - & 6,30 & \\
\hline Solutrense & Vestíbulo & A8.311.34.6 & Columba livia/oenas & UL & 49,01 & 6,49 & - & - & 6,60 & \\
\hline Magd. Sup/fin & Vestíbulo & E2.219. & Columba livia/oenas & $\mathrm{UL}$ & - & 5,85 & 8,42 & - & - & \\
\hline Magd. Inf. & Vestíbulo & E2.232. & Columba livia/oenas & UL & - & - & 9,03 & - & 6,28 & \\
\hline Magd. Inf. & Vestíbulo & E2.236. & Columba livia/oenas & UL & 51,33 & 6,34 & - & - & 7,10 & \\
\hline Epipaleolítico & Vestíbulo & 1E.213.131.10 & Columba livia/oenas & UL & - & - & - & - & 6,61 & \\
\hline Epipaleolítico & Vestíbulo & $1 \mathrm{E} .218$. & Columba livia/oenas & UL & - & 6,34 & - & - & - & \\
\hline Magd. Sup/fin & Vestíbulo & 1E.236.135.13 & Columba livia/oenas & UL & - & 6,08 & 9,02 & - & - & \\
\hline \multirow[t]{2}{*}{ Solutrense } & Vestíbulo & 4E.272.95.3 & Columba livia/oenas & UL & - & 7,17 & 8,74 & - & - & \\
\hline & Sala NO & $2 \mathrm{H} .213 .280 .2$ & Columba livia/oenas & UL & - & - & 8,77 & - & 8,95 & \\
\hline Magd. Inf. & Sala NO & $2 \mathrm{H} .222 .88 .3$ & Columba livia/oenas & UL & - & - & - & - & 6,76 & \\
\hline Solutrense & Vestíbulo & C8.312.76.2 & Columba livia/oenas & UL & - & 6,68 & - & - & - & \\
\hline Magd. Inf. & Vestíbulo & 10A.281.89.2 & Columba livia/oenas & UL & 50,89 & 6,65 & - & 4,18 & - & \\
\hline Solutrense & Vestíbulo & C10.320.156.6 & Columba livia/oenas & UL & - & 6,80 & - & - & - & \\
\hline Epipaleolítico & Vestíbulo & 2C.195.28.6 & Columba livia/oenas & UL & - & - & - & - & 7,27 & \\
\hline Solutrense & Vestíbulo & 8 A.302.112.1 & Columba livia/oenas & UL & 51,77 & 6,53 & 9,73 & 3,58 & 7,09 & \\
\hline Solutrense & Vestíbulo & $8 A .312 .127 .9$ & Columba livia/oenas & UL & 52,42 & 6,65 & 9,82 & 3,64 & 7,15 & \\
\hline Magd. Inf. & Vestíbulo & 10A.278.87.3 & Columba livia/oenas & UL & 50,35 & - & 8,02 & 3,90 & 7,05 & \\
\hline Epipaleolítico & Pasillo & 12C'.296.8 & Columba livia/oenas & UL & - & 7,01 & - & - & 6,43 & \\
\hline Epipaleolítico & Vestíbulo & 12G.194.180 & Columba livia/oenas & UL & - & - & - & - & 7,05 & \\
\hline Magd. Inf. & Vestíbulo & 14F.306. & Columba livia/oenas & UL & - & - & - & - & 6,47 & \\
\hline
\end{tabular}




\begin{tabular}{|c|c|c|c|c|c|c|c|c|c|c|}
\hline Epipaleolítico & Vestíbulo & 2D.222.6.33 & Columba livia/oenas & UL & 51,81 & 6,54 & 9,52 & 3,52 & 6,86 & \\
\hline Epipaleolítico & Vestíbulo & 2D.222.6.21 & Columba livia/oenas & UL & 54,66 & 7,45 & - & 4,04 & 7,03 & \\
\hline Epipaleolítico & Vestíbulo & 2D.222.18 & Columba livia/oenas & UL & 52,16 & 7,40 & - & 3,72 & 7,20 & \\
\hline Epipaleolítico & Vestíbulo & 2D.222.41 & Columba livia/oenas & UL & - & - & - & - & 6,94 & \\
\hline Epipaleolítico & Vestíbulo & 2D.222. & Columba livia/oenas & UL & - & 6,25 & - & - & - & \\
\hline Epipaleolítico & Vestíbulo & 2C.209.27.1 & Columba livia/oenas & UL & - & - & - & - & 6,68 & \\
\hline Epipaleolítico & Vestíbulo & 2C.209.27.8 & Columba livia/oenas & UL & - & 6,89 & - & 4,28 & - & \\
\hline Epipaleolítico & Vestíbulo & 2C.209.27.10 & Columba livia/oenas & UL & - & 6,68 & - & - & - & \\
\hline Epipaleolítico & Vestíbulo & 2D.209.5.16 & Columba livia/oenas & UL & - & 7,08 & - & - & - & \\
\hline Epipaleolítico & Vestíbulo & 2D.209.5.22 & Columba livia/oenas & UL & - & - & - & - & 7,07 & \\
\hline Magd. Sup/fin & Vestíbulo & 2D.231.9.20 & Columba livia/oenas & UL & - & - & - & - & 7,07 & \\
\hline Magd. Sup/fin & Vestíbulo & $2 \mathrm{E} .230 .138 .2$ & Columba livia/oenas & UL & - & 6,76 & - & 3,65 & - & \\
\hline Magd. Inf. & Vestíbulo & 6F.260.95.4 & Columba livia/oenas & UL & 51,21 & 7,12 & 9,26 & 3,46 & 6,77 & \\
\hline Magd. Inf. & Vestíbulo & 6F.260.95.6 & Columba livia/oenas & UL & 51,16 & 6,98 & 9,27 & 3,52 & 6,83 & \\
\hline Magd. Sup/fin & Vestíbulo & 8G.223.343 & Columba livia/oenas & UL & - & - & - & - & 5,99 & \\
\hline Magd. Inf. & Vestíbulo & 10D.278.351.2 & Columba livia/oenas & UL & - & - & - & - & 6,96 & \\
\hline Solutrense & Vestíbulo & 12B.307.229.10 & Columba livia/oenas & UL & - & - & - & - & 6,72 & \\
\hline Magd. Inf. & Vestíbulo & $12 F .301$ & Columba livia/oenas & UL & - & 7,40 & - & - & - & \\
\hline Solutrense & Vestíbulo & 12F.318.310.1 & Columba livia/oenas & UL & 51,68 & 6,76 & - & 3,90 & 6,74 & \\
\hline Magd. Sup/fin & Vestíbulo & $6 F .241 .114 .3$ & Columba livia/oenas & UL & - & - & - & - & 7,01 & \\
\hline Magd. Inf. & Vestíbulo & 12B.273.297.4 & Columba livia/oenas & UL & - & 6,91 & - & - & - & \\
\hline PERIODO & ESPACIO & INVENTARIO & TAXA & HUESO & $\mathbf{L}$ & GL & $\mathrm{Bp}$ & Did & & \\
\hline Solutrense & Vestíbulo & C8.308.75 & Aquila chrysaetos & CMC & 110,32 & 107,37 & 26,71 & 21,81 & & \\
\hline Magd. Inf. & Vestíbulo & 12A.295.175.5 & Columba livia/oenas & $\mathrm{CMC}$ & & 32,69 & & & & \\
\hline Magd. Inf. & Vestíbulo & 12E.317.247.3 & Columba livia/oenas & $\mathrm{CMC}$ & & 32,06 & & & & \\
\hline Magd. Inf. & Vestíbulo & 12E.292.48.2 & Columba livia/oenas & $\mathrm{CMC}$ & & 33,20 & & & & \\
\hline Solutrense & Vestíbulo & 8A.306. 08.2 & Columba livia/oenas & $\mathrm{CMC}$ & & 32,38 & & & & \\
\hline Epipaleolítico & Pasillo & 14B'.307 & Columba livia/oenas & $\mathrm{CMC}$ & & 34,63 & & & & \\
\hline Epipaleolítico & Vestíbulo & 2D.222.6.49 & Columba livia/oenas & $\mathrm{CMC}$ & & 32,81 & & & & \\
\hline Epipaleolítico & Vestíbulo & 2D.222.6.62 & Columba livia/oenas & $\mathrm{CMC}$ & & 32,14 & & & & \\
\hline Epipaleolítico & Vestíbulo & 2C.195.28.7 & Columba livia/oenas & $\mathrm{CMC}$ & & 32,33 & & & & \\
\hline Epipaleolítico & Vestíbulo & 2C.209.27.9 & Columba livia/oenas & $\mathrm{CMC}$ & & 34,10 & & & & \\
\hline Epipaleolítico & Vestíbulo & 2D.209.5.27 & Columba livia/oenas & $\mathrm{CMC}$ & & 31,45 & & & & \\
\hline Magd. Sup/fin & Vestíbulo & 2E.230.138.12 & Columba livia/oenas & $\mathrm{CMC}$ & & 33,12 & & & & \\
\hline Magd. Sup/fin & Vestíbulo & $8 G .248$ & Columba livia/oenas & $\mathrm{CMC}$ & & 31,38 & & & & \\
\hline Magd. Sup/fin & Vestíbulo & 10C.256.222.18 & Columba livia/oenas & $\mathrm{CMC}$ & & 33,63 & & & & \\
\hline Magd. Sup/fin & Vestíbulo & 10E.253 & Columba livia/oenas & $\mathrm{CMC}$ & & 34,31 & & & & \\
\hline Magd. Inf. & Vestíbulo & $6 F .260 .95 .13$ & Columba livia/oenas & $\mathrm{CMC}$ & & 34,20 & & & & \\
\hline Epipaleolítico & Vestíbulo & $6 F .199$ & Apus apus & $\mathrm{CMC}$ & & 21,47 & & & & \\
\hline PERIODO & ESPACIO & INVENTARIO & TAXA & HUESO & GL & Bp & Dp & Bd & Dd & \\
\hline Epipaleolítico & Vestíbulo & 8G.220.339 & Aythya ferina & $\mathrm{FE}$ & - & - & - & 9,33 & 7,74 & \\
\hline Solutrense & Vestíbulo & 12A.300.114.2 & Lagopus sp & $\mathrm{FE}$ & - & 10,89 & 7,24 & - & - & \\
\hline Magd. Inf. & Pasillo & $8 A^{\prime} .309 .91 .9$ & Columba livia/oenas & $\mathrm{FE}$ & - & - & - & 7,18 & 5,55 & \\
\hline Magd. Sup/fin & Vestíbulo & 2D.231.26.6 & Columba livia/oenas & $\mathrm{FE}$ & 42,69 & - & - & - & - & \\
\hline Solutrense & Vestíbulo & 12B.298.219.24 & Columba livia/oenas & $\mathrm{FE}$ & - & 7,85 & 4,44 & - & - & \\
\hline Solutrense & Vestíbulo & 8A.312.127.2 & Columba livia/oenas & $\mathrm{FE}$ & - & 8,32 & - & - & - & \\
\hline PERIODO & ESPACIO & INVENTARIO & TAXA & HUESO & GL & $\mathrm{Bp}$ & SC & BD & Dd & Sexo \\
\hline Magd. Inf. & Vestíbulo & 6B.283.7 & Aquila chrysaetos & TBT & - & - & 13,17 & 23,44 & 14,78 & $\mathrm{H}$ \\
\hline Solutrense & Vestíbulo & A8.333.61 & Aquila chrysaetos & TBT & - & - & - & 20,35 & 14,43 & \\
\hline Magd. Inf. & Sala NO & 1G.222.16.2 & Columba livia/oenas & TBT & - & - & - & 6,17 & 6,45 & \\
\hline
\end{tabular}




\begin{tabular}{|c|c|c|c|c|c|c|c|c|c|}
\hline- & - & $8 A^{\prime} .282 .84 .4$ & Columba livia/oenas & TBT & - & - & - & 6,16 & 6,02 \\
\hline Solutrense & Vestíbulo & 8A.308.111.1 & Columba livia/oenas & TBT & - & - & 2,97 & 6,14 & 6,57 \\
\hline Solutrense & Vestíbulo & 8A.306.108.7 & Columba livia/oenas & TBT & - & - & - & 6,39 & 6,07 \\
\hline Solutrense & Vestíbulo & 8A.337.152.2 & Columba livia/oenas & TBT & 57,80 & 8,84 & 3,00 & 6,30 & - \\
\hline Magd. Sup/fin & Vestíbulo & 2D.231.26.27 & Columba livia/oenas & TBT & - & - & - & 6,31 & - \\
\hline Epipaleolítico & Vestíbulo & 2D.222.6.23 & Columba livia/oenas & TBT & 58,84 & - & 3,32 & 6,85 & - \\
\hline Epipaleolítico & Vestíbulo & 2D.222.6.39 & Columba livia/oenas & TBT & - & - & - & 6,81 & - \\
\hline Magd. Sup/fin & Vestíbulo & 2E.233.42 & Columba livia/oenas & TBT & - & - & - & 6,54 & - \\
\hline Magd. Inf. & Vestíbulo & 10G.265.16.2 & Columba livia/oenas & TBT & - & - & - & 6,52 & - \\
\hline PERIODO & ESPACIO & INVENTARIO & TAXA & HUESO & GL & $\mathrm{Bp}$ & SC & BD & Sexo \\
\hline Ep.-Magd & Galería NO & 21.186 .3 .2 & cf Anas acuta & TMT & - & - & - & 8,83 & \\
\hline Solutrense & Vestíbulo & 12D.304.295.1 & Lagopus lagopus & TMT & 40,85 & 7,53 & 3,35 & 8,06 & \\
\hline $\begin{array}{l}\text { Solutrense- } \\
\text { Gravetiense }\end{array}$ & Galería NO & J1.253.104 & Aquila chrysaetos & TMT & - & 24,37 & - & - & \\
\hline Magd. Inf. & Vestíbulo & 10C.300.28 & Cf. Circus pygargus & TMT & - & - & - & 8,26 & $\mathrm{H}$ \\
\hline Epipaleolítico & Vestíbulo & 6F.214.291.6 & Falco tinnunculus & TMT & 39,11 & 7,41 & 3,25 & 7,55 & $\mathrm{H}$ \\
\hline Magd. Inf. & Pasillo & A8'.306.23.4 & F. tinn /F. columbarius & TMT & 38,20 & 6,61 & 3,20 & 6,77 & \\
\hline Solutrense & Vestíbulo & E8.299.209.11 & Cf. Falco columbarius & TMT & 38,46 & - & - & - & \\
\hline Solutrense & Pasillo & 12A'.317.86.1 & Falco tinnunculus & TMT & - & - & - & 7,30 & $\mathrm{H}$ \\
\hline Solutrense & Vestíbulo & 12B.298.219.16.34 & Falco tinnunculus & TMT & 40,32 & 7,85 & 3,59 & - & $\mathrm{H}$ \\
\hline Solutrense & Vestíbulo & 12E.317.285 & Falco tinnunculus & TMT & - & - & - & 7,89 & $\mathrm{H}$ \\
\hline Epipal-Magd & Galería NO & 1G.212.2081 & Columba livia/oenas & TMT & 29,50 & 6,60 & 2,80 & 6,80 & \\
\hline Magd. Inf. & Vestíbulo & E2.236 & Columba livia/oenas & TMT & 30,61 & 6,52 & 2,85 & 6,66 & \\
\hline Epipaleolítico & Vestíbulo & 1E.213 & Columba livia/oenas & TMT & - & - & - & 7,60 & \\
\hline Solutrense & Vestíbulo & C10.299.120.2 & Columba livia/oenas & TMT & 30,40 & - & - & & \\
\hline Solutrense & Vestíbulo & 8A.337.152.15 & Columba livia/oenas & TMT & - & - & - & 7,14 & \\
\hline Epipaleolítico & Vestíbulo & 2D.209.5.32 & Columba livia/oenas & TMT & 31,34 & 7,08 & 3,29 & 7,49 & \\
\hline Epipaleolítico & Vestíbulo & 2D.209.5.26 & Columba livia/oenas & TMT & - & 7,20 & - & - & \\
\hline Epipaleolítico & Vestíbulo & 2D.209.5.12 & Columba livia/oenas & TMT & 31,82 & 7,34 & 3,15 & 7,57 & \\
\hline Epipaleolítico & Vestíbulo & 2D.222 6.56 & Columba livia/oenas & TMT & 30,92 & 6,70 & 3,12 & 7,87 & \\
\hline Epipaleolítico & Vestíbulo & 2D.222 6.71 & Columba livia/oenas & TMT & 28,39 & 6,49 & 2,89 & 7,15 & \\
\hline Epipaleolítico & Vestíbulo & 2D.222.6.70 & Columba livia/oenas & TMT & 30,49 & 6,39 & 3,02 & 6,62 & \\
\hline Magd. Sup/fin & Vestíbulo & 2D.231.26.28 & Columba livia/oenas & TMT & 31,21 & 6,83 & 3,01 & 7,17 & \\
\hline Magd. Sup/fin & Vestíbulo & 2D.231.26.18 & Columba livia/oenas & TMT & 31,29 & 6,79 & 3,25 & 7,94 & \\
\hline Magd. Sup/fin & Vestíbulo & 2D.231.26.19 & Columba livia/oenas & TMT & 30,75 & 7,08 & 2,90 & 8,20 & \\
\hline Magd. Sup/fin & Vestíbulo & 2D.231.9.11 & Columba livia/oenas & TMT & 28,45 & - & - & - & \\
\hline
\end{tabular}




\section{ANEXO 2}

Praileaitz I. Datos métricos de córvidos, en mm (según Tomek y Bochenski 2000) Praileaitz I. Metrical data of corvids, in mm (after Tomek \& Bochenski 2000)

\begin{tabular}{|c|c|c|c|c|c|}
\hline & TAXA & & $\mathbf{N}$ & Min - Máx. & Media \\
\hline \multirow[t]{27}{*}{ CORACOIDES } & Corvus corax & $\mathrm{a}$ & 1 & 55,56 & \\
\hline & & $\mathrm{b}$ & 1 & 52,38 & \\
\hline & & $d$ & 1 & 4,85 & \\
\hline & & $\mathrm{e}$ & 1 & 20,52 & \\
\hline & & g & 1 & 16,14 & \\
\hline & & $\mathrm{h}$ & 1 & 5,25 & \\
\hline & P. graculus & $\mathrm{a}$ & 94 & $28,58-33,24$ & 30,89 \\
\hline & & $\mathrm{b}$ & 102 & $27,40-31,54$ & 29,55 \\
\hline & & $\mathrm{C}$ & 51 & $5,56-7,52$ & 6,77 \\
\hline & & $d$ & 53 & $2,29-3,27$ & 2,74 \\
\hline & & $\mathrm{e}$ & 7 & $10,77-13,31$ & 12,04 \\
\hline & & $g$ & 9 & $7,87-10,22$ & 9,07 \\
\hline & & $\mathrm{h}$ & 16 & $2,50-3,47$ & 2,96 \\
\hline & P. phyrrhocorax & $\mathrm{a}$ & 39 & $31,08-37,35$ & 34,48 \\
\hline & & $\mathrm{b}$ & 49 & $30,71-35,64$ & 32,86 \\
\hline & & $\mathrm{C}$ & 16 & $6,04-9,06$ & 8,21 \\
\hline & & $d$ & 19 & $2,40-3,55$ & 2,92 \\
\hline & & $\mathrm{e}$ & 7 & $11,56-14,34$ & 13,08 \\
\hline & & $g$ & 6 & $9,11-10,08$ & 9,72 \\
\hline & & $\mathrm{h}$ & 10 & $2,58-3,64$ & 3,12 \\
\hline & Pyrrhocorax sp & $a$ & 24 & $30,44-33,27$ & 32,41 \\
\hline & & $\mathrm{b}$ & 28 & $29,00-31,73$ & 30,90 \\
\hline & & $\mathrm{C}$ & 4 & $6,88-7,25$ & 7,00 \\
\hline & & $d$ & 10 & $2,53-3,36$ & 2,87 \\
\hline & & $\mathrm{e}$ & 3 & $12,43-12,70$ & 12,59 \\
\hline & & $g$ & 4 & $9,33-10,14$ & 9,60 \\
\hline & & $\mathrm{h}$ & 5 & $2,75-3,54$ & 3,10 \\
\hline \multirow[t]{16}{*}{ HUMERO } & P. graculus & $\mathrm{a}$ & 94 & $41,30-46,06$ & 44,16 \\
\hline & & $\mathrm{b}$ & 28 & $12,23-14,73$ & 13,44 \\
\hline & & $\mathrm{C}$ & 64 & $3,70-5,03$ & 4,26 \\
\hline & & $d$ & 19 & $9,96-15,45$ & 12,23 \\
\hline & & $\mathrm{e}$ & 17 & $2,98-4,17$ & 3,50 \\
\hline & & $f$ & 74 & $3,30-4,50$ & 4,06 \\
\hline & & $g$ & 74 & $4,47-5,48$ & 5,03 \\
\hline & & $\mathrm{h}$ & 91 & $9,88-12,28$ & 11,35 \\
\hline & & $\mathrm{i}$ & 82 & $5,12-7,55$ & 6,29 \\
\hline & & j & 90 & $4,91-6,33$ & 5,60 \\
\hline & P. phyrrhocorax & $a$ & 25 & $46,16-54,52$ & 50,92 \\
\hline & & $\mathrm{b}$ & 14 & $13,39-16,14$ & 14,86 \\
\hline & & $\mathrm{C}$ & 28 & $3,56-5,27$ & 4,61 \\
\hline & & $d$ & 17 & $11,63-15,00$ & 13,03 \\
\hline & & $\mathrm{e}$ & 15 & $3,53-4,70$ & 4,16 \\
\hline & & $f$ & 52 & $3,97-4,92$ & 4,38 \\
\hline
\end{tabular}




\begin{tabular}{|c|c|c|c|c|c|}
\hline & TAXA & & $\mathbf{N}$ & Min - Máx. & Media \\
\hline & & $g$ & 55 & $5,08-6,16$ & 5,56 \\
\hline & & $\mathrm{h}$ & 55 & $10,89-13,35$ & 12,11 \\
\hline & & $\mathrm{i}$ & 52 & $5,64-7,80$ & 6,73 \\
\hline & & j & 49 & $5,30-6,73$ & 6,00 \\
\hline & Pyrrhocorax sp & $\mathrm{a}$ & 13 & $45,77-46,78$ & 46,35 \\
\hline & & $\mathrm{b}$ & 9 & $13,35-15,55$ & 14,47 \\
\hline & & $\mathrm{C}$ & 12 & $4,22-4,75$ & 4,50 \\
\hline & & d & 3 & $12,22-13,83$ & 13,00 \\
\hline & & $\mathrm{e}$ & 2 & $3,78-3,87$ & 3,82 \\
\hline & & $f$ & 25 & $3,59-4,90$ & 4,14 \\
\hline & & $g$ & 26 & $4,50-5,56$ & 5,13 \\
\hline & & $\mathrm{h}$ & 144 & $10,17-12,90$ & 11,56 \\
\hline & & i & 125 & $5,16-7,24$ & 6,47 \\
\hline & & j & 127 & $4,83-6,38$ & 5,74 \\
\hline \multirow[t]{24}{*}{ ULNA } & P. graculus & $\mathrm{a}$ & 70 & $52,75-61,00$ & 57,39 \\
\hline & & $\mathrm{b}$ & 85 & $7,22-8,87$ & 8,05 \\
\hline & & $\mathrm{C}$ & 76 & $7,59-9,50$ & 8,63 \\
\hline & & $d$ & 85 & $3,34-4,65$ & 3,99 \\
\hline & & $\mathrm{e}$ & 90 & $3,24-4,37$ & 3,94 \\
\hline & & $f$ & 133 & $6,73-8,17$ & 7,36 \\
\hline & & $g$ & 131 & $5,74-7,21$ & 6,59 \\
\hline & & $\mathrm{h}$ & 128 & $3,81-6,13$ & 4,69 \\
\hline & P. phyrrhocorax & $\mathrm{a}$ & 29 & $59,61-70,02$ & 65,88 \\
\hline & & $\mathrm{b}$ & 76 & $7,84-9,40$ & 8,82 \\
\hline & & $\mathrm{C}$ & 65 & $8,39-10,35$ & 9,57 \\
\hline & & $d$ & 73 & $3,31-5,04$ & 4,43 \\
\hline & & $\mathrm{e}$ & 51 & $3,97-5,05$ & 4,42 \\
\hline & & $f$ & 58 & $7,41-8,53$ & 8,12 \\
\hline & & $g$ & 58 & $6,24-7,69$ & 7,12 \\
\hline & & $\mathrm{h}$ & 56 & $4,78-5,96$ & 5,46 \\
\hline & Pyrrhocorax sp & $\mathrm{a}$ & 11 & $55,89-62,12$ & 58,83 \\
\hline & & $\mathrm{b}$ & 168 & $7,12-9,37$ & 8,17 \\
\hline & & $\mathrm{C}$ & 129 & $3,62-9,86$ & 8,71 \\
\hline & & $d$ & 158 & $3,52-7,61$ & 4,10 \\
\hline & & $\mathrm{e}$ & 72 & $3,58-4,67$ & 4,00 \\
\hline & & $f$ & 246 & $6,89-8,42$ & 7,68 \\
\hline & & $g$ & 246 & $5,10-7,85$ & 6,83 \\
\hline & & $\mathrm{h}$ & 243 & $4,02-5,57$ & 4,87 \\
\hline \multirow[t]{9}{*}{ CARPOMETACARPO } & Corvus corax & $\mathrm{a}$ & 1 & 63,79 & \\
\hline & & $\mathrm{b}$ & 1 & 58,21 & \\
\hline & & $\mathrm{C}$ & 1 & 10,35 & \\
\hline & & $d$ & 1 & 7,31 & \\
\hline & & $\mathrm{e}$ & 1 & 14,84 & \\
\hline & & $f$ & 1 & 7,51 & \\
\hline & & g & 1 & 6,11 & \\
\hline & & $\mathrm{i}$ & 1 & 14,33 & \\
\hline & & j & 1 & 7,21 & \\
\hline
\end{tabular}




\begin{tabular}{|c|c|c|c|c|c|}
\hline & TAXA & & $\mathbf{N}$ & Min - Máx. & Media \\
\hline & P. graculus & $\mathrm{a}$ & 87 & $30,56-36,78$ & 35,03 \\
\hline & & $\mathrm{b}$ & 88 & $28,90-33,30$ & 31,78 \\
\hline & & $\mathrm{C}$ & 55 & $5,70-7,21$ & 6,47 \\
\hline & & $d$ & 55 & $4,03-5,16$ & 4,54 \\
\hline & & $\mathrm{e}$ & 55 & $7,77-9,27$ & 8,47 \\
\hline & & $f$ & 58 & $4,23-5,87$ & 5,00 \\
\hline & & $g$ & 57 & $3,07-4,92$ & 3,78 \\
\hline & & $\mathrm{h}$ & 49 & $4,81-6,36$ & 5,75 \\
\hline & & $\mathrm{i}$ & 82 & $7,28-9,00$ & 8,26 \\
\hline & & j & 84 & $3,35-4,89$ & 4,01 \\
\hline & P. phyrrhocorax & a & 49 & $36,05-40,24$ & 38,42 \\
\hline & & $\mathrm{b}$ & 48 & $32,50-37,25$ & 35,01 \\
\hline & & C & 35 & $6,28-8,06$ & 7,03 \\
\hline & & $d$ & 35 & $4,13-5,29$ & 4,88 \\
\hline & & $\mathrm{e}$ & 35 & $8,57-9,89$ & 9,04 \\
\hline & & $f$ & 35 & $4,51-6,06$ & 5,42 \\
\hline & & $g$ & 35 & $3,42-4,96$ & 4,13 \\
\hline & & $\mathrm{h}$ & 32 & $4,78-6,77$ & 5,94 \\
\hline & & $\mathrm{i}$ & 45 & $7,38-9,74$ & 8,88 \\
\hline & & j & 43 & $3,41-4,90$ & 4,20 \\
\hline & Pyrrhocorax sp & $\mathrm{a}$ & 47 & $33,73-38,16$ & 36,73 \\
\hline & & $\mathrm{b}$ & 51 & $31,59-34,59$ & 33,37 \\
\hline & & $\mathrm{C}$ & 47 & $5,87-7,78$ & 6,71 \\
\hline & & $d$ & 46 & $3,91-5,38$ & 4,71 \\
\hline & & $\mathrm{e}$ & 48 & $7,94-9,35$ & 8,63 \\
\hline & & $f$ & 49 & $4,33-6,33$ & 5,15 \\
\hline & & $g$ & 49 & $3,33-4,81$ & 3,78 \\
\hline & & $\mathrm{h}$ & 32 & $5,13-6,58$ & 5,87 \\
\hline & & $i$ & 42 & $7,61-9,97$ & 8,54 \\
\hline & & j & 42 & $3,51-4,87$ & 4,14 \\
\hline & Pica pica & $\mathrm{a}$ & 2 & $28,77-30,69$ & 29,84 \\
\hline & & $\mathrm{b}$ & 2 & $26,13-28,88$ & 27,37 \\
\hline & & C & 1 & 4,78 & \\
\hline & & $d$ & 1 & 3,65 & \\
\hline & & $\mathrm{e}$ & 1 & 6,60 & \\
\hline & & $f$ & 1 & 4,17 & \\
\hline & & $g$ & 1 & 2,93 & \\
\hline & & $\mathrm{h}$ & 1 & 4,34 & \\
\hline & & $\mathrm{i}$ & 2 & $6,63-6,74$ & 6,68 \\
\hline & & j & 2 & $3,20-3,69$ & 3,44 \\
\hline \multirow[t]{7}{*}{ FEMUR } & Corvus corax & $a$ & 1 & 66,66 & \\
\hline & & $\mathrm{b}$ & 2 & $14,86-15,63$ & 15,24 \\
\hline & & $\mathrm{c}$ & 2 & $6,36-6,38$ & 6,37 \\
\hline & & $d$ & 1 & 5,67 & \\
\hline & & $\mathrm{e}$ & 1 & 6,62 & \\
\hline & & $f$ & 2 & $13,97-15,75$ & 14,86 \\
\hline & & g & 1 & 8,22 & \\
\hline
\end{tabular}




\begin{tabular}{|c|c|c|c|c|c|}
\hline & TAXA & & $\mathbf{N}$ & Min - Máx. & Media \\
\hline & & $\mathrm{h}$ & 1 & 10,75 & \\
\hline & & $\mathrm{i}$ & 1 & 9,03 & \\
\hline & P. graculus & $a$ & 16 & $37,09-40,39$ & 38,91 \\
\hline & & $\mathrm{b}$ & 18 & $7,22-8,07$ & 7,61 \\
\hline & & $\mathrm{C}$ & 19 & $2,80-3,46$ & 3,24 \\
\hline & & $d$ & 16 & $2,90-3,45$ & 3,20 \\
\hline & & $\mathrm{e}$ & 16 & $3,02-3,47$ & 3,25 \\
\hline & & $f$ & 21 & $7,12-8,25$ & 7,70 \\
\hline & & $g$ & 19 & $4,15-4,87$ & 4,57 \\
\hline & & $\mathrm{h}$ & 19 & $5,34-6,63$ & 6,01 \\
\hline & & $\mathrm{i}$ & 19 & $4,32-5,52$ & 5,02 \\
\hline & P. phyrrhocorax & $\mathrm{a}$ & 47 & $38,55-43,71$ & 40,92 \\
\hline & & $\mathrm{b}$ & 72 & $7,68-9,25$ & 8,40 \\
\hline & & $\mathrm{C}$ & 72 & $3,19-4,30$ & 3,61 \\
\hline & & $d$ & 50 & $3,17-4,28$ & 3,62 \\
\hline & & $\mathrm{e}$ & 49 & $3,14-4,30$ & 3,67 \\
\hline & & $f$ & 55 & $7,52-9,70$ & 8,62 \\
\hline & & $g$ & 54 & $3,90-5,85$ & 5,05 \\
\hline & & $\mathrm{h}$ & 50 & $5,20-7,96$ & 6,64 \\
\hline & & $\mathrm{i}$ & 50 & $4,59-6,55$ & 5,43 \\
\hline & Pyrrhocorax sp & $a$ & 17 & $38,21-41,84$ & 39,60 \\
\hline & & $\mathrm{b}$ & 61 & $7,23-8,24$ & 7,80 \\
\hline & & $\mathrm{C}$ & 61 & $3,06-3,73$ & 3,37 \\
\hline & & $d$ & 18 & $3,00-3,82$ & 3,37 \\
\hline & & $\mathrm{e}$ & 17 & $3,02-3,77$ & 3,36 \\
\hline & & $f$ & 58 & $7,41-9,66$ & 8,12 \\
\hline & & $g$ & 58 & $4,31-5,77$ & 4,80 \\
\hline & & $\mathrm{h}$ & 56 & $5,50-7,37$ & 6,21 \\
\hline & & $\mathrm{i}$ & 55 & $4,52-6,14$ & 5,10 \\
\hline \multirow[t]{18}{*}{ TIBIOTARSO } & P. graculus & $a$ & 10 & $64,99-73,80$ & 68,32 \\
\hline & & $\mathrm{b}$ & 7 & $6,45-7,10$ & 6,89 \\
\hline & & $\mathrm{C}$ & 5 & $9,03-10,16$ & 9,62 \\
\hline & & $d$ & 4 & $8,16-10,05$ & 9,37 \\
\hline & & $\mathrm{e}$ & 6 & $4,32-5,20$ & 4,76 \\
\hline & & $f$ & 10 & $2,83-3,16$ & 2,93 \\
\hline & & $g$ & 10 & $3,07-3,46$ & 3,26 \\
\hline & & $\mathrm{h}$ & 102 & $5,11-6,44$ & 5,80 \\
\hline & & $\mathrm{i}$ & 101 & $4,66-6,04$ & 5,40 \\
\hline & & j & 102 & $5,48-6,85$ & 6,14 \\
\hline & P. phyrrhocorax & $\mathrm{a}$ & 4 & $70,50-77,54$ & 73,83 \\
\hline & & $\mathrm{b}$ & 1 & 8,24 & \\
\hline & & $\mathrm{C}$ & 1 & 12,27 & \\
\hline & & $d$ & 1 & 9,51 & \\
\hline & & $\mathrm{e}$ & 1 & 5,73 & \\
\hline & & $f$ & 2 & $3,35-3,43$ & 3,39 \\
\hline & & $g$ & 2 & $3,76-4,03$ & 3,89 \\
\hline & & $\mathrm{h}$ & 30 & $5,91-7,18$ & 6,62 \\
\hline
\end{tabular}




\begin{tabular}{|c|c|c|c|c|c|}
\hline & TAXA & & $\mathbf{N}$ & Min - Máx. & Media \\
\hline & & $\mathrm{i}$ & 31 & $5,52-6,62$ & 6,13 \\
\hline & & j & 32 & $6,55-7,58$ & 7,00 \\
\hline & Pyrrhocorax sp & a & 1 & 71,70 & \\
\hline & & $\mathrm{h}$ & 46 & $5,34-6,69$ & 6,11 \\
\hline & & $\mathrm{i}$ & 46 & $5,24-6,11$ & 5,74 \\
\hline & & j & 46 & $5,62-6,91$ & 6,41 \\
\hline & Pica pica & $\mathrm{h}$ & 6 & $5,02-5,68$ & 5,26 \\
\hline & & $\mathrm{i}$ & 6 & $4,69-5,04$ & 4,94 \\
\hline & & j & 7 & $5,27-6,18$ & 5,70 \\
\hline \multirow[t]{24}{*}{ TARSOMETATARSO } & Corvus corax & a & 1 & 64,67 & \\
\hline & & $b$ & 1 & 13,43 & \\
\hline & & C & 1 & 5,04 & \\
\hline & & d & 2 & $9,20-9,54$ & 9,37 \\
\hline & & $\mathrm{e}$ & 2 & $6,21-6,22$ & 6,21 \\
\hline & & $f$ & 2 & $3,45-3,49$ & 3,47 \\
\hline & P. graculus & a & 45 & $42,27-48,10$ & 44,94 \\
\hline & & $\mathrm{b}$ & 45 & $6,42-7,83$ & 7,11 \\
\hline & & C & 51 & $2,31-3,22$ & 2,70 \\
\hline & & $d$ & 94 & $4,60-5,87$ & 5,30 \\
\hline & & $\mathrm{e}$ & 93 & $2,33-2,97$ & 2,69 \\
\hline & & $f$ & 95 & $1,26-2,21$ & 1,53 \\
\hline & P. phyrrhocorax & a & 17 & $46,35-54,29$ & 49,44 \\
\hline & & $\mathrm{b}$ & 11 & $7,30-8,47$ & 7,90 \\
\hline & & C & 16 & $2,72-3,55$ & 3,00 \\
\hline & & $d$ & 33 & $5,12-6,13$ & 5,67 \\
\hline & & $\mathrm{e}$ & 35 & $2,36-3,36$ & 3,08 \\
\hline & & $f$ & 35 & $1,57-2,31$ & 1,94 \\
\hline & Pyrrhocorax sp & $\mathrm{a}$ & 7 & $46,33-48,52$ & 47,33 \\
\hline & & $b$ & 11 & $7,27-7,82$ & 7,50 \\
\hline & & $\mathrm{C}$ & 10 & $2,47-3,14$ & 2,77 \\
\hline & & d & 35 & $5,00-5,68$ & 5,42 \\
\hline & & $\mathrm{e}$ & 36 & $2,39-3,50$ & 2,81 \\
\hline & & $f$ & 36 & $1,54-1,99$ & 1,67 \\
\hline
\end{tabular}


